\title{
CASCADE APPROACHES TOWARDS THE SYNTHESIS OF DAPHNIOLDHANIN A ALKALOID
}

by

Ashna Ashneen Khan

VICTORIA UNIVERSITY OF WELLINGTON

Te Whare Wananga o te Upoko o te Ika a Maui

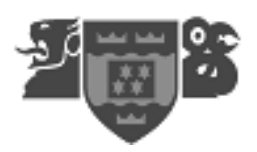

\author{
A thesis \\ submitted to Victoria University of Wellington \\ in fulfilment of the \\ requirements for the degree of \\ Masters in Chemistry
}




\begin{abstract}
$\underline{\text { Abstract }}$
Daphnioldhanin A 1.6 is a recent alkaloid obtained from Daphyniphyllum plants.

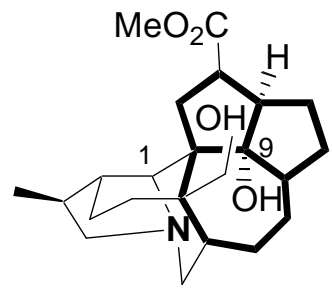

1.6

The core structure as shown consists of a 5,5,7 tricyclic ring system, which is a challenging ring system and to date has not been reported in any other natural product. This project focussed on using two cascade approaches in forming this ring system, namely radical addition and cyclisation cascade and carbene cycloaddition cyclisation cascade CCCC.
\end{abstract}
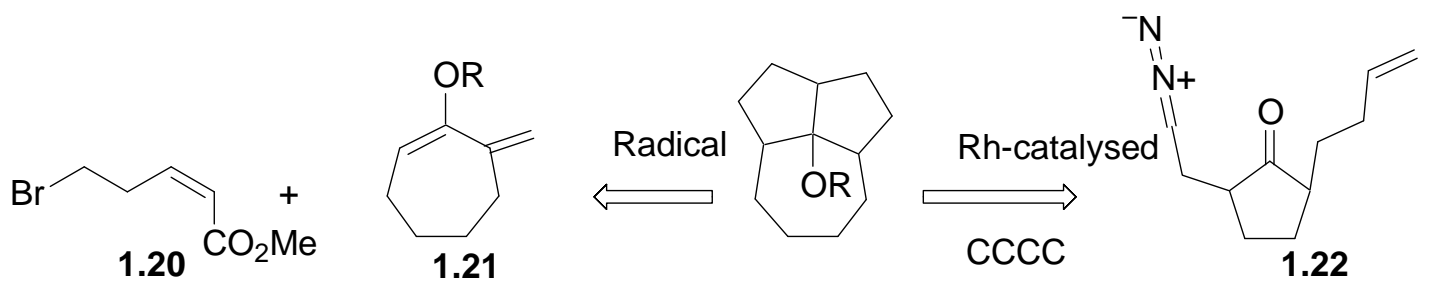

Using the radical approach would require a 5-endo trig cyclisation, which is disfavoured by Baldwin's rules, but has been reported in systems which have an hetereoatom (carbonyl, nitrogen or sulfur) incorporated in the ring. In our case, the 5endo trig cyclisation is needed in an all carbon containing ring, and preliminary modelling studies have shown that the energy for the 4-exo trig cyclisation product is higher than that of the 5-endo trig cyclisation product. Therefore, the radical approach if successful will eventuate in a novel 5-endo trig cyclisation in an all carbon system. However, due to stability issues with the radical precursors this method had to be abandoned and attention focused on the CCCC approach. 
For the CCCC approach, rhodium catalysed cascade cyclisation is intended on diazo compound 1.22. The presence of the intramolecular double bond enhances the second cyclisation to occur which will form the 5 and 7-membered ring simultaneously along with oxo-bridge resulting in the functionalised pentacyclic ring system which would be very similar to the proposed 5,5,7 core of Daphnioldhanin A.

The desired diazo compound could not synthesised due to failure in forming the anhydride for the acid and future work would be focussed on forming acid derivatives in order to form the diazo compound $\mathbf{1 . 2 2}$ before using rhodium catalysed cyclisation to form the functionalised pentacyclic compound. 


\section{Acknowledgements}

To begin with, I would like to thank my supervisor, Dr. Brendan Burkett. Throughout the past year, he had been providing constant guidance and helpful suggestion, which helped me to learn so much about chemistry. Thanks also for taking me out for coffee and having time to chat with me during those gloomy days!!!

Secondly, I have to thank Dr. Mattie Timmer, for being my in-lab supervisor in the early days of my research and providing so many useful hints and suggestions from the beginning of my project to the end.

I also have to thank Russell, who has been so helpful throughout my research and also for kindly offering to proof read my thesis. Lynton, who has been my thesis-writing buddy and who has helped learn all the weird (and helpful!!!) things that computers could do. I also have to thank all the people who drifted into our lab, especially Jim and the occupants of 209 in particular Russell, Lynton, Febly, Anita, Thomas, Sam and Shi for being there for a chat whenever I felt lonely!!!

Thanks also to Dr. Joanne Harvey and Dr, Paul-Teesdale-Spittle for their interest in the project and providing helpful advice and suggestions every now and then. Thanks also to the remaining staff of SCPS who have provided assistance to me in so many ways.

Thanks to Nelly for being my friend. My friend Kalpana for keeping in touch over the long distance.

Finally I have to thank my family for supporting me through a very intensive year. My mum and dad for believing in me and for providing me with constant encouragement. My brothers Azwal and Amaan for being there for me, helping me out financially and giving me their love and support. Last but not the least my husband, Razeen, whose support and encouragement has been phenomenal, and without whom my dreams would not have been possible. 
Abstract. .. $\mathrm{i}$

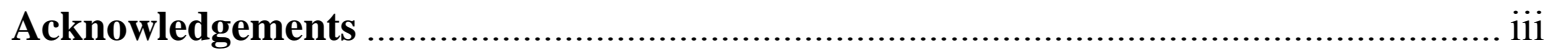

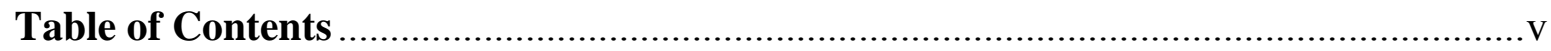

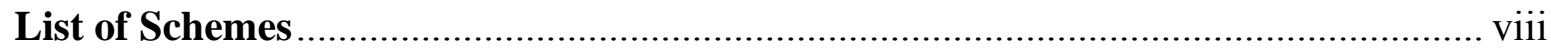

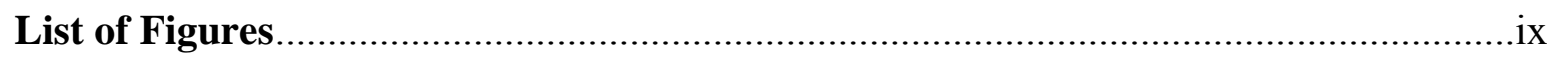

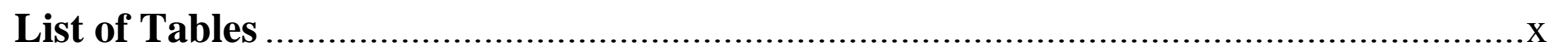

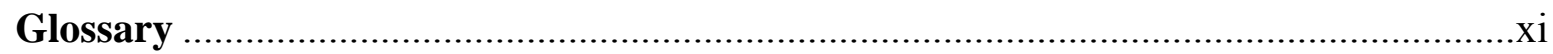

\section{Chapter 1: Introduction}

1.1 Overview -Daphniphyllum Alkaloids 1

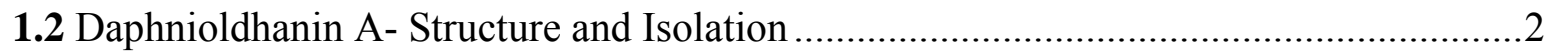

1.3 Reported Syntheses of Daphniphyllum alkaloids .......................................................2

1.4 Radical Approach towards Synthesis of Daphnioldhanin A ........................................6

1.4.1 Radical Approach in Synthesis of Polycyclic Systems.............................................6

1.4.2 Radical Approach towards Daphnioldhanin A Synthesis ..................................... 10

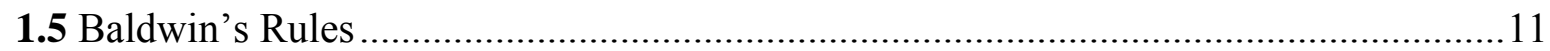

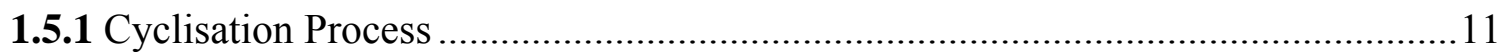

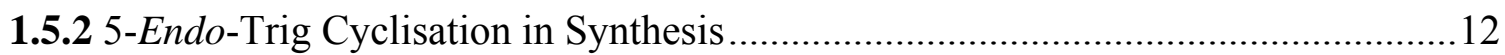

1.6 Carbene Cycloaddition Cyclisation Cascade (CCCC) Approach ..................................15

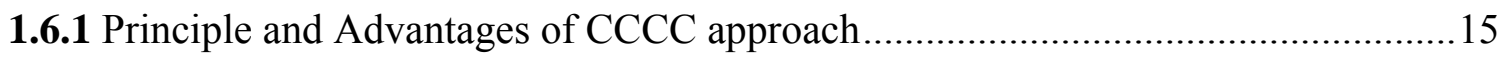

1.6.2 CCCC Approach in Synthesis of Polycyclic System..............................................19

1.6.3 CCCC Approach towards Daphnioldhanin A Synthesis .....................................21

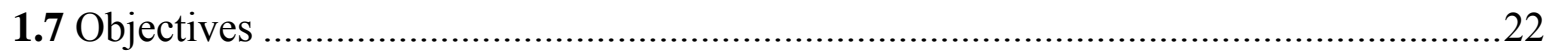

\section{Chapter 2: Results- Radical Approach}

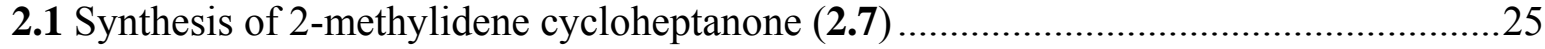

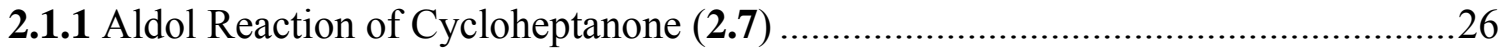

2.1.2 Mannich-Type reaction using Eschenmoser's salt ..............................................27

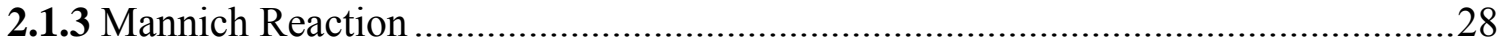

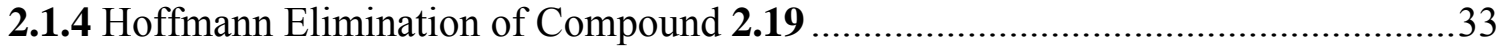

2.1.5 Cope Elimination Reaction of Compound 2.19 ...................................................33

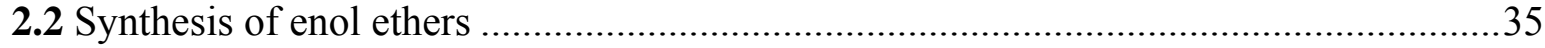

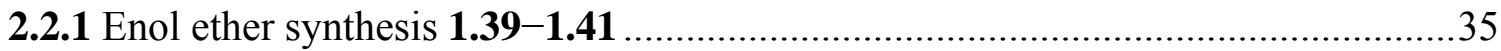

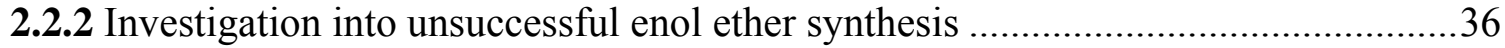


2.3 Radical Reactions on Various Systems..... .39

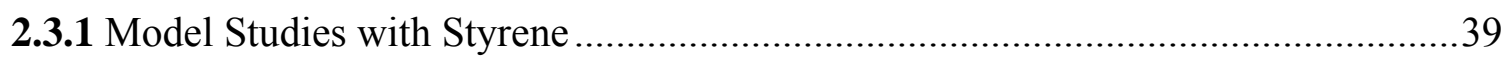

2.3.2 Radical reaction of 1-methoxy cycloheptene (2.24) ...........................................4

2.3.3 Radical reaction of 2-methylidene cycloheptanone (2.7) ...................................42

\section{Chapter 3: Results- CCCC Approach}

3.1 Carbene Cyloaddition Cyclisation Cascade Approach ..............................................4

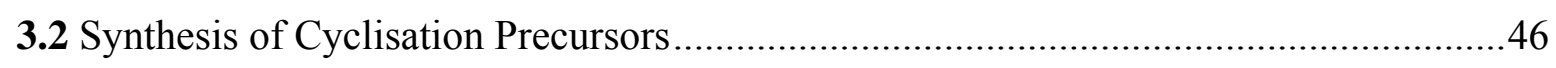

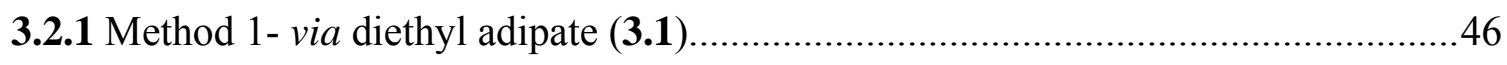

3.2.2 Method 2 - via LDA mediated diazo reaction on $1.86 \ldots \ldots \ldots \ldots \ldots \ldots \ldots \ldots \ldots \ldots \ldots \ldots \ldots . . .52$

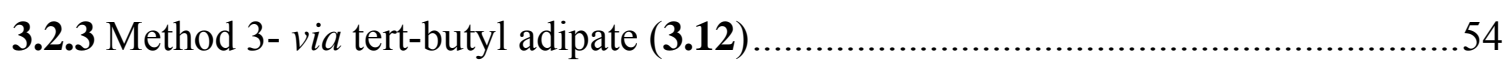

Chapter4: Conclusion and Future Work

\section{Chapter 5: Experimental}

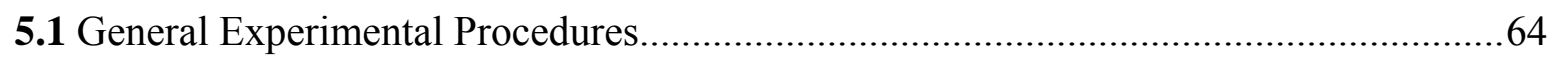

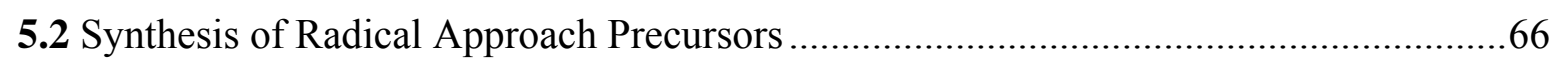

5.2.1 2-(diethylamino) methyl cycloheptanone (2.19)..............................................66

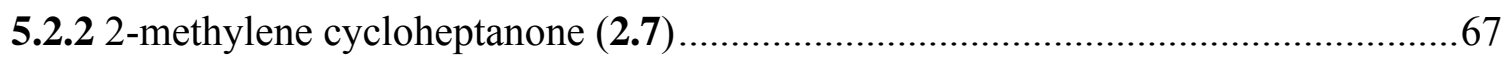

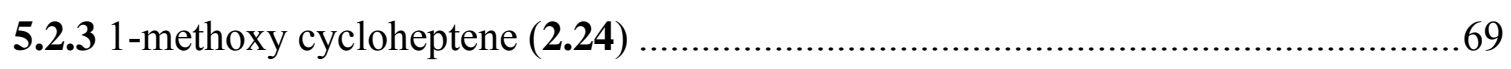

5.2.4 Representative procedure for Radical reactions: ................................................ 70

5.3 Synthesis of Carbene Cycloaddition Cyclisation Cascade precursors........................... 71

5.3.1 Synthesis of ethyl 1-(2-oxo) cyclopentane carboxylate (1.84) ..............................71

5.3.2 Synthesis of ethyl 1-(but-3-ene) (2-oxo) cyclopentane carboxylate (1.86) .............72

5.3.3 Synthesis of ethyl, 1-(but-3-ene) (2-oxo-3-methylacetyl) cyclopentane

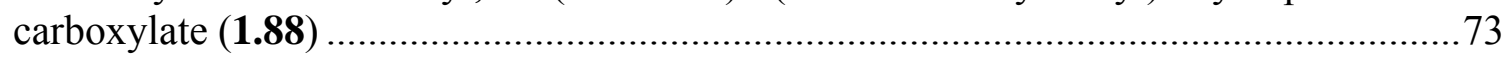

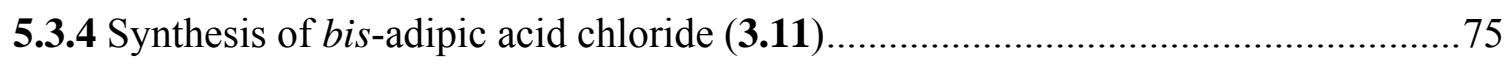

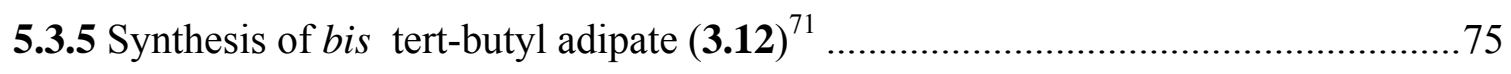

5.3.6 Synthesis of tert-butyl (2-oxo)- cyclopentane carboxylate (1.85) ..........................76

5.3.7 Synthesis of tert-butyl 1-(but-3-ene)-(2-oxo) cyclopentane carboxylate (1.87)......77

5.3.8 Synthesis of tert-butyl 1-(but-3-ene, 2-oxo, 3-methyl acetyl) cyclopentane carboxylate (1.89)

5.3.9 Attempted synthesis of 2- ((2-oxo) -(3-but-3-ene)-3-tert butyl carboxylate cyclopentane) acetic acid (1.91)

5.3.10 Synthesis of 2- ((2-oxo)- (3-but-3-ene) 3-tert-butyl carboxylate cyclopentane) acetic acid (1.91) 
5.3.11 Representative Procedure for mixed anhydride formation of compound $1.91 \ldots . . .80$

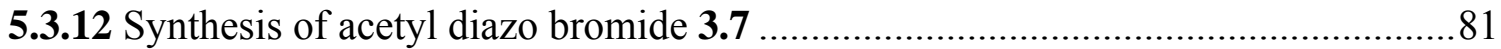

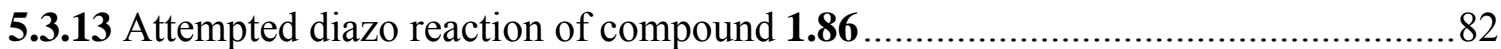

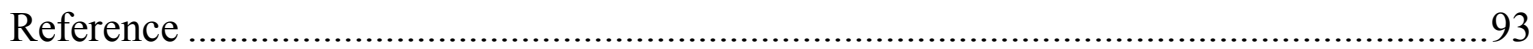




\section{List of Schemes}

Chapter 1

Scheme 1.1 Generalised biomimetic approach for the total synthesis of

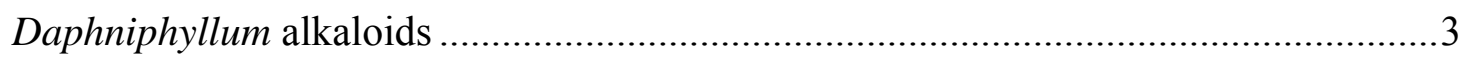

Scheme 1.2 Limitations of the biomimetic approach ..................................................

Scheme 1.3 Synthesis of methyl homodaphniphyllate 1.18 ............................................4

Scheme 1.4 Proposed approaches for daphnioldhanin A 5,5,7 core system. …..................5

Scheme 1.5 Tandem 6-endo-trig cyclisation in heptacycle 1.23 synthesis ........................6

Scheme 1.6 Radical reactions in lasonolide A (1.25) synthesis .........................................

Scheme 1.7 Radical reactions in synthesis of $(+)$ dihydrocanadenoside (1.28) and $(+)$

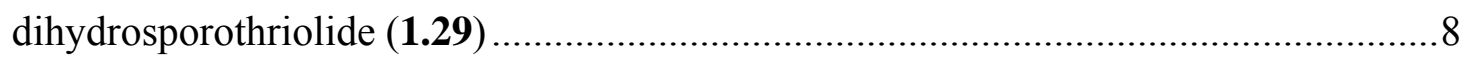

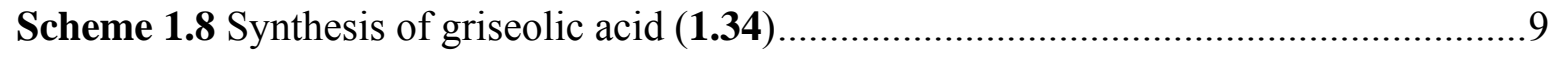

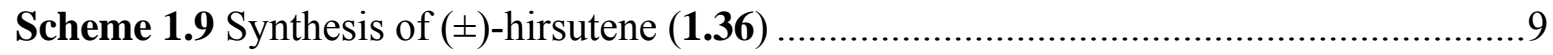

Scheme 1.12 5-endo-Trig cyclisation in sulphur containing compound 1.54 ....................12

Scheme 1.15 5-endo-Trig cyclisation of 2-formylbenzaldehyde (1.63)............................14

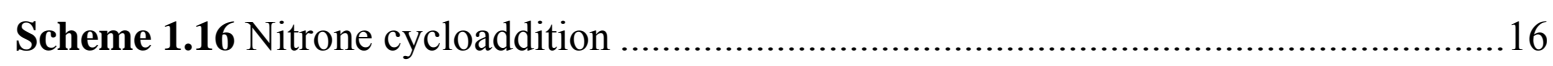

Scheme 1.17 General Scheme for the CCCC approach ..............................................17

Scheme 1.18 Rhodium and DMAD reaction with diazo compound 1.68 .........................18

Scheme 1.19 Example of rhodium-mediated CCCC approach .......................................18

Scheme 1.20 CCCC approach in synthesis of (-) colchicine and (-) isocolchicine..............19

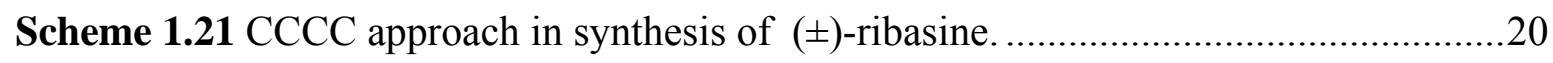

Scheme 1.22 CCCC approach in the synthesis of kopsifoline alkaloid 1.83 ....................20

Scheme 1.23 Proposed CCCC approach towards synthesis of Daphnioldhanin A.............21

\section{Chapter 2}

Scheme 2.1 Competing regioselective radical additions ..............................................23

Scheme 2.2 Contributing resonance structures of the radical addition ..............................24

Scheme 2.3 Alternate approach to regioselective radical addition...................................24

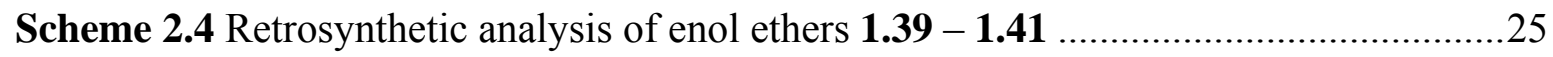

Scheme 2.5 Synthesis of compound 2.10 via radical nitrification ...................................25

Scheme 2.6 Synthesis of compound 2.10 via Ramberg-Backlund reaction........................26

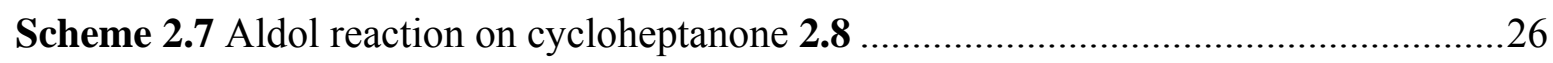


Scheme 2.8 Eschenmoser's salt reaction with cycloheptanone (2.8) ................................27

Scheme 2.9 Proposed piperidine reaction with Eschenmoser's salt..................................28

Scheme 2.10 General Mannich reaction........................................................................29

Scheme 2.11 Proposed Mannich reaction of cycloheptanone (2.8) with piperidine ...........29

Scheme 2.12 Proposed piperidine reaction with 2-methylidene cycloheptanone (2.7) .......31

Scheme 2.13 Mannich reaction with diethylamine hydrochloride....................................32

Scheme 2.14 Hoffmann elimination of compound 2.19.................................................33

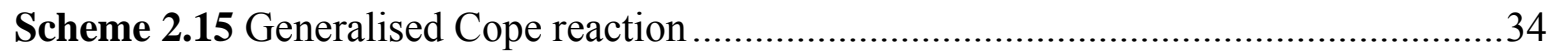

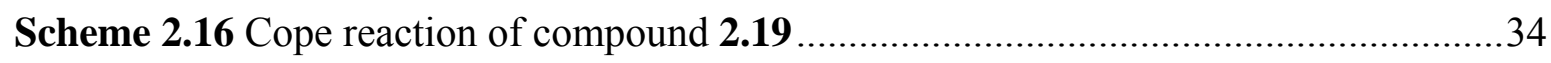

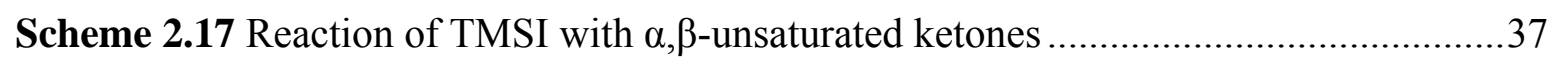

Scheme 2.18 Proposed mechanism of the reaction of TMSI with $\alpha, \beta$-unsaturated

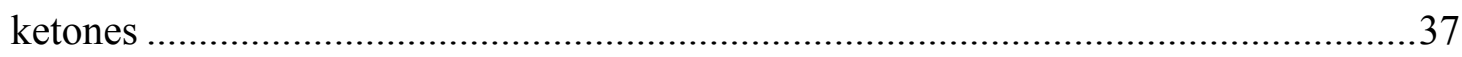

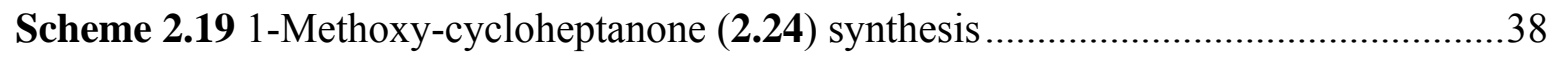

Scheme 2.20 Radical reaction of styrene (2.25) with bromobenzene (2.26) ......................39

\section{Chapter 3}

Scheme 3.1 Retrosynthetic analysis for CCCC approach ...................................................44

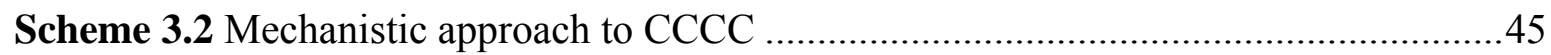

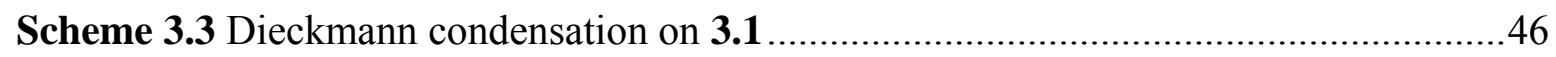

Scheme 3.4 Mechanism of Dieckmann condensation of compound 3.1 ...........................47

Scheme 3.5 Sodium hydroxide mediated initial alkylation of compound 1.84 .................47

Scheme 3.6 LDA mediated alkylation of compound 1.86 ..............................................48

Scheme 3.7 Methyl ester hydrolysis of $\mathbf{1 . 8 8}$ with $1 \mathrm{M} \mathrm{NaOH}$ in EtOH solution ...................50

Scheme $3.8 \mathrm{NaOH}$ mediated methyl ester hydrolysis of $1.88 \ldots \ldots \ldots \ldots \ldots \ldots \ldots \ldots \ldots \ldots \ldots \ldots . . . .51$

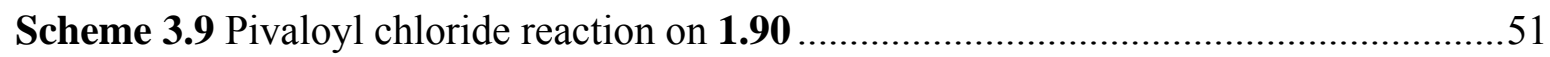

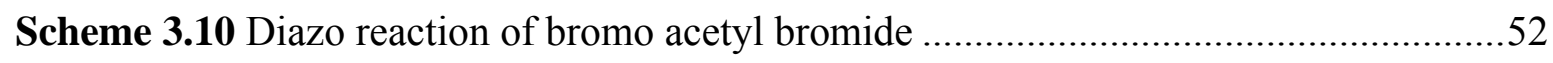

Scheme 3.11 Attempted formation of diazo compound 1.94 ..........................................53

Scheme 3.12 Reported substitution reaction of diazo compound .....................................54

Scheme 3.14 Dieckmann condensation of bis-tert-butyl adipate 3.12 ..............................55

Scheme 3.15 Sodium hydride mediated alkylation on compound 3.20 .............................56

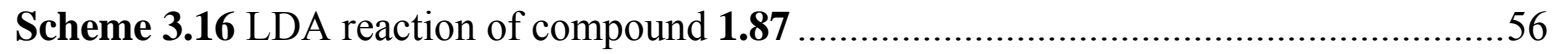

Scheme 3.17 Mechanism for ring opening of compound 1.91 ........................................58

Scheme 3.18 Proposed diazomethane reaction on anhydrides 1.93 and 3.16 ..................61 
Scheme 3.19 Diazomethane as a methylating agent 61

Chapter 4

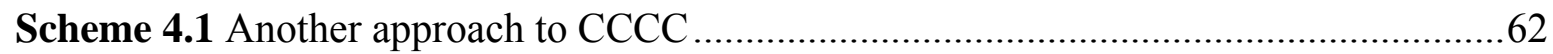

Scheme 4.2 Another CCCC approach to 5,5,7 ring system ..................................................63 


\section{$\underline{\text { List of Figures }}$}

\section{Chapter 1}

Figure 1.1 Two daphniphyllum alkaloids skeletal types...............................................

Figure 1.2 Selected Daphniphyllum alkaloids ..........................................................

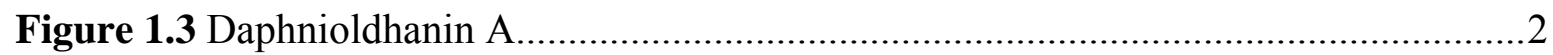

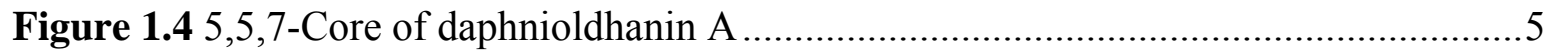

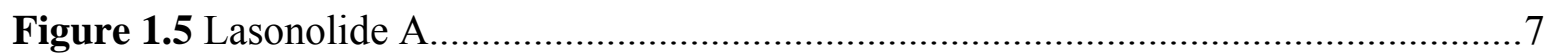

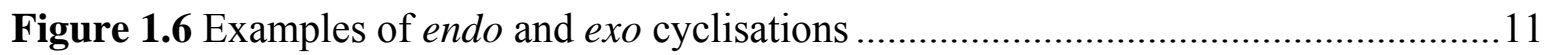

Figure 1.7 4-exo-Trig versus 5-endo-trig cyclisation in daphnioldhanin A precursor

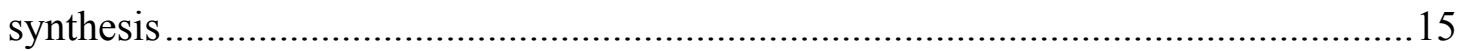

\section{Chapter 2}

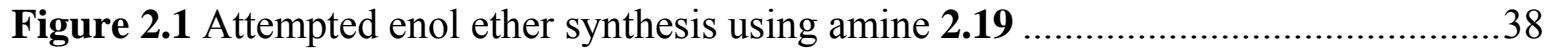

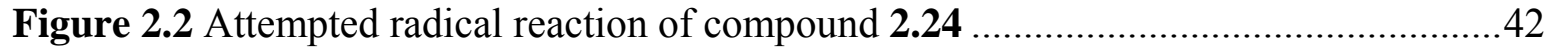

Figure 2.3 Attempted radical reaction on compound 2.7 ............................................43

\section{Chapter 3}

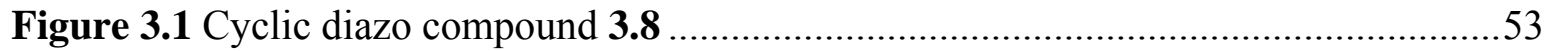

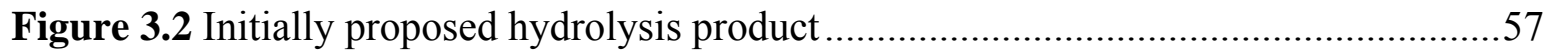

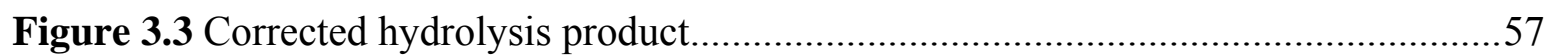

Figure 3.4 Corrected structure for molecule 3.5 ..........................................................59

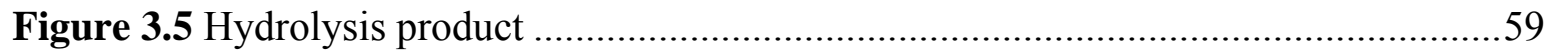

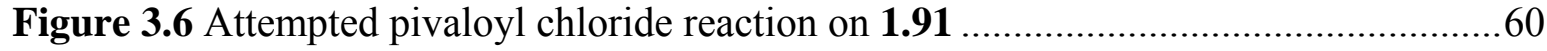

Figure 3.7 Attempted methyl chloroformate reaction of 1.91 .....................................60 


\section{List of Tables}

\section{Chapter 1}

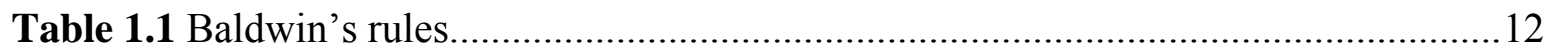

\section{Chapter 2}

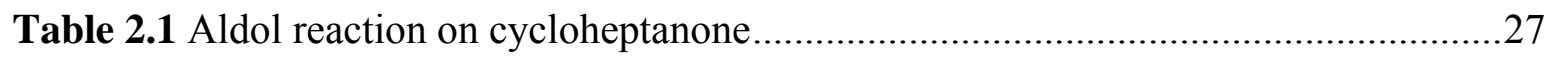

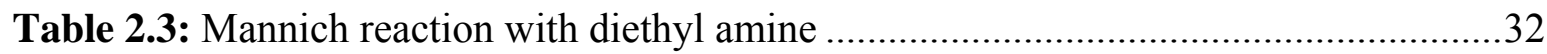

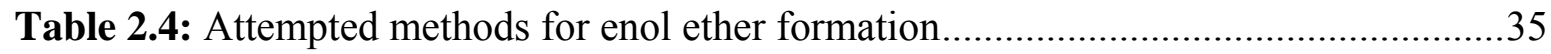

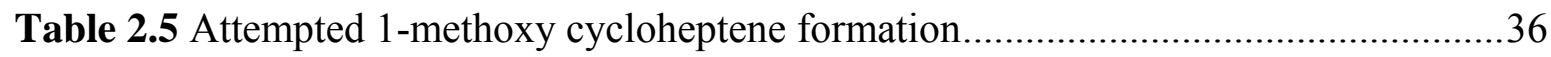

Table 2.6 Radical reaction of styrene with bromobenzene ...............................................40

Table 2.7 Radical reactions of styrene and isopropyl bromide ..........................................41

\section{$\underline{\text { Chapter } 3}$}

Table 3.1 LDA reaction conditions 


\section{Glossary}

AIBN

$\mathrm{ACN}$

aq.

b.p

${ }^{\mathrm{t}} \mathrm{BuOH}$

n-BuLi

$\mathrm{Bu}_{3} \mathrm{SnH}$

CCCC

COSY

d

dd

d.e.

DBN

DBU

DCM

DMA

$\mathrm{DMF}$

eq.

FTIR

HRMS

HSQC

IR

$J$

LDA

$\mathrm{m}$

mCPBA

$\min$

MS

mw

NMR

[O] azobisisobutyronitrile

azobiscyclohexylnitrile

aqueous

boiling point

tert-butanol

n-butyl lithium

tributyltin hydride

carbene cycloaddition cyclisation cascade

Correlation spectroscopy

doublet

doublet of doublets

diastereomeric excess

1,5-Diazabicyclo[4.3.0]non-5-ene

1,8-Diazabicyclo[5.4.0]undec-7-ene

dichloromethane

$N, N$ dimethylaniline

$\mathrm{N}, \mathrm{N}$-dimethylforamide

equivalent

Fourier Transform InfraRed

High Resolution Mass Spectrometyr

Heteronuclear Single Quantum Coherence

Infra-red

coupling constant

lithium diisopropylamide

multiplet

meta-chloroperbenzoic acid

minute

mass spectrometry

microwave

nuclear magnetic resonance

oxidation 
Piv chloride

Ppm

PTSA

$\mathrm{R}_{\mathrm{f}}$

$\mathrm{rt}$

ROESY

$\mathrm{Rh}_{2}(\mathrm{OAc})_{4}$

$\mathrm{S}$

$\mathrm{t}$

TBDMS

THF

Tf

TFA

TLC

TMS

UV

${ }^{1} \mathrm{H}$ NMR

${ }^{13} \mathrm{C}$ NMR

$\delta$ pivaloyl chloride

parts per million

para-toulene sulfonic Aacid

retention factor

room temperature

rotating frame Overhause effect

spectroscopy

dirhodium tetra-acetate

singlet

triplet

tert-butyldimethylsilyl

tetrahydrofuran

trifluoromethanesulfonyl

trifluoroacetic acid

thin layer chromatography

trimethylsilyl

ultra violet

proton nuclear magnetic resonance

carbon-13 nuclear magnetic resonance

chemical shift (ppm) 


\section{Chapter 1: Introduction}

\section{$\underline{1.1 \text { Overview -Daphniphyllum Alkaloids }}$}

Daphniphyllum alkaloids are complex nitrogen containing polycyclic alkaloids, isolated from trees of genus Daphniphyllum. The Daphniphyllum genus consist of about 30 species which are distributed over southeast Asia, with 10 found in southern China. ${ }^{1}$ Some Daphniphyllum species such as D.calycinum, D.macropodum and D.oldhami have found use in traditional medicine for treatment of conditions such as; asthma, snake bites, rheumatism and cough. ${ }^{1}$ To date more than 60 new alkaloids have been isolated, mostly from the stems and leaves of Daphniphyllum plants. ${ }^{2}$ The carbon skeletons are derived from squalene with more than seven skeletal types described. ${ }^{3}$ Two of these skeletal types are daphniphylline 1.1 and secodaphyniphylline 1.2 (figure 1.1). The complex structures of these alkaloids have been targets for bioactivity studies and elegant total synthesis. ${ }^{4,5,6}$

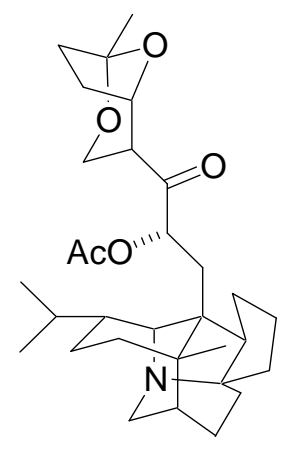

1.1

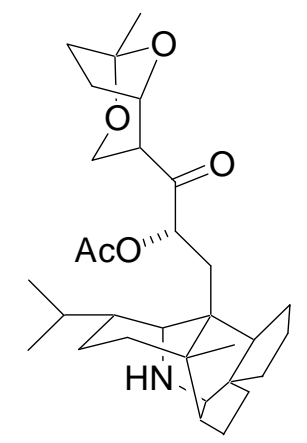

1.2

Figure 1.1 Two daphniphyllum alkaloids skeletal types

Some alkaloids isolated from these plants in recent years include (figure 2.2); daphnezomines F (1.3) and G (from stems of Daphniphyllum humile), ${ }^{7}$ daphmanidins A (1.4) and B (from the leaf extracts of D. teijsmanii), ${ }^{8}$ 17-hydroxyhomodaphniphyllic acid ( and yuzurimine $\mathrm{E}$ (1.5) (from the seeds of D. calycinum), ${ }^{2}$ and many more. ${ }^{9,10}$ 


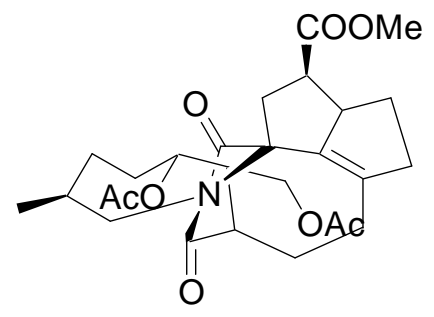

1.3

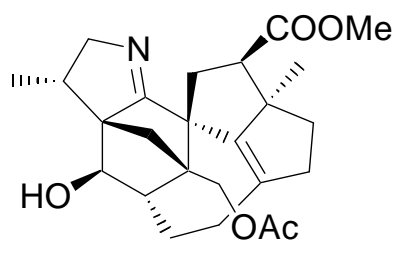

1.4

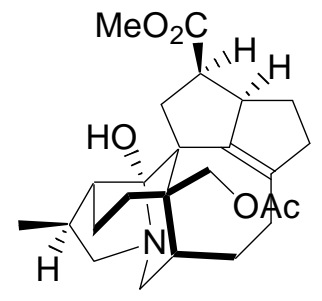

1.5

Figure 1.2 Selected Daphniphyllum alkaloids

\subsection{Daphnioldhanin A-Structure and Isolation}

Daphnioldhanin A (1.6, figure 1.3) is a natural product alkaloid which had been recently isolated from the aerial parts of plant saplings of Daphniphyllum Oldhami. ${ }^{11}$ A number of other natural alkaloids had also been isolated from the saplings of the same plant; namely daphnioldhanins B-F. Daphnioldhanin A has a yuzurimine-type skeleton with a hydroxyl group at C-9 and is composed of six fused heterocyclic rings. It was the first compound with this type of skeleton to be analysed with single-crystal X-ray diffraction.

The structural elucidation of daphnioldhanin A, 1.6, was achieved by Mu and co-workers in 2006 using comprehensive NMR studies including ROESY, IR spectroscopy, and singlecrystal X-ray diffraction. ${ }^{11}$

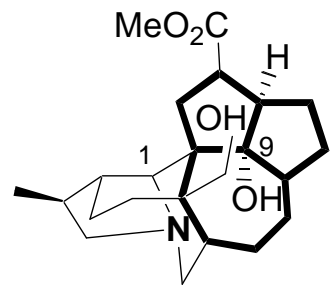

\section{6}

Figure 1.3 Daphnioldhanin A

\subsection{Reported Syntheses of Daphniphyllum alkaloids}

The total syntheses of certain Daphniphyllum alkaloids have been achieved successfully with stereocontrolled synthesis using a biomimetic approach, employing a Diels-Alder reaction and an aza-Prins cyclisation. As reported by Wallace and Heathcock, the 
biomimetic approach to the synthesis of alkaloids was developed in the 1980s and since then has been applied in the total synthesis of five Daphniphyllum alkaloids. ${ }^{12}$

This method was remarkable in that it generated six stereocenters in a 'one-pot' reaction. As seen from scheme 1.1, the first step was the oxidation of the 1,5-diol, 1.7 to dialdehyde 1.8, followed by treatment with ammonia and acetic acid, which leads to the dihydropyridine 1.10 This dihydro-pyridine can undergo an intramolecular Diels-Alder reaction to form the imine 1.11, which when heated as an acetic acid solution undergoes an intramolecular aza-Prins cyclisation to provide pentacyclic amine $\mathbf{1 . 1 2} .^{13}$

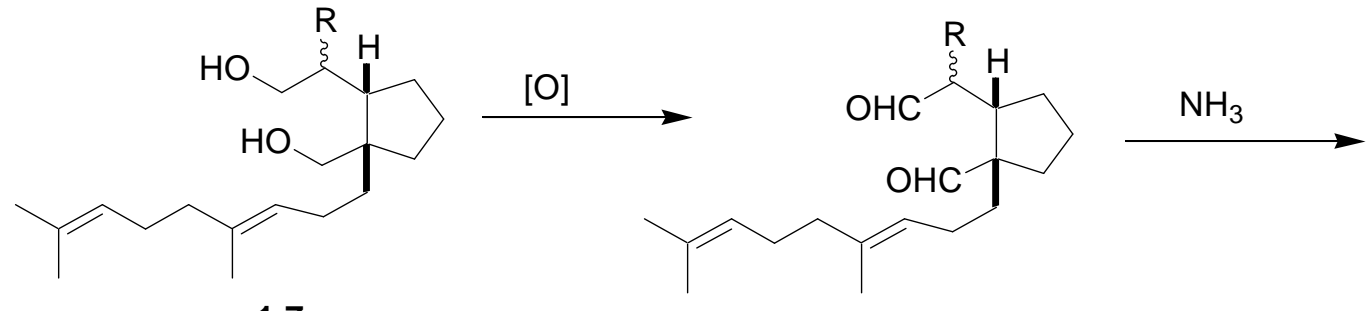

1.7

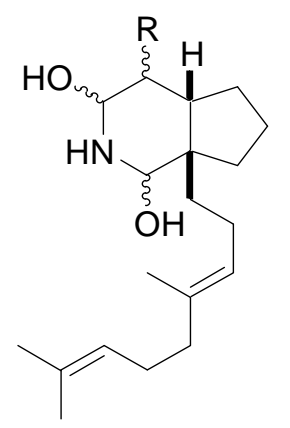

1.8

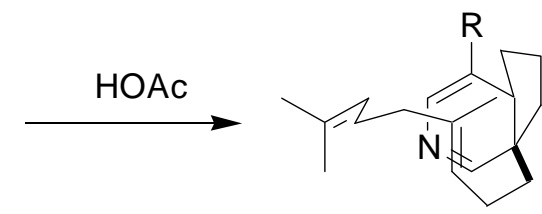

1.10
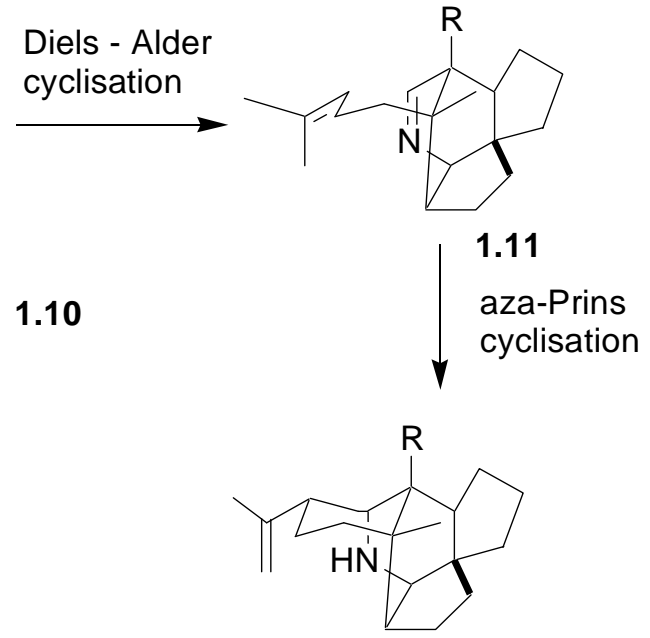

1.12

Scheme 1.1 Generalised biomimetic approach for the total synthesis of Daphniphyllum alkaloids

This method has its limitations, as discovered by Wallace and Heathcock. ${ }^{13}$ They found that the intramolecular inverse-electron demand Diels-Alder cycloaddition was tolerant to a range of alkyl substitution patterns of the dienophiles, but as expected they observed a decrease in the rate of reaction when an electron deficient dienophile was employed. As 
shown in scheme 1.2, diol 1.13 was oxidised to the dialdehyde 1.14 successfully, but subsequent reactions to form the imine $\mathbf{1 . 1 6}$ failed. The authors believed that failure to form the pyrrole 1.15 was responsible for the failure of this reaction cascade.

They also found that the structure of the pyrrole, cyclopentyl ring, quaternary carbon and all tertiary carbon centres in the starting diols (1.13) were crucial as alteration of this structure could cause competing side reaction or complete failure of the reaction cascade.

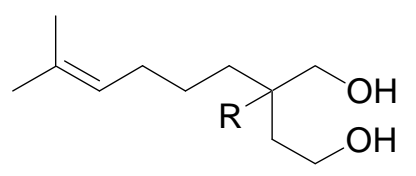

1.13

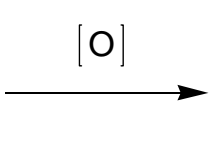

$\overbrace{R}^{N}$

1.16<smiles>[R]C(C=O)(CC)CCCC=C(C)C</smiles>

1.14
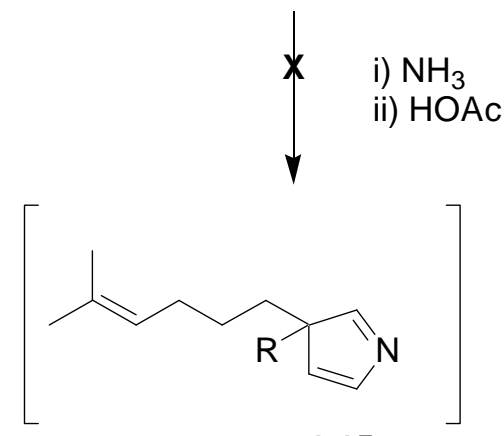

1.15

Scheme 1.2 Limitations of the biomimetic approach

In 1992, Heathcock and co-workers described the total synthesis of methyl homodaphniphyllate $\mathbf{1 . 1 8}$ (scheme 1.3). ${ }^{12}$ The synthesis required a total of 15 steps starting from known keto acid $\mathbf{1 . 1 7}$ to provide $\mathbf{1 . 1 8}$ and $\mathbf{1 . 1 9}$ in 1:1 ratio, with an overall yield of $1.1 \%$.

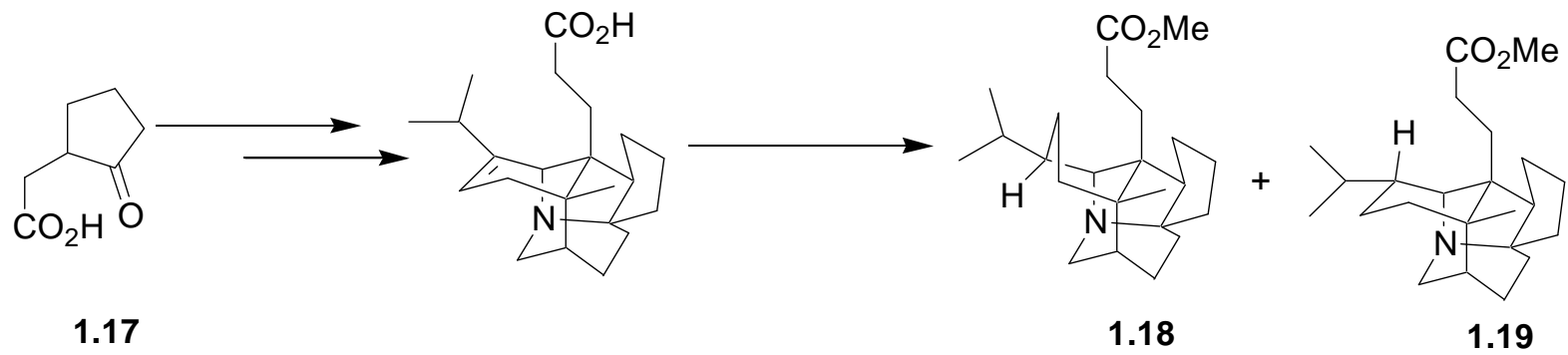

Scheme 1.3 Synthesis of methyl homodaphniphyllate $\mathbf{1 . 1 8}$ 
These methods, due to their limitations could not be applied to formation of other Daphniphyllum alkaloids, like daphnioldhanin A, and new methods for the synthesis of these compounds are actively searched for.

Daphnioldhanin A is a very interesting molecule as it contains a 5,5,7-fused tricyclic ring system (figure 1.4), presenting a significant synthetic challenge. This complex ring system has not been previously synthesised, and we envisaged that the 5,5,7-core could be used as a scaffold for the daphnioldhanin alkaloids. Specifically, we were interested in using a cascade approach to this tricyclic system.

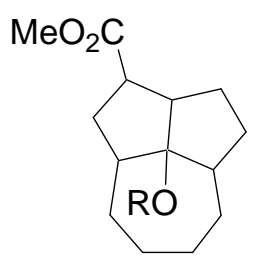

Figure 1.4 5,5,7-Core of daphnioldhanin A

We viewed that this challenging tricyclic ring system could be synthesised (scheme 1.4) via a radical cascade sequence from an acrylic ester (1.20) and the appropriate cycloheptene derived precursor (1.21). Alternatively, a carbene cycloaddition cyclisation cascade (CCCC) approach using rhodium catalyst could be applied - notably from a diazoketone derived from cyclopentanone (1.22), as in Heathcock's synthesis of methyl homodaphniphyllate. ${ }^{12}$ These will be discussed further in chapter 2 and 3.
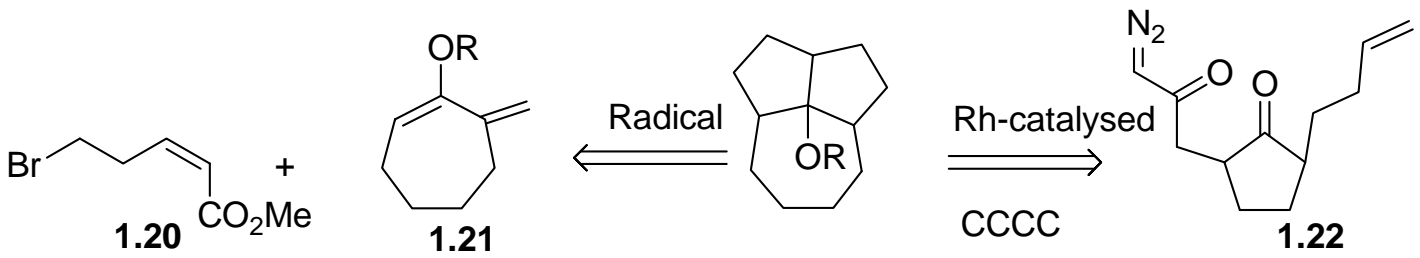

Scheme 1.4 Proposed approaches for daphnioldhanin A 5,5,7 core system. 


\subsection{Radical Approach towards Synthesis of Daphnioldhanin A}

\subsubsection{Radical Approach in Synthesis of Polycyclic Systems}

The use of radical reactions in the formation of polycyclic compounds has been well studied and is now commonly utilised methodology. Radical addition and radical cyclisations are important in the formation of new carbon-carbon bonds and carbonheteroatom bonds, which are often required for the synthesis of precursors of more complex natural products and bioactive compounds. The use of cascade of radical reactions in synthesising organic compounds is appealing because it provides chemists with elegant ways of designing 'one-pot' reactions where bonds can be constructed between carbons atoms in a cascade of highly selective reactions.

For example, as shown in scheme 1.5, the novel steroidal heptacycle 1.23 was formed involving a cascade of seven 6-endo trig cyclisations. ${ }^{14}$ The cascade begins with chain initiation through loss of the selenophenyl group from compound 1.24, generating the radical centre. Successive 6-endo trig radical cyclisations occur with the double bonds, until a termination of the radical species occurs. Importantly, these reactions proceed with high selectivity (both regioselectivity and stereoselectivity).
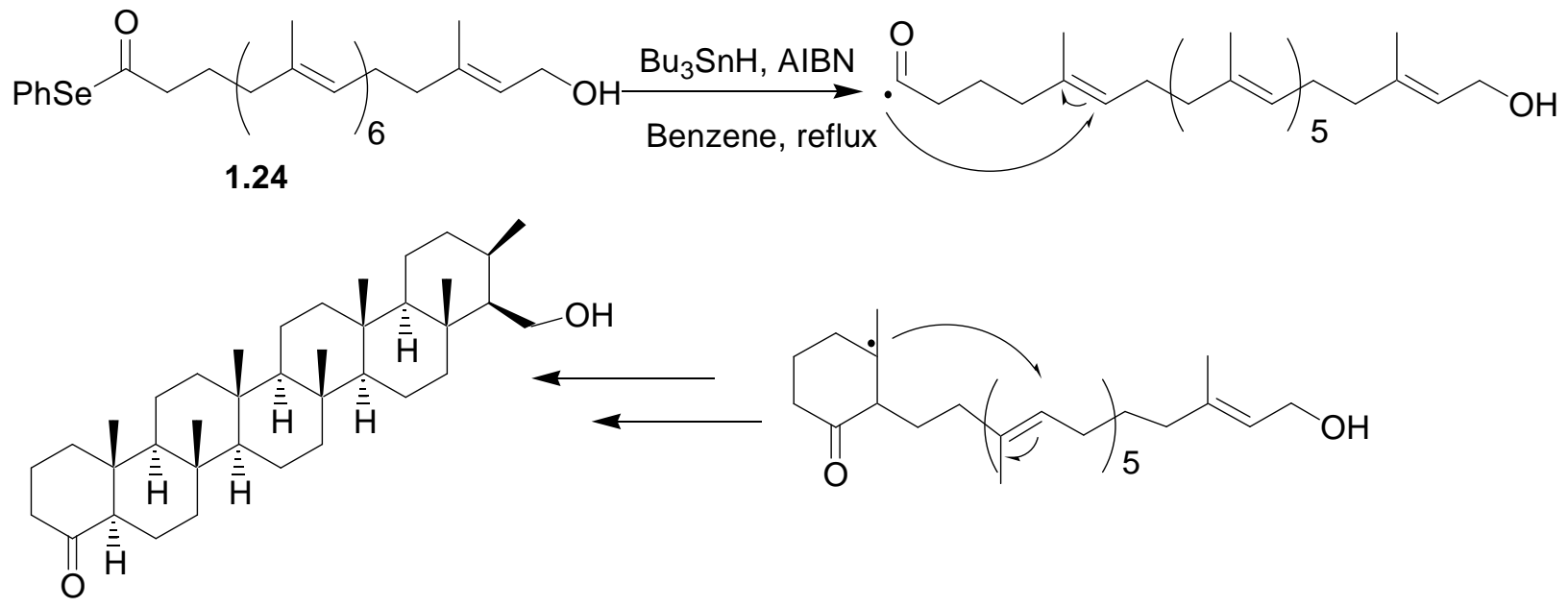

1.23

Scheme 1.5 Tandem 6-endo-trig cyclisation in heptacycle 1.23 synthesis 
Lee and co-workers also used a radical reaction in the synthesis of natural product lasonolide A (1.25), a cytotoxic macrolide isolated from the Caribbean marine sponge Forcepia sp. Radical cyclisation reactions of $\beta$-alkoxyacrylates were used in the synthesis of both of the tetrahydropyran rings found in lasonolide A. ${ }^{15}$

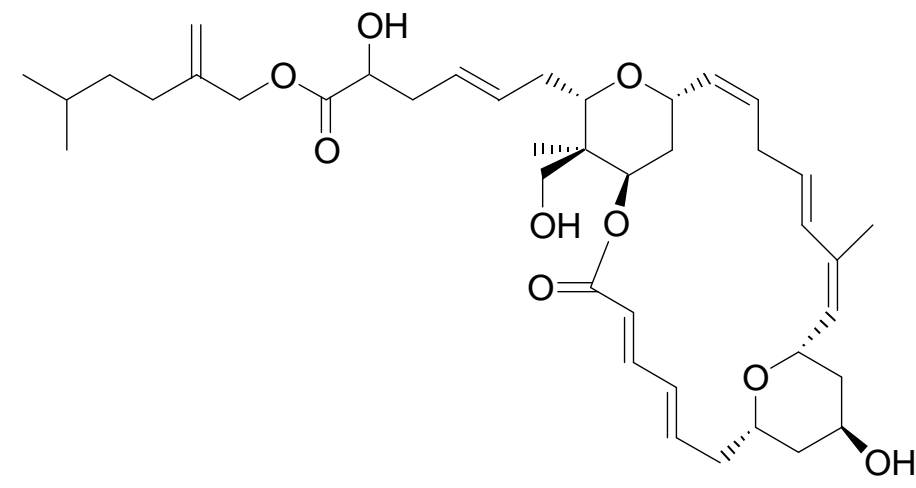

1.25

Figure 1.5 Lasonolide A

Retro-synthetically, the molecule was divided into two fragments and radical reactions were used as key steps in synthesising these precursors (scheme 1.6). As seen again, the radical reactions are selective, resulting in structures 1.26 and 1.27 in high yields. Subsequent reaction of these intermediates and coupling them ultimately led to lasonolide A 1.25.
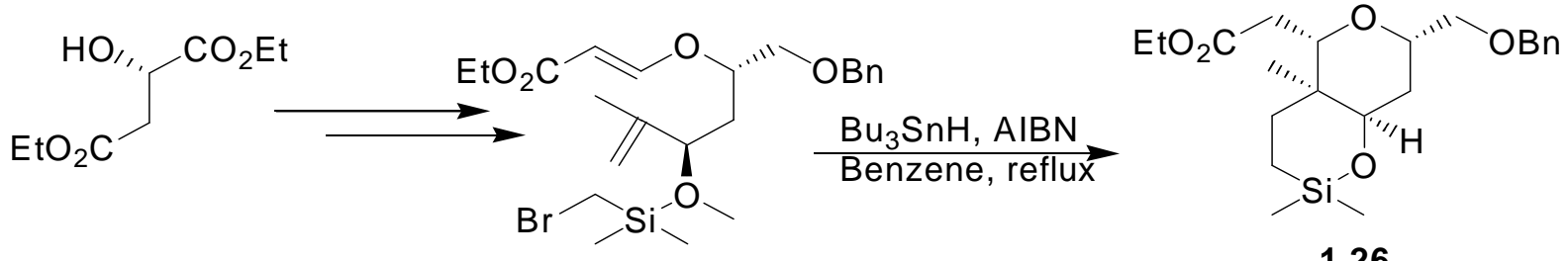

1.26

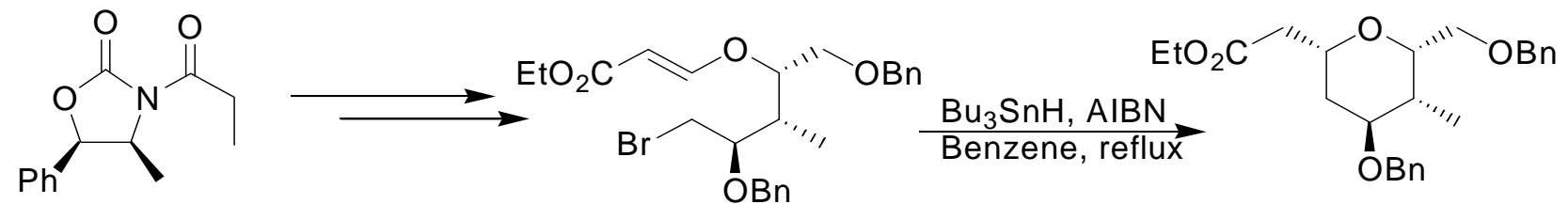

Scheme 1.6 Radical reactions in lasonolide A (1.25) synthesis 
Sharma and Gopinath have reported the use of radical cyclisations in the synthesis of natural products $(+)$-dihydrocanadenoside (1.28) and (+)-dihydrosporothriolide (1.29) from D-xylose (scheme 1.7) ${ }^{16}$ In this case, Barton-McCombie deoxygenation of xanthates 1.30 and $\mathbf{1 . 3 1}$ led to the initial radical centre, which cyclises selectively to afford the 5-exo-trig products.
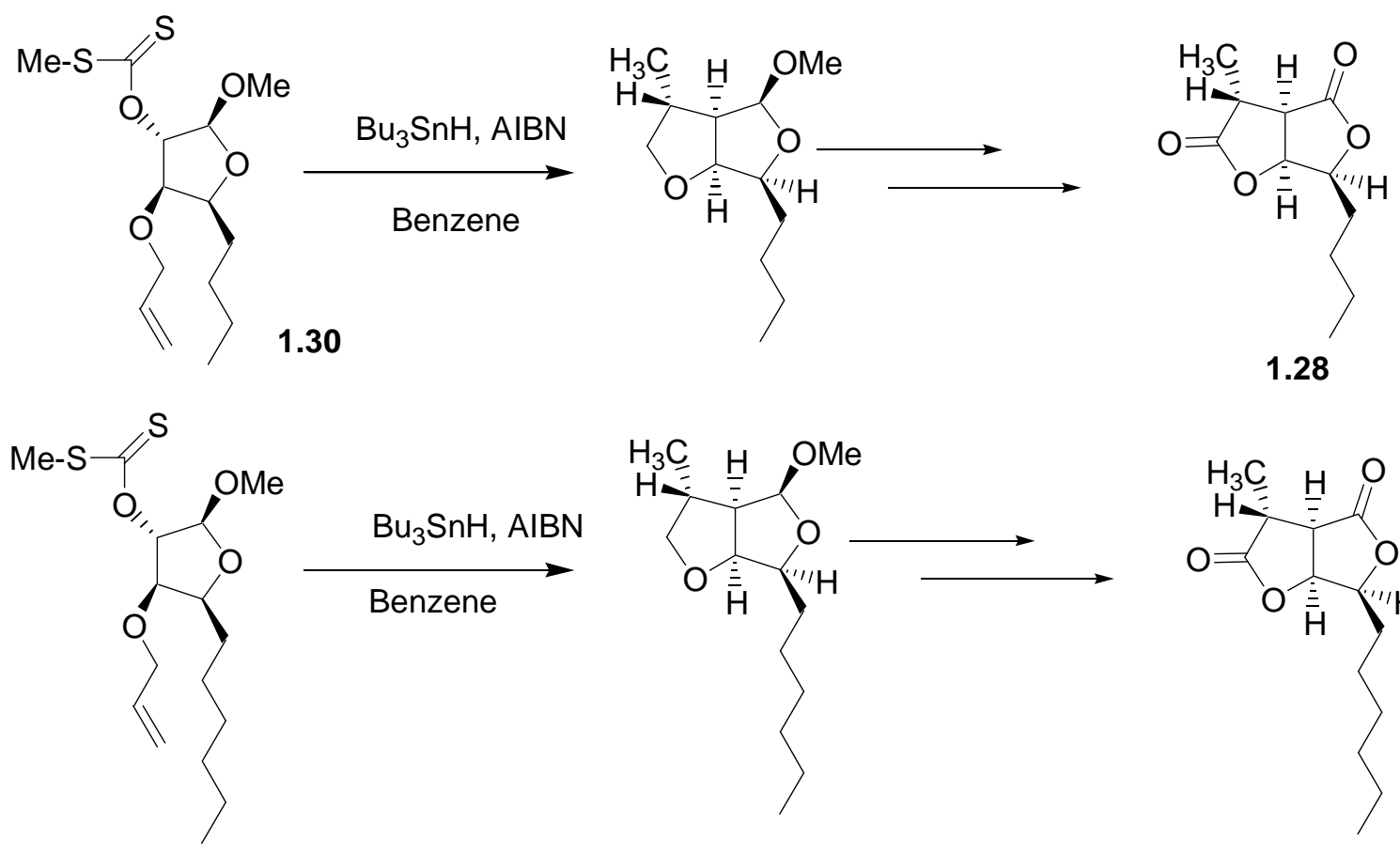

1.31

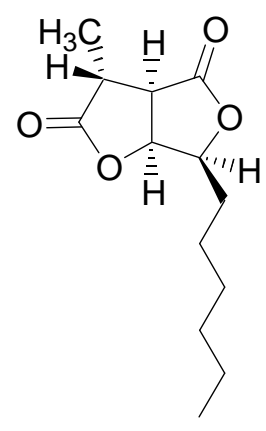

1.29

Scheme 1.7 Radical reactions in synthesis of $(+)$ dihydrocanadenoside (1.28) and $(+)$ dihydrosporothriolide (1.29)

Clark and colleagues used a radical cyclisation to synthesise griseolic acid, (1.33) an unusual monosaccharide derivative (scheme 1.8). Vinyl iodide 1.32, after initiation, underwent cyclisation onto the tethered alkene leading to both the required 5-exo-trig as well as 6-endo-trig cyclisation products in good yields. ${ }^{17}$ The 5-exo-trig product 1.33, subsequently led to griseolic acid (1.34). 


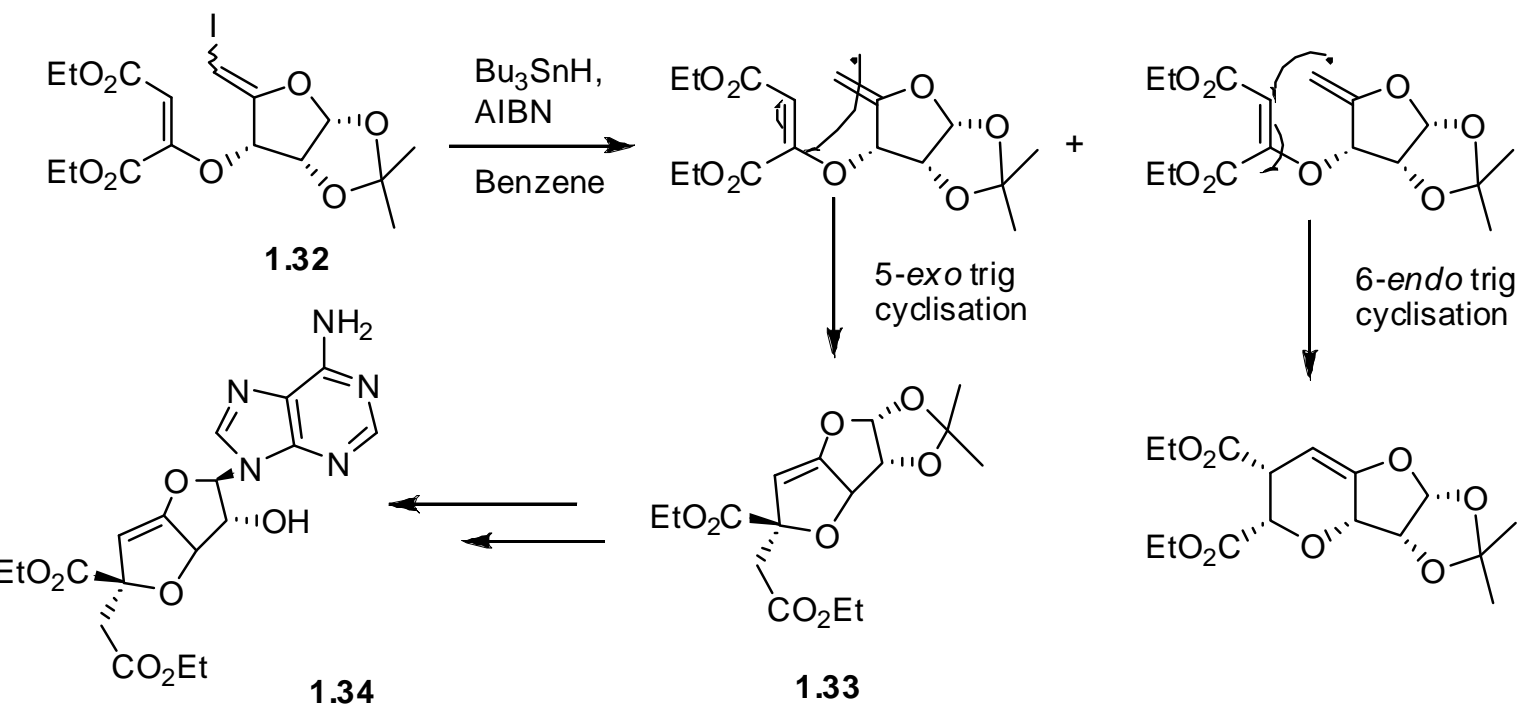

Scheme 1.8 Synthesis of griseolic acid (1.34)

Perhaps the most classic example of radical cyclisation in natural product synthesis is by Curran and Rakiewicz, ${ }^{18}$ whereby they synthesised $( \pm$ )-hirsutene (1.36) from compound 1.35 via tandem radical reactions (scheme 1.9). This method offers a synthetic strategy which can be used to prepare both simple and complex analogous and also allowed the synthesis of isomeric relatives of ( \pm )-hirsutene, which was often difficult to do using standard methods.

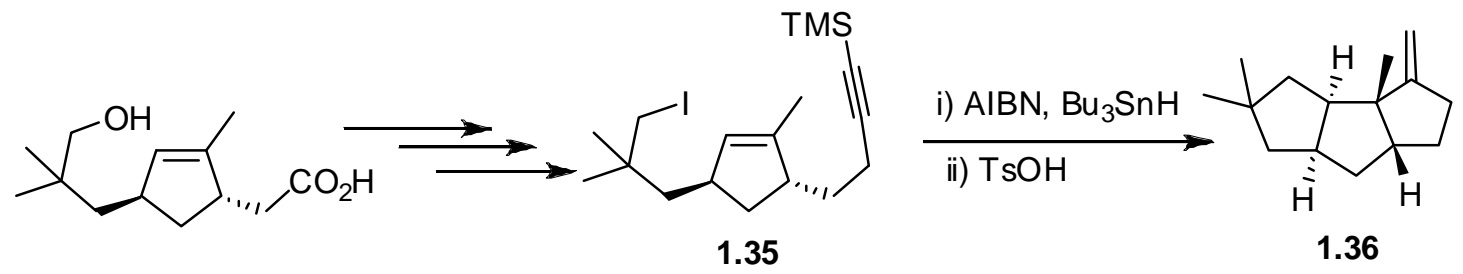

Scheme 1.9 Synthesis of $( \pm$ )-hirsutene (1.36)

Parsons and colleagues used a novel free radical cyclisation approach to synthesise lysergic acid analogue 1.38 (scheme 1.10). The synthesis was accomplished through selective tandem double 5-exo-trig and 6-endo trig cyclisations of the aryl radical $\mathbf{1 . 3 7}$ as shown in scheme 1.10. ${ }^{19}$ 

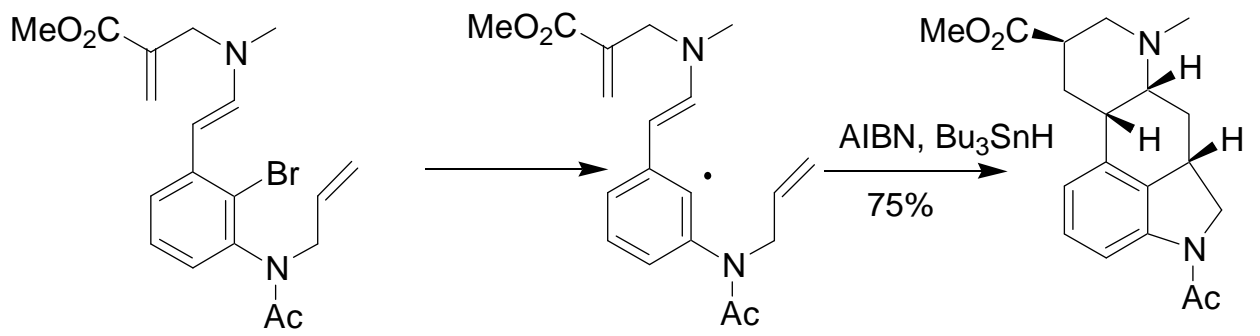

1.37

1.38

Scheme 1.10 Synthesis of lysergic acid analogue (1.38)

\subsubsection{Radical Approach towards Daphnioldhanin A Synthesis}

The use of radical reactions as a synthetic tool for natural product synthesis is very well established. Our vision for the synthesis of the 5,5,7 core of daphnioldhanin A is shown in scheme 1.11.

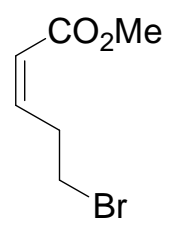

1.20

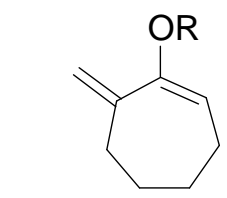

Radical Addition

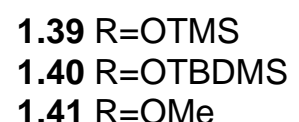

$1.41 \mathrm{R}=\mathrm{OMe}$

$\mathrm{MeO}_{2} \mathrm{C}$

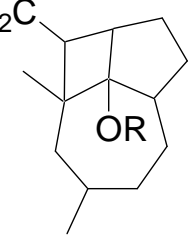

$1.48 \mathrm{R}=\mathrm{OTMS}$

$1.49 \mathrm{R}=\mathrm{OTBDMS}$

$1.50 \mathrm{R}=\mathrm{OMe}$

$\mathrm{MeO}_{2} \mathrm{C}$
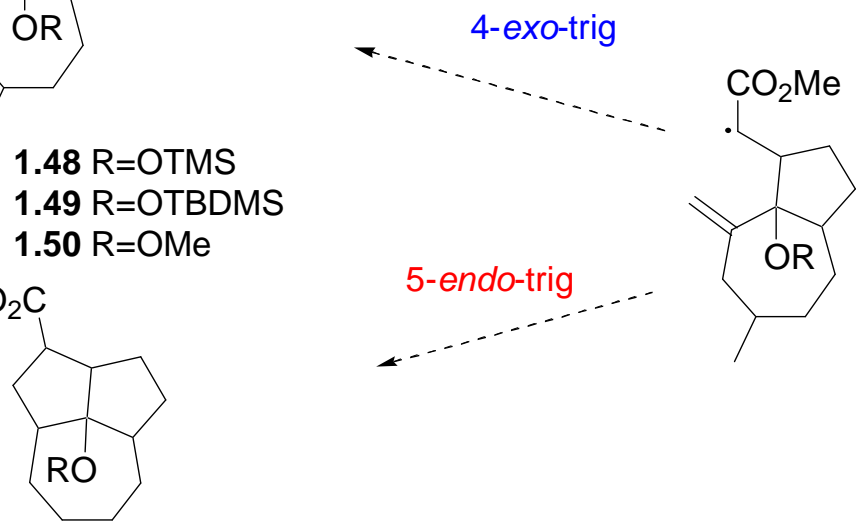

$1.45 \mathrm{R}=\mathrm{OTMS}$

$1.46 \mathrm{R}=\mathrm{OTBDMS}$

1.47 $\mathrm{R}=\mathrm{OMe}$

\section{$1.51 \mathrm{R}=\mathrm{OTMS}$ \\ $1.52 \mathrm{R}=\mathrm{OTBDMS}$ \\ $1.53 \mathrm{R}=\mathrm{OMe}$}

Scheme 1.11 Proposed radical approach towards the synthesis of daphnioldhanin A 
In order to use this approach for making the 5,5,7 ring system of daphnioldhanin A, incorporation of a 5-endo-trig cyclisation is required as a key step in the synthesis. Prior to discussing some recent examples of the criteria for 5-endo-trig cyclisation, it is necessary to provide some background on Baldwin's rules. According to Baldwin's rules, 5-endo-trig cyclisation is disfavoured over 4-endo-trig cyclisation, and to the best of our knowledge this disfavoured cyclisation has yet to be demonstrated in an all carbon ring system (as in the case of daphnioldhanin A).

\section{$\underline{1.5 \text { Baldwin's Rules }}$}

\subsubsection{Cyclisation Process}

Ring forming reactions are an important part of organic synthesis since they lead to formation of precursors of many complex natural products. Ring closing reactions can be classified as exo- and endo- depending on where the breaking bond is in relation to the smallest ring formed. Thus, to form an exo-bond the breaking bond would be exo-cyclic to the smallest ring formed and for an endo- bond the breaking bond would be endo-cyclic and be incorporated into the ring. The suffixes tet, trig and dig indicate the geometry of the carbon which is undergoing the ring-closure reaction (i.e. tetrahedral, trigonal planar and digonal). Some examples are shown in figure $1.6:^{20}$

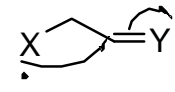

3-exo-trig

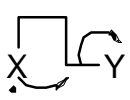

4-exo-tet

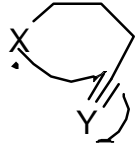

5-exo-dig

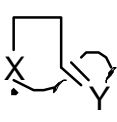

4-exo-trig

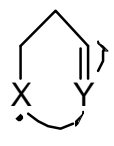

5-endo-trig

Figure 1.6 Examples of endo and exo cyclisations

Baldwin's rules state that the favoured cyclisation is one in which the length and nature of the linking chain enables the terminal atom to obtain the required trajectory. ${ }^{21}$ The disfavoured process require severe distortion of bond angles and distances to achieve orbital alignment, and thus if alternate pathways exist, these will dominate over the disfavored process. $^{21}$ 
The rules are summarized in table 1.1: ${ }^{21}$

Table 1.1 Baldwin's rules

\begin{tabular}{|l|l|l|}
\hline Type of System & Favoured & Disfavoured \\
\hline Tetrahedral system & 3 to 7-exo-tet & 5 to 6-endo-tet \\
\hline Trigonal systems & 3 to 7-exo-trig, 6 to 7-endo trig & 3 to 5-endo-trig \\
\hline Digonal Systems & 5 to 7-exo-dig, 3 to 7-endo-dig & 3 to 4-exo-dig \\
\hline
\end{tabular}

\subsubsection{5-Endo-Trig Cyclisation in Synthesis}

Although the 5-endo-trig cyclisation is considered to be a disfavoured process relative to the competing 4-exo-trig cyclisation, it has been seen in a number of systems where certain constraints are present. Baldwin and co-workers were the first to report this unusual cyclisation in systems containing sulfur. They found that thiol 1.54 reacted with $\mathrm{NaOMe}$ and $\mathrm{MeOH}$ at reflux to provide sulfide 1.55 (scheme 1.12). They concluded that as second row elements have larger radii and bond length, molecules containing these elements may form conformations which are difficult for the first row elements to achieve. ${ }^{22}$

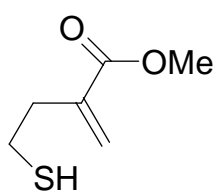

1.54

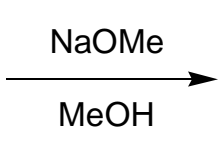

$\mathrm{MeOH}$

Scheme 1.12 5-endo-Trig cyclisation in sulphur containing compound 1.54

Ishabashi and co-workers found that radical cyclisation on $N$-vinylic $\alpha$-chloroacetamide 1.56 proceeded through the 'disfavoured' 5-endo-trig cyclisation of radical as opposed to the 4-exo-trig cyclisation to afford 5-membered lactams 1.57 (scheme 1.13). ${ }^{23}$ 


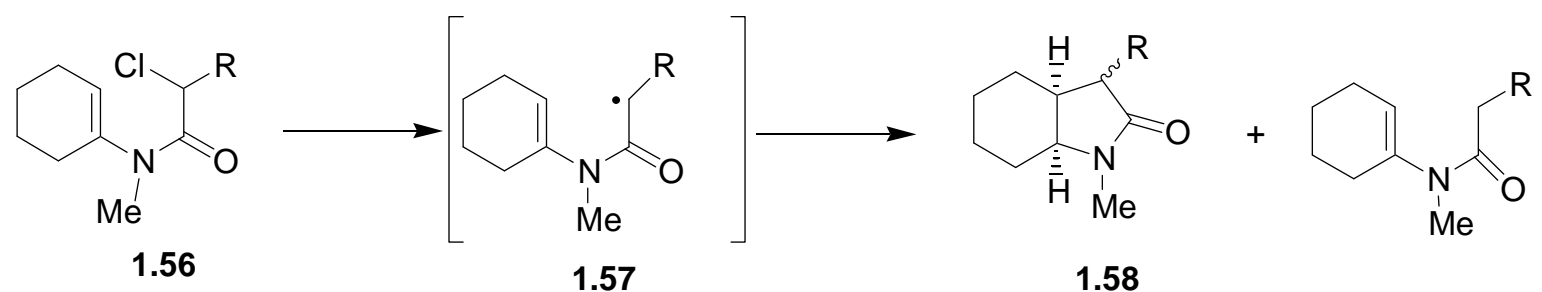

Scheme 1.13 'Disfavoured' 5-endo-trig cyclisation in carbonyl containing compound 1.56

The authors believed that the carbonyl group of amide $\mathbf{1 . 5 6}$ played an essential role in the 5-endo-trig cyclisation. To test their theory, they performed a series of reaction with dithioacetals 1.59 and $\mathbf{1 . 6 0}$ (scheme 1.14). The results showed that the five-membered ring 1.61 only formed if the carbonyl group was incorporated in the ring system as shown for compound 1.59. Absence of the carbonyl group, led, to only reduction product 1.62, as in the case of $\mathbf{1 . 6 0 .}$

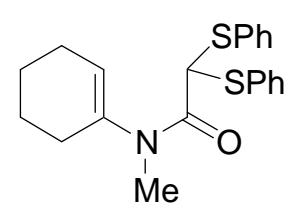

1.59

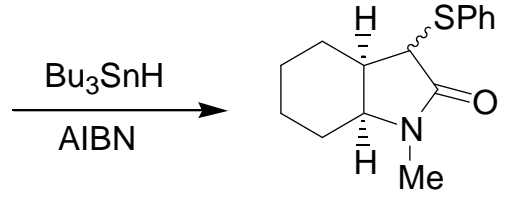

1.61

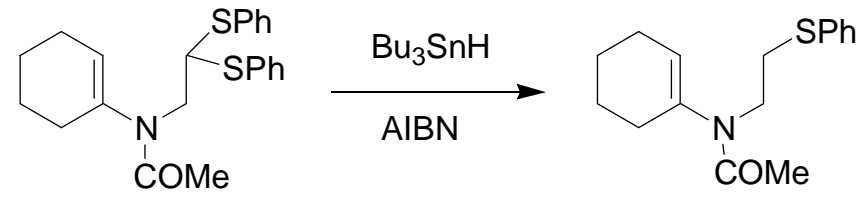

1.60

1.62

Scheme 1.14 Radical cyclisation in dithioacetals $\mathbf{1 . 5 9}$ and $\mathbf{1 . 6 0}$

Mendenhall and co-workers found that 5-endo-trig cyclisation of 2-formylbenzadehyde radical is highly favored as compared to the 4-exo-trig cyclisation (scheme 1.15). They found that the thermal decomposition of aldehyde 1.63, lead to a mixture of stereoisomeric 3,3-biphthalides 1.65. This could have only occurred through a 5-endo-trig closure of the 2formylbenzaldehyde radical to form the lactone radical 1.64, which dimerised to form compound 1.65. Electron Spin Resonance and laser flash photolysis studies of the radical intermediate provided evidence of this cyclisation. ${ }^{24}$ 


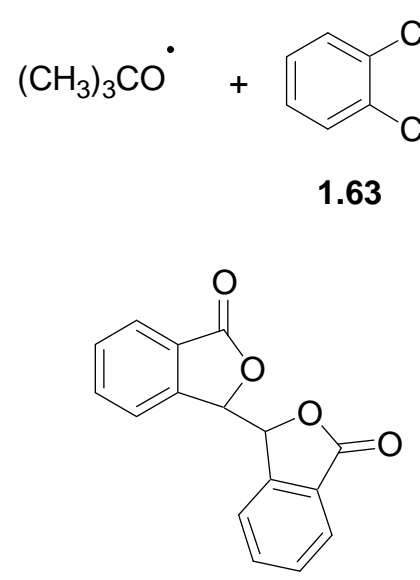

1.65
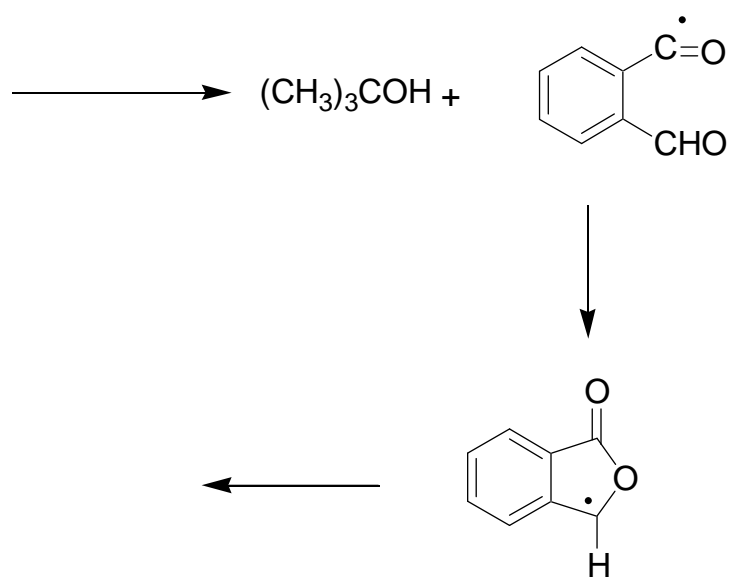

1.64

Scheme 1.15 5-endo-Trig cyclisation of 2-formylbenzaldehyde (1.63)

Most cases of 5-endo-trig cyclisation have only been seen in molecules, which have a carbonyl or a heteroatom (such as nitrogen), incorporated into the ring system. This constraint system prevents the 4-exo-trig cyclisation from occurring, as the resulting 4-exotrig cyclisation product is higher in energy as compared to the 5-endo-trig cyclisation product. So far, there has been no reported example of this cyclisation in an all carbon ring system.

Preliminary computer-aided modelling studies of 4-exo-trig cyclisation products (1.481.50) and the 5-endo-trig cyclisation products (1.51-1.53) from our proposed system (figure 1.7), ${ }^{25}$ have shown that the radical resulting from the 4-exo-trig cyclisation is significantly higher in energy than the radical from the 5-endo-trig cyclisation. In addition, the differences in transition state energy, whilst not fully optimised, were closer in energy. To us, this suggested the intriguing possibility that, if the 4-exo-trig was a favoured process, ring opening of the resultant highly strained radical product 1.48-1.50, and subsequent 5endo-trig closure to the more thermodynamically stable compound 1.51-1.53 may occur. 


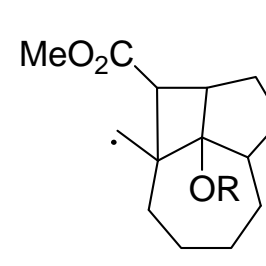

$1.48 \mathrm{R}=\mathrm{OTMS}$

$1.49 \mathrm{R}=\mathrm{OTBDMS}$

$1.50 \mathrm{R}=\mathrm{OMe}$

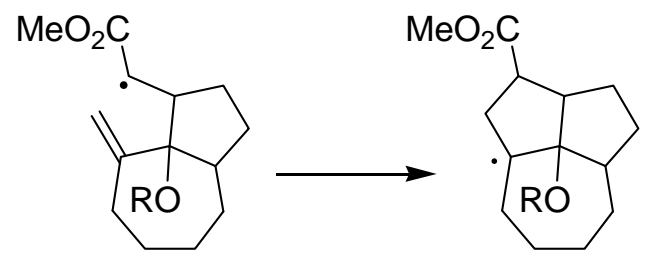

$1.51 \mathrm{R}=\mathrm{OTMS}$

$1.52 \mathrm{R}=$ OTBDMS

$1.53 \mathrm{R}=\mathrm{OMe}$

Figure 1.7 4-exo-Trig versus 5-endo-trig cyclisation in daphnioldhanin A precursor synthesis

In addition to the possibilities offered by a radical cascade sequence, we also considered investigation of an alternate cascade sequence involving rhodium-carbene chemistry that will be discussed in the following section.

\subsection{Carbene Cycloaddition Cyclisation Cascade (CCCC) Approach}

\subsubsection{Principle and Advantages of CCCC approach}

Over the years the use of carbene 1,3-dipolar cycloaddition cascades have been of great interest in the total synthesis of compounds. The major attraction of this cycloaddition method is the stereoselective formation of ring systems, which are vital in the synthesis of complex natural products. The discovery of new classes of dipoles and dipolarophiles has also lead to greater versatility of this synthetic strategy. ${ }^{26}$ These dipolar moieties have been used in tandem cyclisation reactions with olefinic, acetylenic and hetero-multiple-bonded dipolarophiles. The simplest additions of these types involve addition of a carbene to the oxygen atom of a carbonyl group to afford an oxonium ylide. Some dipoles, which are commonly used in synthesis, are nitrones, nitrile oxides, carbonyl ylides, azomethine ylides and azides. The choice of dipole depends on the type of heterocyclic system that is to be produced. For example, as shown in scheme 1.16, nitrones have been used as dipoles to synthesise bridged, medium-sized rings (1.67) through intramolecular nitrone cycloaddition. $^{27}$ 


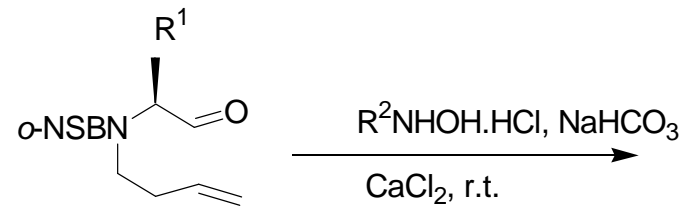

1.66

$\mathrm{R}^{1}=$ alkyl

$\mathrm{R}^{2}=\mathrm{Me}, \mathrm{Bn}$
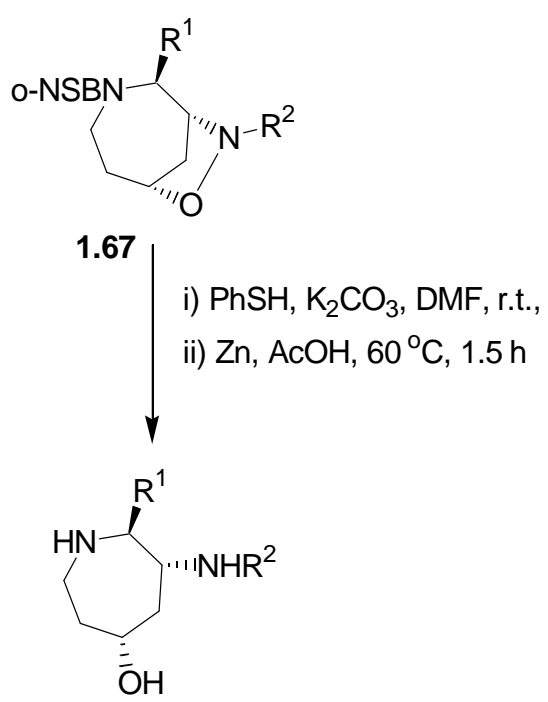

Scheme 1.16 Nitrone cycloaddition

In a similar manner, carbonyl ylides can be used to generate oxo-bridged ring systems. Carbonyl ylides can be generated 'in situ' by photolysis of oxiranes or 1,3,4-oxazolidines. ${ }^{27}$ Another well-known method of oxonium ylide generation involves the use of rhodium catalysts, which may decompose $\alpha$-diazoketones and subsequently form oxonium ylides with another carbonyl group. Carbonyl ylides are very reactive and readily undergo facile dipolar cycloaddition with alkenes and alkynes. ${ }^{26}$

The use of rhodium acetate has been very effective, as a catalyst for keto carbenoid generation. ${ }^{27}$ This method follows the formation of a carbonyl ylide through the attack of the rhodium carbenoid intermediate onto a lone pair of electrons on the carbonyl group. The resultant dipole leads subsequently to intramolecular cycloaddition. A general scheme of this is shown in scheme 1.17. ${ }^{28}$ 


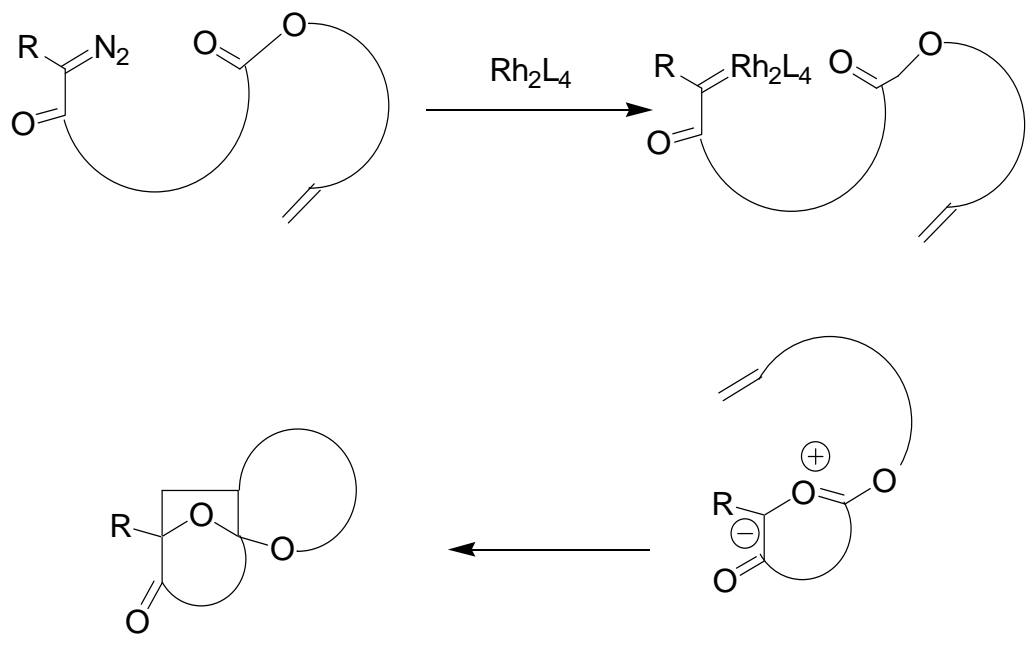

Scheme 1.17 General Scheme for the CCCC approach

In 1988, Padwa and co-workers demonstrated the use of $\mathrm{Rh}_{2}(\mathrm{OAc})_{4}$ for the intramolecular synthesis of six-membered rings from carbonyl ylides. ${ }^{28}$ The reaction of diazo ketone 1.68, (scheme 1.18) with the rhodium catalyst was consistent with the mechanism, in which the key step involves the intramolecular cyclisation of the keto carbenoid onto the oxygen atom of the ester carbonyl. The resulting resonance stabilised six-membered carbonyl ylide intermediate was then trapped by the internal double bond to give the desired major product $\mathbf{1 . 6 9}$, and 1.70 as a by-product.

In the presence of excess dimethyl acetylenedicarboxylate (DMAD) the internal cycloaddition was entirely suppressed, as bases such as pyridine and DMAD are excellent traps for carbenes, ${ }^{29}$ and the expected bimolecular dipolar cycloadduct 1.71 was formed as the major product. ${ }^{28}$ 


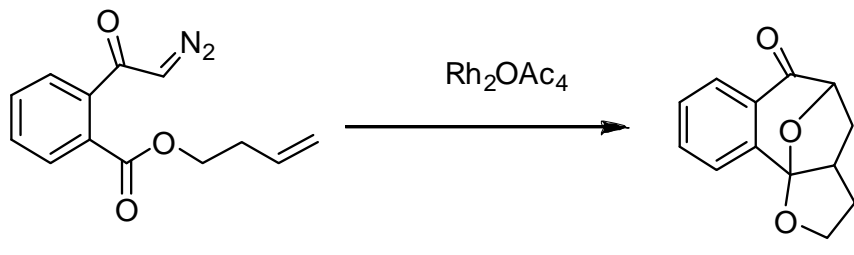

1.68

1.69

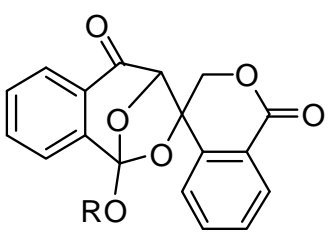

1.70<smiles>[R20]C(=O)OCC(=O)OCC(=O)OC</smiles>

1.71

Scheme 1.18 Rhodium and DMAD reaction with diazo compound $\mathbf{1 . 6 8}$

The use of rhodium (II) catalysed reactions in the formation of bimolecular cycloadducts has been studied by England and co-workers, whereby they looked into tandem carbonyl ylide formation and 1-3 dipolar cycloaddition of highly functionalised diazo compounds. ${ }^{30}$ The rhodium-catalysed reaction took place intramolecularly to form products derived from trapping of the carbonyl with a tethered alkene. ${ }^{30}$ An example involved rhodium (II) catalysed intramolecular cycloaddition of alkenyl ether 1.72, in which the cycloaddition ran smoothly to give cycloadduct $\mathbf{1 . 7 3}$ containing 4 stereocenters in good yield as shown in scheme 1.19.

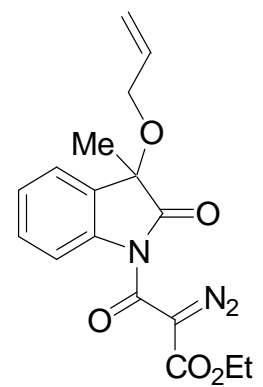

1.72

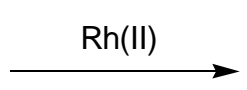

1.73

Scheme 1.19 Example of rhodium-mediated CCCC approach 


\subsubsection{CCCC Approach in Synthesis of Polycyclic System}

The versatility of carbene cycloaddition cyclisation cascade (CCCC) methodology has made it a useful tool in natural product synthesis. Schmatz and co-workers used a rhodiumcatalysed intramolecular dipolar cycloaddition reaction as an integral step in the synthesis of (-)-colchicine 1.76 and (-)-isocolchicine 1.77 (scheme 1.20). Colchicine is an alkaloid obtained from meadow saffron, which is known to exhibit antimitotic activity. The CCCC reaction of $\alpha$-diazoketone $\mathbf{1 . 7 4}$ with the tethered alkyne was carried out in the presence of $\mathrm{Rh}_{2}(\mathrm{OAc})_{4}$ at $110{ }^{\circ} \mathrm{C}$. This led to the formation of oxatetracyclic compound $\mathbf{1 . 7 5}$ in $98 \%$ d.e. which was then converted to $\mathbf{1 . 7 6}$ and $\mathbf{1 . 7 7}$ over subsequent steps. ${ }^{31}$<smiles>C#CC([Se-])CCc1cc(OC)c(OC)c(OC)c1C(=O)CCC(=O)C=[W]</smiles>

1.74

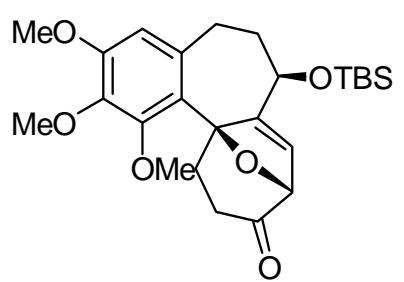

1.75

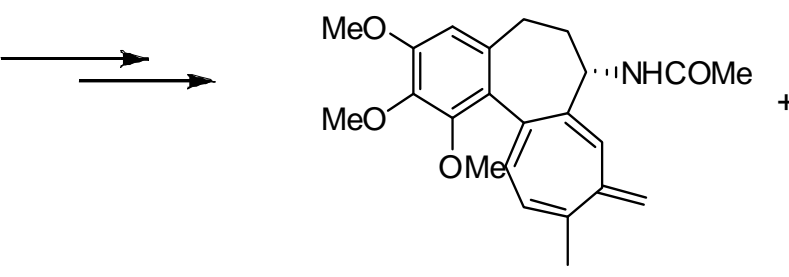

1.76



1.77

Scheme 1.20 CCCC approach in synthesis of (-) colchicine and (-) isocolchicine

Padwa and co-workers used CCCC approach to synthesise the oxabicyclo-[3.2.1]octane ring of $( \pm$ )-ribasine 1.80 . They subjected diazoketone 1.78 to CCCC reaction in the presence of $\mathrm{Rh}_{2}(\mathrm{TFA})_{4}$ leading to the formation of $\mathbf{1 . 7 9}$ (scheme 1.21). This product can be easily converted to $\mathbf{1 . 8 0}$, the exact core structure of ribasine, through insertion of an aldehyde group in place of the ethoxycarbonyl and an imino group instead of the alkenyl moiety in compound 1.79. ${ }^{32}$ 


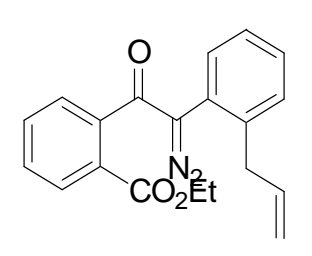

1.78

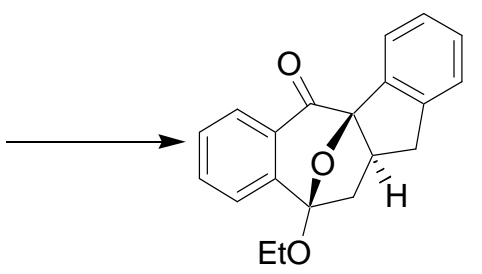

1.79

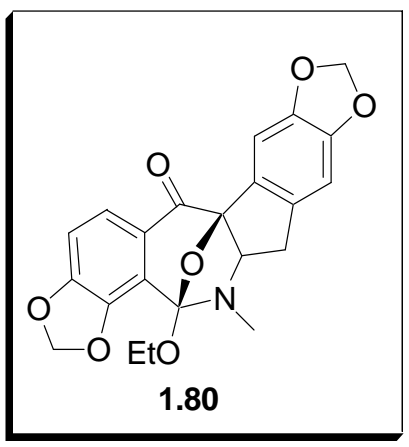

Scheme 1.21 CCCC approach in synthesis of $( \pm)$-ribasine.

In another study, Padwa and co-workers used the CCCC reaction of carbonyl ylides to synthesise the hexacyclic framework found in kopsifoline alkaloids (scheme 1.22), which are possibly derived from aspidosperma alkaloids. Diazoketone $\mathbf{1 . 8 1}$ underwent a CCCC reaction to form cycloadduct $\mathbf{1 . 8 2}$ as a single isomer. Further synthetic transformations led to the hexacyclic skeleton (1.83) of the kopsifoline alkaloid. ${ }^{33}$

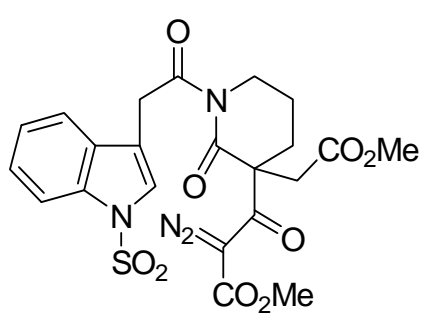

1.81

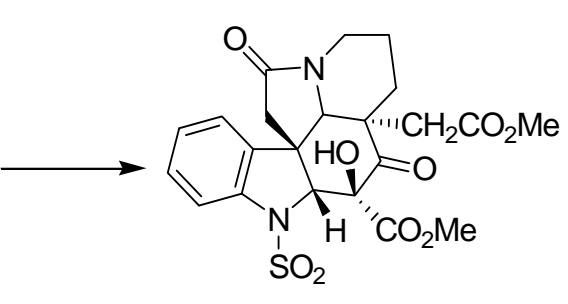

1.82

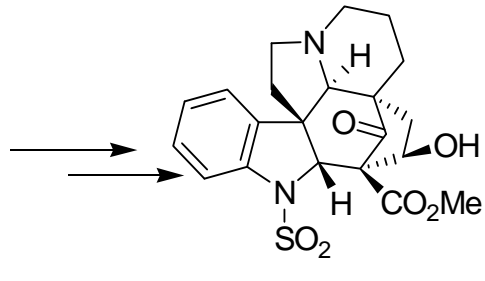

1.83

Scheme 1.22 CCCC approach in the synthesis of kopsifoline alkaloid $\mathbf{1 . 8 3}$

The complexity of these systems and efficiency observed in the cyclisation process compelled us to consider the CCCC approach as a viable means for construction of the 5,5,7-core of daphnioldhanin A. 


\subsubsection{CCCC Approach towards Daphnioldhanin A Synthesis}

An alternate strategy for making the 5,5,7 ring system of daphnioldhanin A involves utility of a 1,3 intramolecular carbene cycloaddition cyclisation cascade CCCC approach (scheme 1.23). The CCCC precursor 1.94 and $\mathbf{1 . 9 5}$ (which is subjected to treatment with rhodium catalyst) could be accessed over a series of transformation of cyclopentanone derivatives 1.84 and 1.85. CCCC reaction on 1.94 and 1.95 should afford 1.100 (which is similar to daphnioldhanin A 5,5,7 core system) after subsequent decarboxylation of $\mathbf{1 . 9 8}$ and $\mathbf{1 . 9 9}$
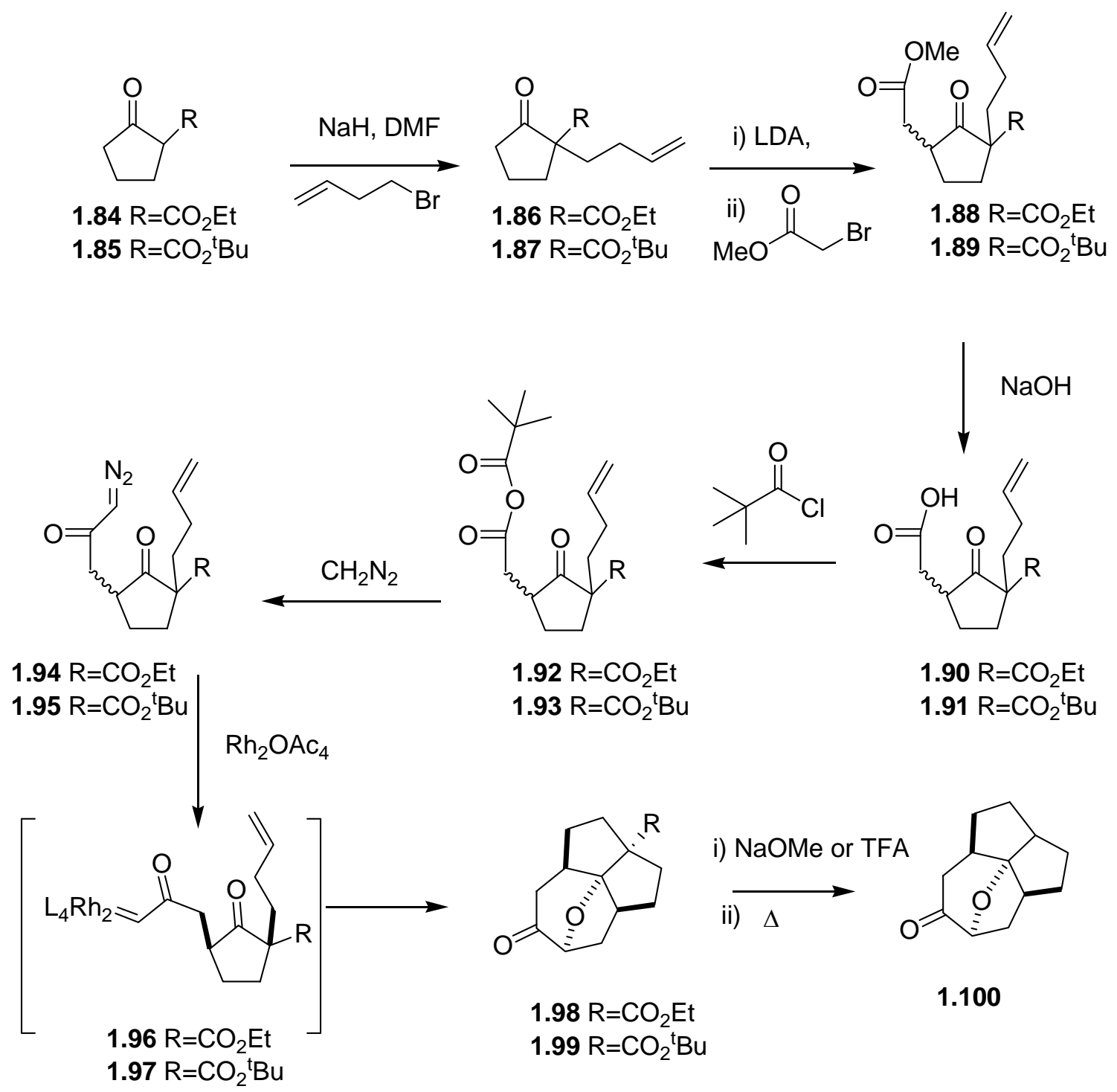

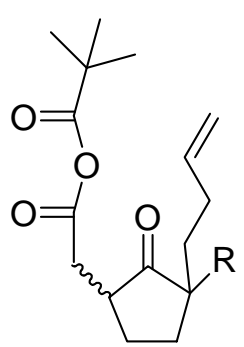

$1.92 \mathrm{R}=\mathrm{CO}_{2} \mathrm{Et}$

$1.93 \mathrm{R}=\mathrm{CO}_{2}{ }^{\mathrm{t}} \mathrm{Bu}$

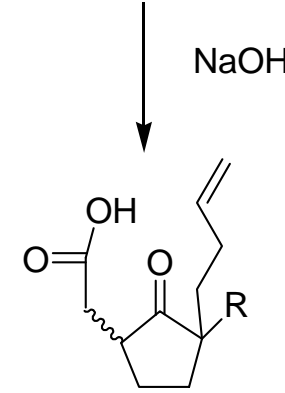

$1.90 \mathrm{R}=\mathrm{CO}_{2} \mathrm{Et}$ $1.91 \mathrm{R}=\mathrm{CO}_{2}{ }^{\mathrm{t}} \mathrm{Bu}$<smiles>CC(C)(C)C(=O)Cl</smiles><smiles></smiles>

i) NaOMe or TFA

ii) $\Delta$<smiles>O=C1CC2CCC3CCC(CC13)C2O</smiles>

$1.98 \mathrm{R}=\mathrm{CO}_{2} \mathrm{Et}$

1.100

Scheme 1.23 Proposed CCCC approach towards synthesis of Daphne A 


\section{$\underline{1.7 \text { Objectives }}$}

The objectives of this research are to investigate the viability of two different cascade approaches for the assembly of the 5,5,7-carbocyclic core of daphnioldhanin A.

Firstly, we aim to investigate a radical addition/cyclisation cascade in which a 5-endo trig cyclisation is the key step. These reactions would be carried out on cycloheptanone derivatives and successive 5-exo-trig followed by 5-endo-trig cyclisation would result in the desired tricyclic system.

Secondly, we aim to lay the foundation for the rhodium catalysed carbene cyclisation cascade sequence. The starting point for these reactions would be cyclopentanone derivatives and through rhodium-catalysed CCCC reaction, would provide another pathway to attain the targeted 5,5,7-tricyclic ring system. 


\section{Chapter 2: Synthesis of Radical Precursors and Radical $\underline{\text { Reactions: Results and Discussion }}$}

The proposed radical addition-cyclisation cascade as a synthetic for the formation of the 5,5,7-core of daphnioldhanin A represents a significant challenge for a variety of reasons. As previously discussed, the key step in this approach relies on the typically disfavoured 5endo-trig cyclisation. However, equally important is the regioselectivity of the initial radical addition to the system. For the proposed sequence to be successful, the reaction of the adduct radical with the diene (1.39-1.41) must proceed with complete regioselectivity at the endo-cyclic olefin resulting in compounds 2.1-2.3 (scheme 2.1). Alkyl radicals are generally accepted to be nucleophilic in nature, ${ }^{34}$ and one might therefore predict that the preferred selectivity for the radical addition would proceed at the more electron deficient exo-cyclic alkene to provide 2.1-2.3, as opposed to the more electron rich enol ether moiety, which would provide our desired products 1.42-1.44.
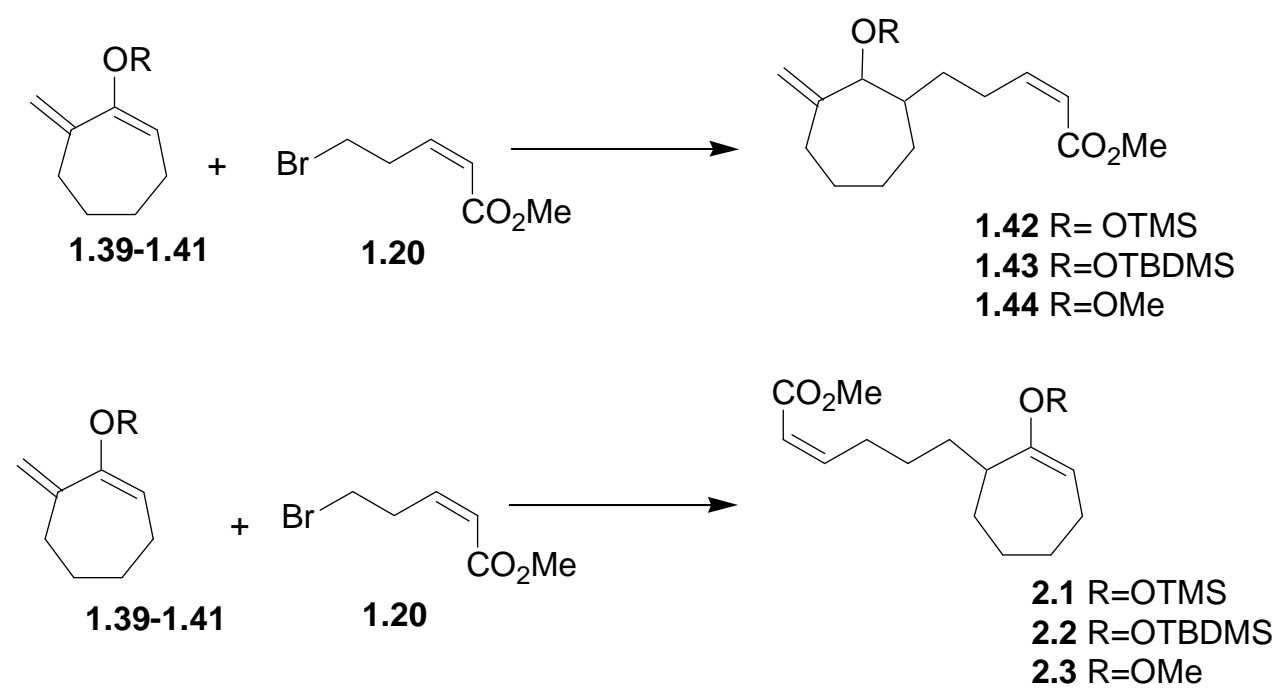

Scheme 2.1 Competing regioselective radical additions

However, the contribution of the stabilities of the adduct radicals to any possible regioselectivity cannot be ignored (scheme 2.2). Therefore, our initial studies were focused on determining the regioselectivity as a function of the properties of the adduct radical. 


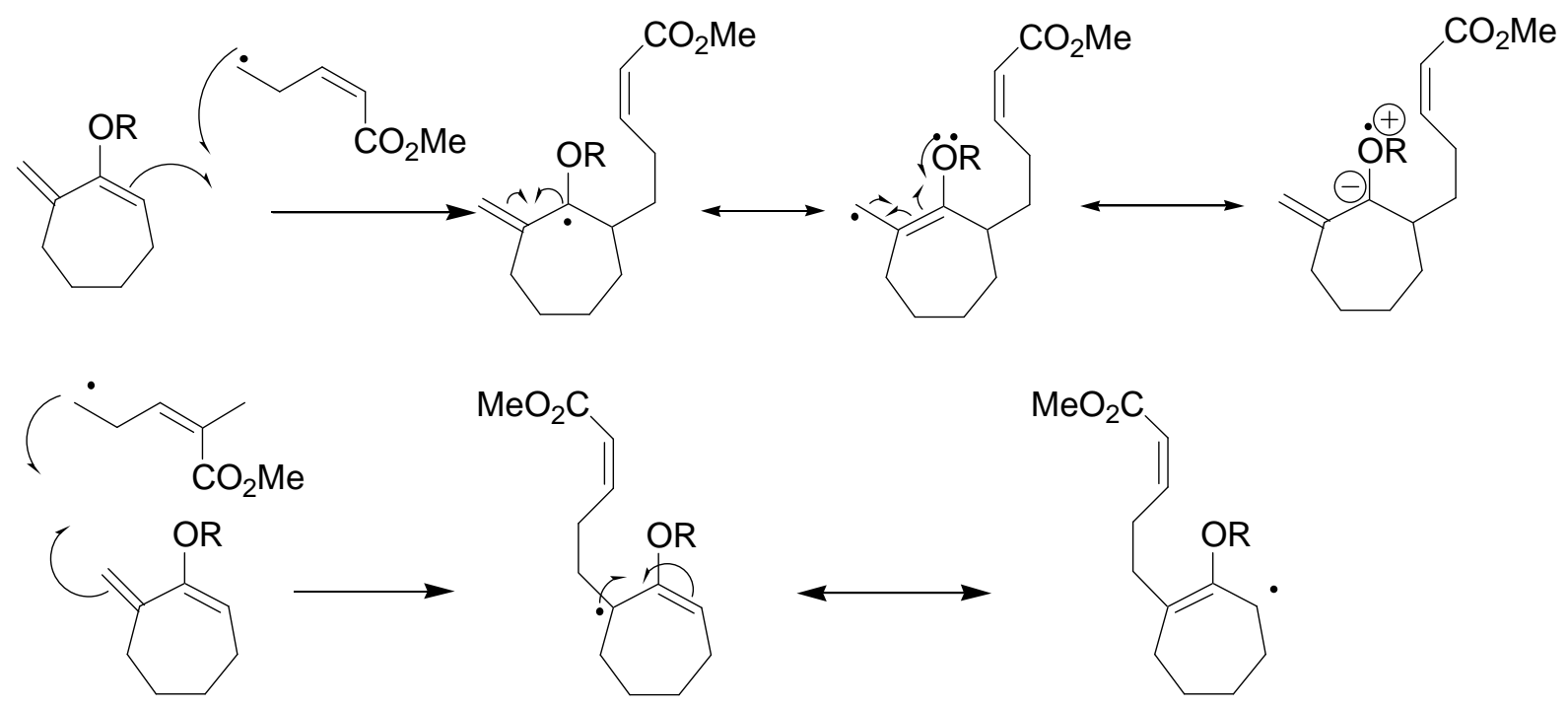

Scheme 2.2 Contributing resonance structures of the radical addition

If selectivity is an issue and the radical addition reaction occurs at the exo-cyclic double bond, then this could be prevented by employing the use of an ester derivatives (2.4) instead of enol ethers (1.39-1.41) as the initial starting material (scheme 2.3). This methyl ester would enhance the electrophilic nature of the internal bond, which could help to drive the addition of the nucleophilic alkyl radical to the internal double bond. Once the expected addition resulting in 2.5 has taken place, the methyl ester can be hydrolysed, decarboxylated and later oxidised to provide the desired cycloheptanone derivative 2.6.

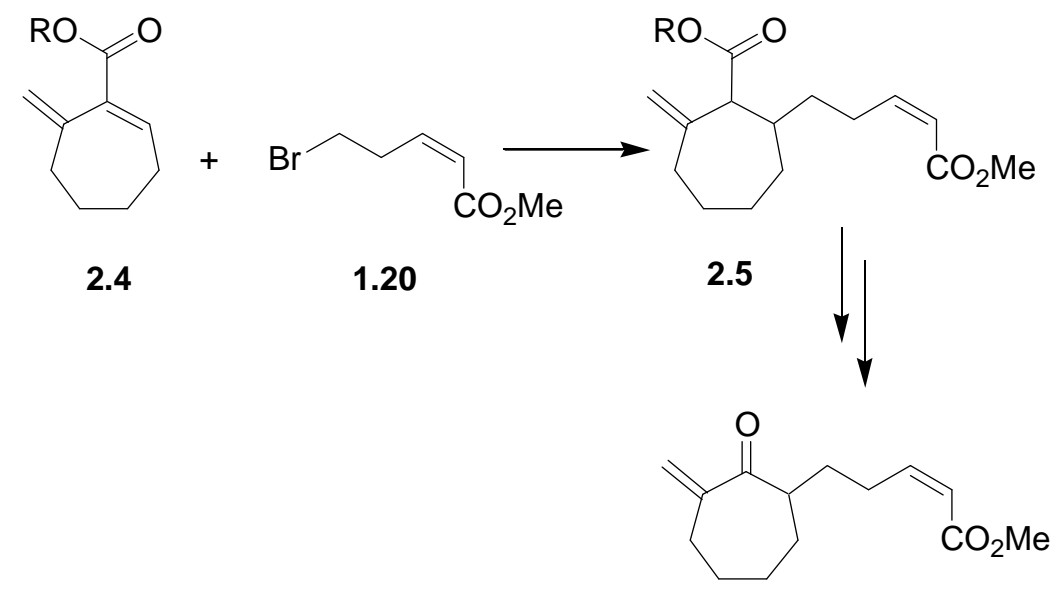

2.6

Scheme 2.3 Alternative approach to regioselective radical addition 


\subsection{Synthesis of 2-methylidene cycloheptanone (2.7)}

Whilst a number of alkyl and aryl radical precursors were readily available in our laboratories, the syntheses of 1.39-1.41 has yet to be reported. The retrosynthetic analysis of 1.39-1.41 shows that these molecules could be readily derived from 2-methylidene cycloheptanone (2.7) as a common intermediate, which in turn could be derived from commercially available cycloheptanone (2.8). It was rationalised that the formation of the enol ether 1.39-1.41 would be readily achieved under standard conditions. ${ }^{35,36,37}$

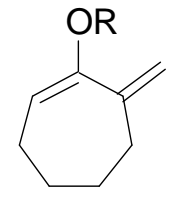

1.39-1.41

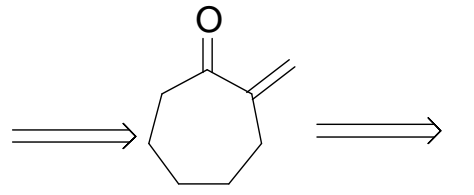

2.7

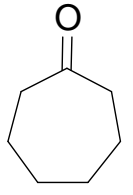

2.8

\section{$1.39 \mathrm{R}=$ OTMS \\ $1.40 \mathrm{R}=\mathrm{OTBDMS}$ \\ $1.31 \mathrm{R}=\mathrm{OMe}$}

Scheme 2.4 Retrosynthetic analysis of enol ethers $\mathbf{1 . 3 9}-\mathbf{1 . 4 1}$

Ono and colleagues, ${ }^{38}$ were able to furnish 2.7 via radical denitrification of $\alpha$ hydroxymethyl cycloheptanone (2.11). The purpose of the nitro group in compound 2.9, in this case was presumably to further activate the $\alpha$-position for alkylation resulting in 2.10. Subsequent elimination of the resulting $\alpha$-hydroxymethyl cycloheptanone (2.11) led to the formation of the desired enone 2.7 in $85 \%$ yield.



2.9

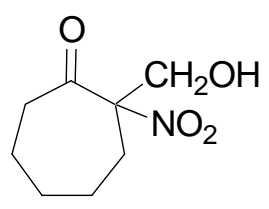

2.10

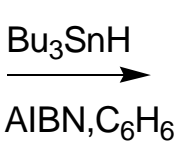

AIBN, $\mathrm{C}_{6} \mathrm{H}_{6}$

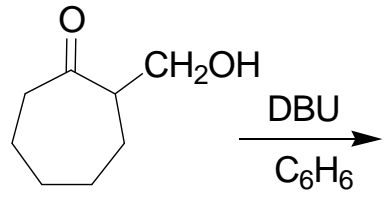

2.11

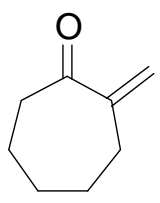

2.7

Scheme 2.5 Synthesis of compound 2.10 via radical nitrification

Block and colleagues reported another method for the formation of compound 2.7 using a Ramberg-Backlund reaction (scheme 2.6), in 77\% overall yield. ${ }^{39}$ Although attractive, the formation of by-product 2.13, and the necessity to employ photochemical conditions for this reaction rendered this synthesis unsatisfactory for our purposes. 


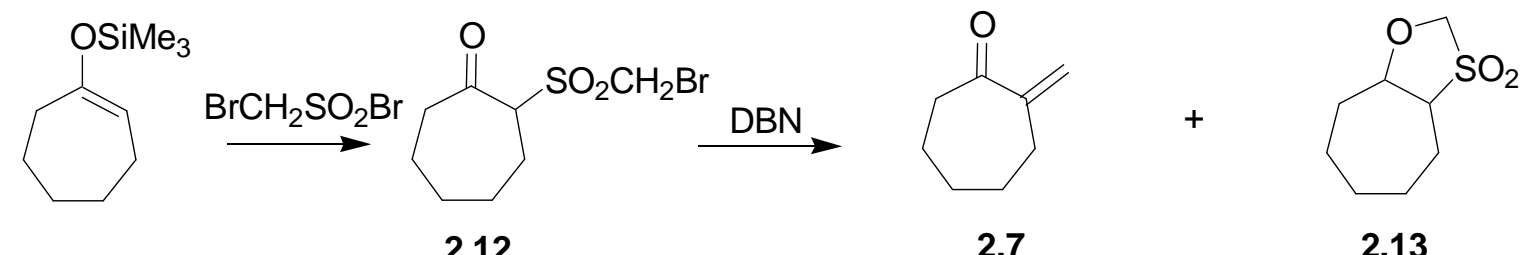

Scheme 2.6 Synthesis of compound 2.10 via Ramberg-Backlund reaction

Although there have been only a few literature reports involving exo-cyclic functionality in cycloheptanone, the cyclohexanone analogues have been widely reported. Many methods exist for the installation of the exo-cyclic double bond, including aldol chemistry, ${ }^{40}$ the Mannich reaction, ${ }^{41}$ and the use of Eschenmoser's salt to form activated $\alpha$-cycloketones which can then undergo elimination to form methylidene cycloketones. These methods were attractive as the starting materials in these cases were readily available cycloketones (in our case cycloheptanone). We decided to evaluate the merits of all these chemistries as outlined in the discussion below.

\subsubsection{Aldol Reaction of Cycloheptanone (2.7)}

The first method we used involved the synthesis of cycloheptanone with $\alpha$-hydroxymethyl functionality, (scheme 2.7) which can undergo elimination under strong basic conditions, ${ }^{38}$ or by activation/elimination to yield the methylene compound. Formation of the hydroxymethyl derivative $\mathbf{2 . 1 4}$ was achieved using the procedure reported by Wipf and Aslan. $^{40}$

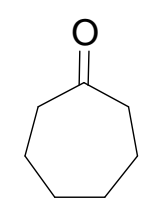

2.8

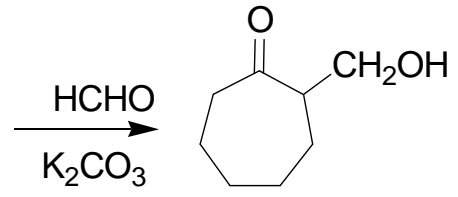

2.14

Scheme 2.7 Aldol reaction on cycloheptanone $\mathbf{2 . 8}$

This method was investigated using a variety of conditions to improve the yield of the desired $\alpha$-hydroxymethyl compound 2.14. As shown in table 2.1, the first attempt was carried out using conventional heating, with no reaction observed. We decided to see if performing microwave-based heating would result in any products, in which case (entry 2) the formation of compound 2.7 was seen. Attempts to optimise this reaction by varying the amounts of reactants, reaction time and the type of base used, unfortunately, did not result 
in any significant change in product quantity. This method was abandoned and other procedures investigated.

Table 2.1 Aldol reaction on cycloheptanone

\begin{tabular}{|c|c|c|}
\hline Entry & Conditions $^{£}$ & Results ${ }^{*}$ \\
\hline 1 & $\begin{array}{l}\mathrm{HCHO} \text { (1.9 eq. }), \mathrm{K}_{2} \mathrm{CO}_{3}(0.015 \text { eq. }), \mathrm{H}_{2} \mathrm{O} \text {, r.t. } 2 \\
\text { hours }\end{array}$ & Starting material \\
\hline 2 & $\begin{array}{l}\mathrm{HCHO} \text { (1.9 eq.), } \mathrm{K}_{2} \mathrm{CO}_{3} \text { (0.015 eq.), } \mathrm{H}_{2} \mathrm{O}, \mu \text { wave } \\
120^{\circ} \mathrm{C}, 2 \text { Bar, } 10 \text { mins }\end{array}$ & $\begin{array}{l}\text { Starting material and minor } \\
\text { compound } 2.7^{\wedge}\end{array}$ \\
\hline 3 & $\begin{array}{l}\mathrm{HCHO}(1.9 \text { eq. }), \mathrm{K}_{2} \mathrm{CO}_{3}(0.015 \text { eq. }), \mathrm{MeCN} \text {, } \\
\mu \text { wave } 120^{\circ} \mathrm{C}, 2 \text { Bar, } 15 \text { mins }\end{array}$ & $\begin{array}{l}\text { Starting material and minor } \\
\text { compound } 2.7^{\wedge}\end{array}$ \\
\hline 4 & $\begin{array}{l}\mathrm{HCHO}(1.9 \text { eq. }), 1 \mathrm{M} \mathrm{NaOH}(0.015 \text { eq. }) 1 \mathrm{M} \mathrm{HCl} \\
(0.015 \text { eq. }), \mathrm{H}_{2} \mathrm{O}, \mu \text { wave } 120^{\circ} \mathrm{C}, 2 \mathrm{Bar}, 15 \text { mins }\end{array}$ & $\begin{array}{l}\text { Starting material and minor } \\
\text { compound } 2.7^{\wedge}\end{array}$ \\
\hline
\end{tabular}

${ }^{*}$ Results are based on ${ }^{1} \mathrm{H}$ NMR spectroscopic analysis

${ }^{\wedge}$ None of the expected $\alpha$-hydroxymethyl cycloheptanone was seen in the ${ }^{1} \mathrm{H}$ NMR spectrum.

${ }^{\mathfrak{A}}$ Formaldehyde (HCHO) was used as a $37 \%$ aq. solution

\subsubsection{Mannich-Type reaction using Eschenmoser's salt}

The next method employed in the attempt to form compound 2.7 involved the use of Eschenmoser's salt $\left(\mathrm{CH}_{2} \mathrm{~N}\left(\mathrm{CH}_{3}\right)_{2} \mathrm{I}\right)$. This salt consists of the iodide salt of an iminium ion and can react directly with cycloheptanone to form amino derivative 2.15 through the pathway shown in scheme 2.8.

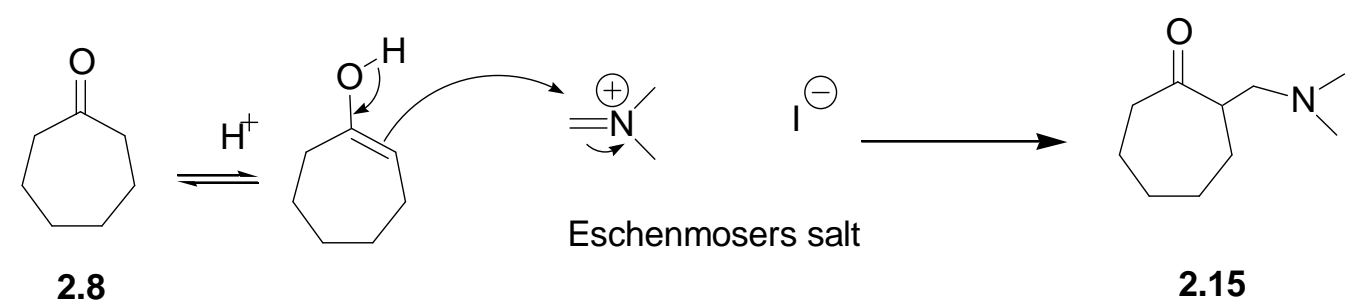

Scheme 2.8 Eschenmoser's salt reaction with cycloheptanone (2.8) 
This method has been widely used in a variety of substrates ${ }^{42}$ and is an attractive procedure, as the Eschenmoser's salt is readily available and the reaction involves simple reflux conditions. However, despite numerous attempts, only trace amounts of 2.15 was detected in the ${ }^{1} \mathrm{H}$ NMR data of the crude mixture, with majority being starting material. We rationalised that the addition of a base may assist the reaction. Hence piperidine was added to the reaction; however no improvement in conversion was noted. In retrospect, piperidine may not have been a wise choice of base for this reaction as it could have added to the Eschenmoser's salt, leading to compound 2.16 (scheme 2.9), although, no evidence of the diamine 2.16 was detected.

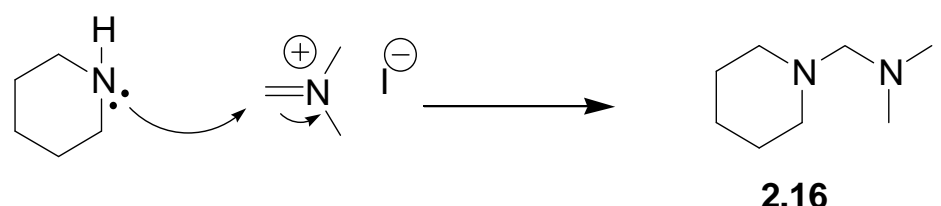

Scheme 2.9 Proposed piperidine reaction with Eschenmoser's salt

\subsubsection{Mannich Reaction}

We next investigated the Mannich reaction for the synthesis of compound 2.7. This reaction has been extensively used for the synthesis of $\alpha$-amino-alkylated products, which upon elimination of an amine provides a bis-methylene compound. ${ }^{43}$ The Mannich reaction involves reacting an enolisable carbonyl with formaldehyde and any primary or secondary imines. Since, the reaction is carried out under acidic condition, keto-enol tautomerisation occurs with the enol form reacting with the resulting iminium ion to form the Mannich product (scheme 2.10$){ }^{43}$ 


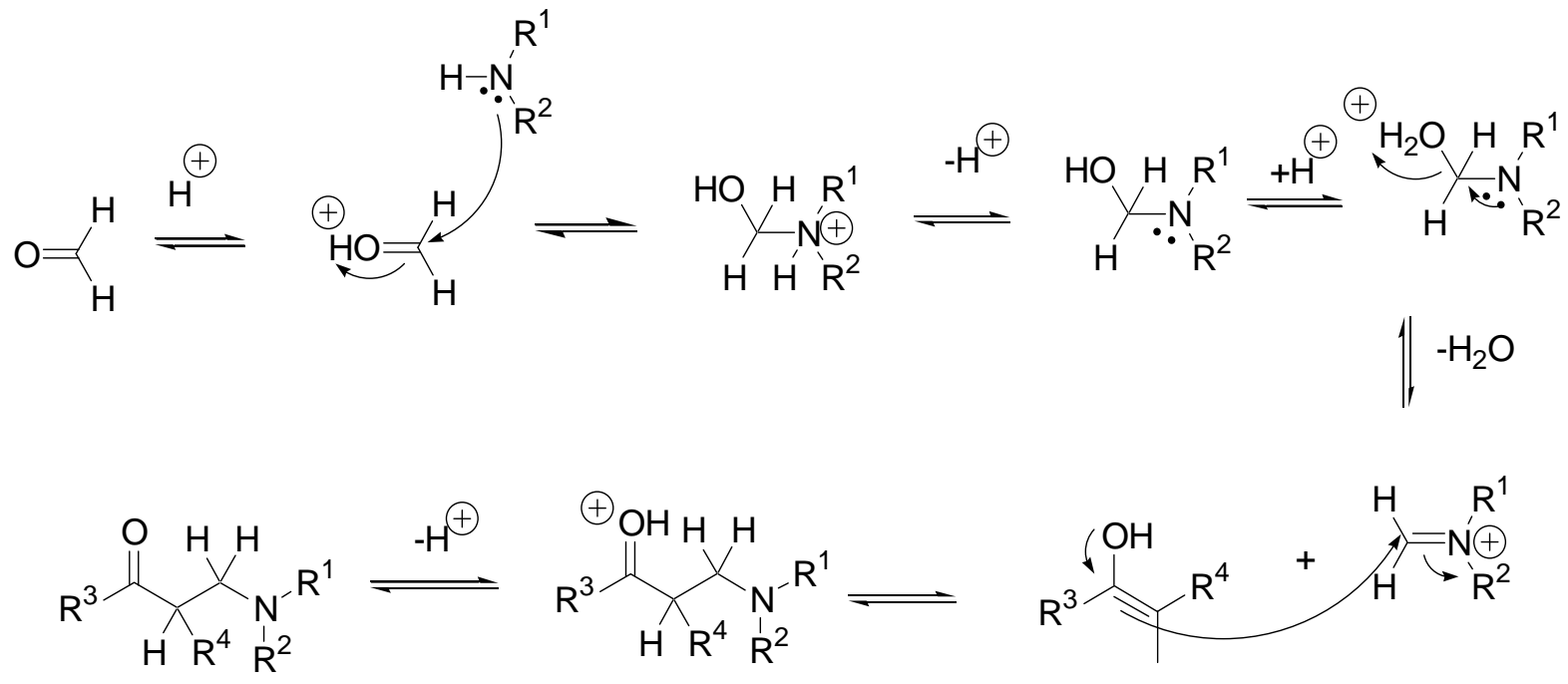

Scheme 2.10 General Mannich reaction

The first conditions attempted for the Mannich reaction involved treatment of cycloheptanone with formaldehyde and catalytic piperidine in the presence of acetic acid. ${ }^{44}$ This was an attractive method as we thought that would allow direct access to 2.7 without the need to isolate any $\alpha$-alkyl amine intermediates as shown in scheme 2.11.

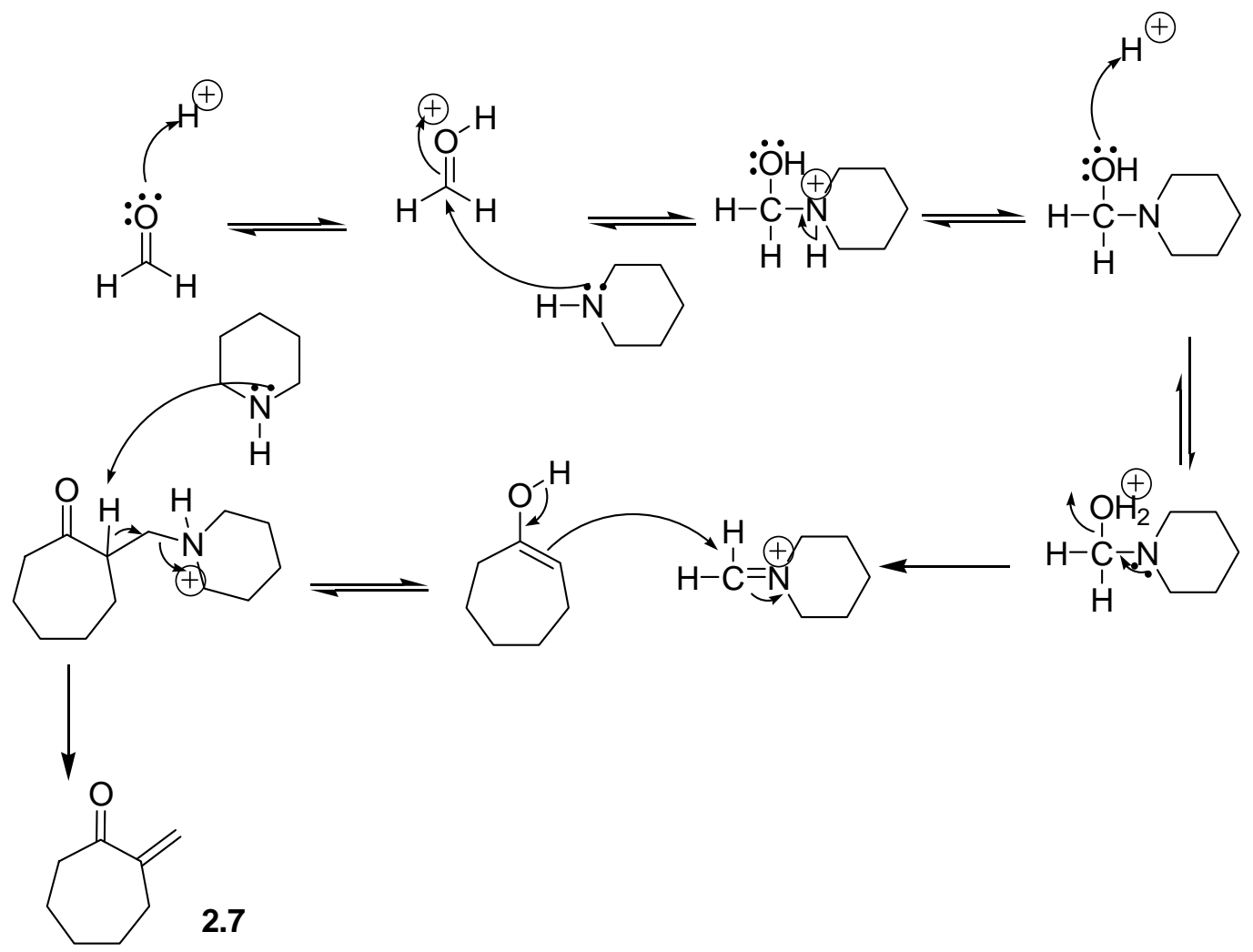

Scheme 2.11 Proposed Mannich reaction of cycloheptanone (2.8) with piperidine 
Gratifyingly, we were able to achieve 33\% conversion to the desired enone 2.7 with the reminder being starting material. We were unable to improve the yield of this reaction despite numerous attempts to optimise the reaction conditions.

As seen in table 2.2, the first reaction attempted with this method resulted in $30 \%$ product. At this point it was thought that excess of formaldehyde might help to drive the reaction further (entry 2), but this also resulted in similar yield. When amounts of piperidine and acetic acid were increased (entry 3), 4 signals were seen in the alkene proton region at 5.92, 5.42, 5.25 and $4.93 \mathrm{ppm}$ in the ${ }^{1} \mathrm{H}$ NMR spectrum. We rationalised these signals were due to the presence of compound 2.7 and the bis-methylidene product 2.17 in the product mixture. Interestingly, despite formation of this bis-methylidene compound 2.17, we were unable to obtain more than $33 \%$ conversion of products, regardless of the reaction scale.

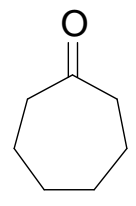

2.8

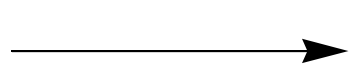



2.7



2.17

Table 2.2: Mannich reaction with piperidine

\begin{tabular}{|c|c|c|c|c|}
\hline \multirow[t]{2}{*}{ Entry } & \multirow[t]{2}{*}{ Conditions } & \multicolumn{3}{|c|}{ Results * } \\
\hline & & 2.8 & 2.7 & 2.17 \\
\hline 1 & $\begin{array}{l}\mathrm{HCHO} \text { ( } 1 \text { eq.), piperidine (cat.), } \mathrm{CH}_{3} \mathrm{COOH} \text { (cat.), } \\
\text { in EtOH reflux overnight }\end{array}$ & $60 \%$ & $30 \%$ & - \\
\hline 2 & $\begin{array}{l}\mathrm{HCHO} \text { ( } 2 \text { eq.), piperidine (cat.), } \mathrm{CH}_{3} \mathrm{COOH} \text { (cat.), } \\
\text { EtOH reflux overnight }\end{array}$ & $50 \%$ & $30 \%$ & - \\
\hline 3 & $\begin{array}{l}\mathrm{HCHO} \text { ( } 1 \text { eq. }) \text {, piperidine ( } 0.5 \text { eq. }), \mathrm{CH}_{3} \mathrm{COOH} \\
(0.1 \text { eq. }), \text { EtOH reflux overnight }\end{array}$ & $50 \%$ & $15 \%{ }^{\wedge}$ & $<15 \%{ }^{\wedge}$ \\
\hline
\end{tabular}

${ }^{*}$ Results are based on ${ }^{1} \mathrm{H}$ NMR, resulting from peak integration

${ }^{\wedge}$ Results as obtained from $1 \mathrm{H}$ NMR spectral data of the crude mixture, showing 4 peaks in the double bond region 
It was rationalised that perhaps the piperidine was able to perform a 1,4 addition to compound 2.7, resulting in equilibrium of the mixture, (scheme 2.12), thereby preventing the conversion of $\mathbf{2 . 8}$ to $\mathbf{2 . 7}$ from improving. However, we did not pursue this avenue further and instead decided to perform this reaction on a large scale and separate out the $33 \%$ of the product formed and then resubject the recovered starting material to the Mannich reaction conditions.



Scheme 2.12 Proposed piperidine reaction with 2-methylidene cycloheptanone (2.7)

Unfortunately, separation of cycloheptanone and compound 2.7 was unable to be achieved satisfactorily by either distillation or flash column chromatography. Compound 2.7 also appeared to be degrading during column chromatography so this method was abandoned and further alternatives were pursued.

We next investigated, another reported Mannich procedure, using diethylamine and acetic acid with formaldehyde, and refluxing it over two days in ethanol. ${ }^{45}{ }^{1} \mathrm{H}$ NMR spectroscopic analysis indicated formation of the 2-(dimethylamino) compound 2.19 (scheme 2.13), but the yield was very poor, resulting in approximately $5 \%$ of isolated product.

We then decided to use diethylamine hydrochloride salt and formaldehyde with hydrochloric acid. ${ }^{46-48}$ The use of commercially available diethylammonium hydrochloride proved to be problematic with yields of approximately $30 \%$ of compound 2.15, which was not purified or characterised. Finally, we decided to synthesise our own diethylamine hydrochloride (2.18) from hydrochloric acid and diethylamine, then reacting this with cycloheptanone (2.11) and formaldehyde (scheme 2.13). Analysis of the ${ }^{1} \mathrm{H}$ NMR spectrum of the crude reaction mixture revealed the presence of desired product 2.19, which was purified by distillation and collected in $76 \%$ yield. 


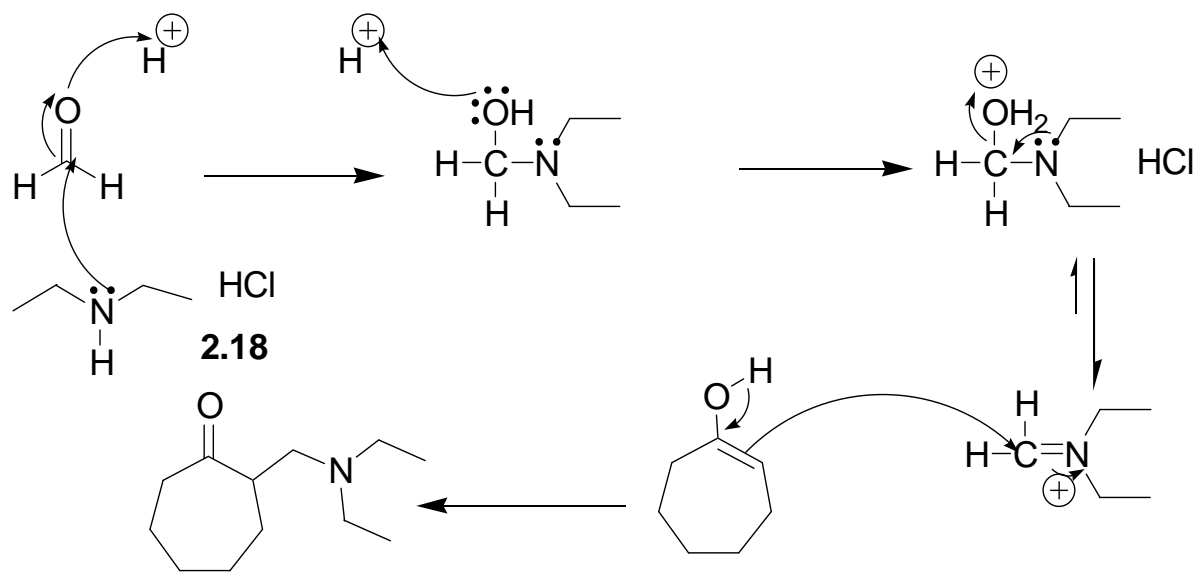

2.19

Scheme 2.13 Mannich reaction with diethylamine hydrochloride

Table 2.3 summarises the various methods used and the yields obtained in the reactions to achieve compound 2.19.

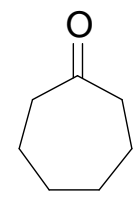

2.8

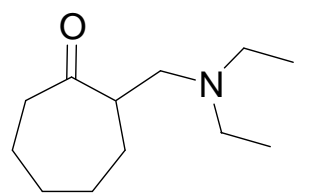

2.19

Table 2.3: Mannich reaction with diethyl amine

\begin{tabular}{|c|c|c|c|}
\hline \multirow[t]{2}{*}{ Entry } & \multirow[t]{2}{*}{ Conditions } & \multicolumn{2}{|c|}{ Results* } \\
\hline & & 2.8 & 2.19 \\
\hline 1 & $\begin{array}{l}\mathrm{HCOH} \text { (1 eq.), }\left(\mathrm{CH}_{2} \mathrm{CH}_{3}\right)_{2} \mathrm{NH}(1.2 \text { eq. }) \\
\mathrm{CH}_{3} \mathrm{COOH} \text { (1.2 eq.), reflux overnight }\end{array}$ & $75 \%$ & $5 \%$ \\
\hline 2 & $\begin{array}{l}\mathrm{HCOH} \text { (1 eq.), }\left(\mathrm{CH}_{2} \mathrm{CH}_{3}\right)_{3} \mathrm{NH} . \mathrm{HCl}(1.2 \text { eq.), } \\
\text { conc. } \mathrm{HCl} \text { (cat.), reflux overnight }\end{array}$ & - & $50 \%$ \\
\hline 3 & $\begin{array}{l}\mathrm{HCOH}(1 \text { eq. }),\left(\mathrm{CH}_{2} \mathrm{CH}_{3}\right)_{3} \mathrm{NH} . \mathrm{HCl}(1.2 \text { eq. }) \\
\text { conc. } \mathrm{HCl} \text {, reflux } 5 \mathrm{~h}\end{array}$ & - & $70 \%$ \\
\hline
\end{tabular}

* Results are based on ${ }^{1} \mathrm{H}$ NMR spectral data, resulting from peak integration 


\subsubsection{Hoffmann Elimination of Compound 2.19}

With compound 2.19 in hand, the next step was generation of 2-methylidene cycloheptanone (2.7). Initially, Hoffmann elimination was performed using methyl iodide to form a quaternary ammonium salt, ${ }^{47}$ then subsequent treatment with silver oxide to allow elimination of the amine moiety (facilitated through in situ generation of hydroxide ions). ${ }^{49}$ Silver oxide and water lead to formation of hydroxide ions, which would participate in the elimination of the amine, as shown in the scheme 2.14. To our dismay, only trace amounts of the desired alkene were detected. Attempts to improve this by heating or extending reaction times led to degradation of the product.

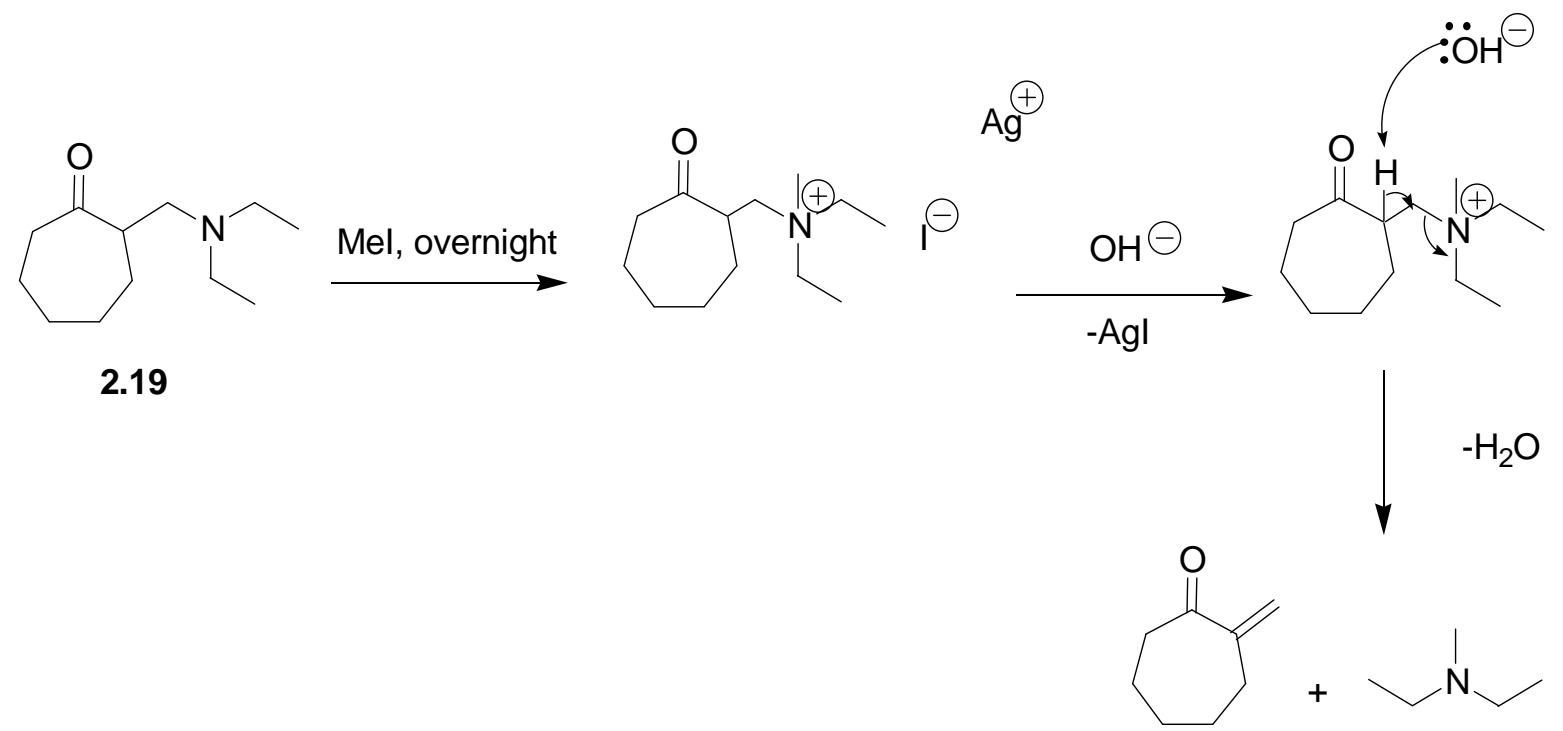

2.7

Scheme 2.14 Hoffmann elimination of compound 2.19

\subsubsection{Cope Elimination Reaction of Compound 2.19}

An alternate method was found whereby a Cope elimination reaction was used to form methylene compounds from amino compounds. ${ }^{50}$ This reaction involves oxidation of an $\alpha$ amino-methyl moiety to furnish an amine oxide and subsequent syn-elimination to afford an alkene as shown in scheme $\mathbf{2 . 1 5}$. 


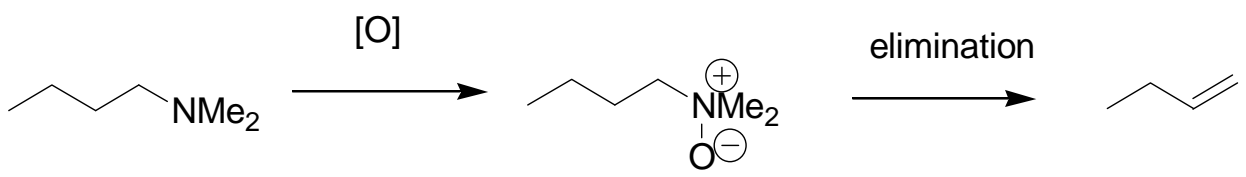

Scheme 2.15 Generalised Cope reaction

The advantage of this method was that the crude amino compound 2.19 could be used without purification, and involves short reaction time. Thus, compound 2.19 was treated with 1.5 eq. of $m \mathrm{CPBA}$ in dichloromethane at room temperature. This reaction proceeded well, providing yields of up to $80 \%$ upon heating to $30-35^{\circ} \mathrm{C}$. None of the amine oxide intermediate 2.20, was isolated in this reaction and complete conversion of the amine compound to the alkene 2.7 occurred. The product was purified using Kugelrohr distillation apparatus.

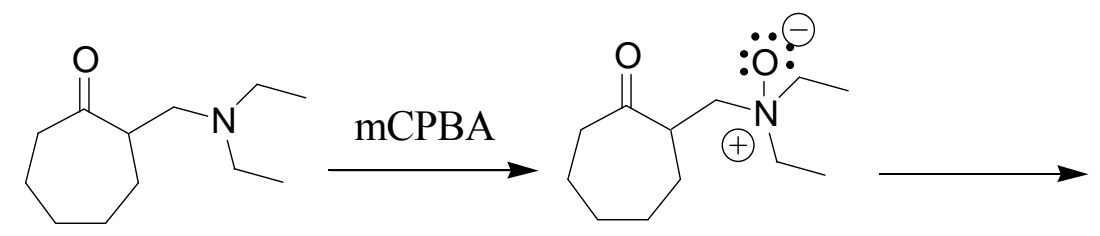

2.19

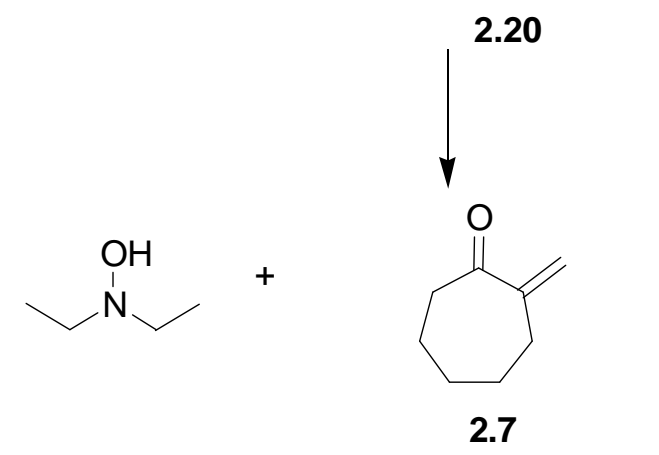

Scheme 2.16 Cope reaction of compound 2.19 


\subsection{Synthesis of Enol Ethers}

\subsubsection{Enol ether synthesis $\mathbf{1 . 3 9}-\mathbf{1 4 1}$}

Upon synthesis of the desired alkene 2.7, we turned our attention to formation of the corresponding silyl and methyl enol ethers. The reaction conditions used to form silyl enol ethers obtained from the literature were first employed using cycloheptanone for initial studies, and then successful methods were applied to the formation of the enol ether of compound 2.7.

Unfortunately, as seen from table 2.4, formation of the enol ethers of $\mathbf{2 . 7}$ was not possible under these set, reported conditions. Upon reaction of compound 2.7 with LDA and $\mathrm{TMSCl}^{51,35}$ only starting material was isolated. Interestingly, when strong Lewis acid such as TBDMSOTf, (prepared using a reported procedure ${ }^{52}$ ) was used ${ }^{36}$ or TMSI (generated from TMSCl and NaI) was used, ${ }^{53}$ loss of the olefinic protons was seen in the ${ }^{1} \mathrm{H}$ NMR spectrum.

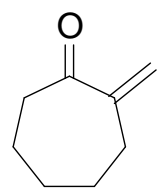

2.7

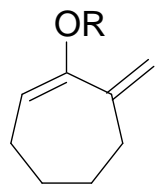

$1.39 \mathrm{R}=\mathrm{TMS}$,

$1.40 \mathrm{R}=\mathrm{TBDMS}$

Table 2.4: Attempted methods for enol ether formation

\begin{tabular}{|l|l|l|}
\hline Entry & Conditions & Results $^{*}$ \\
\hline 1 & $\begin{array}{l}\text { LDA (1.2 eq. }), \mathrm{TMSCl}(1.2 \text { eq. }),-78{ }^{\circ} \mathrm{C}-\text {-r.t., } \\
\text { overnight }\end{array}$ & Starting material recovered \\
\hline 2 & TBMSOTf $(1$ eq. $), \mathrm{Et}_{3} \mathrm{~N}(1.5$ eq. $)$, r.t., $3 \mathrm{~h}$ & Undesired product \\
\hline 3 & TMSCl (1.2 eq. $), \mathrm{NaI}(1.2$ eq. $), \mathrm{Et}_{3} \mathrm{~N}$, r.t., $5 \mathrm{~h}$ & Undesired product \\
\hline
\end{tabular}

* As analyzed from the ${ }^{1} \mathrm{H}$ NMR spectral data of the crude reaction mixture 
A deuterium study using LDA and cycloheptanone was also done, whereby the reaction was quenched with $\mathrm{D}_{2} \mathrm{O}$. The ${ }^{1} \mathrm{H}$ NMR spectrum of the resulting product was compared with the ${ }^{1} \mathrm{H}$ NMR spectrum of cycloheptanone. The product ${ }^{1} \mathrm{H}$ NMR data showed two peaks, (as expected) seen at $2.3 \mathrm{ppm}$, which integrated for 3 protons, and at $1.6 \mathrm{ppm}$, which integrated for 8 protons. This clearly showed that one of the $\alpha$-protons was missing, (replaced by deuterium), which provided evidence that the LDA deprotonation step was working.

Attempts to generate methyl enol ether also proved to be futile as seen from table 2.5. As seen from table 2.5, when either trimethyl orthoformate (entry 1), ${ }^{37}$ or Meerwein's salt was used (entry 2$)^{54}$, loss of olefinic protons was seen.

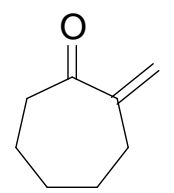

2.7

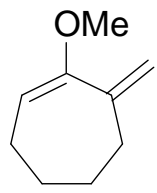

1.41

Table 2.5 Attempted 1-methoxy cycloheptene formation

\begin{tabular}{|l|l|l|}
\hline Entry & Conditions & Results \\
\hline 1 & $\begin{array}{l}\mathrm{HC}(\mathrm{OMe})_{3}(1.2 \text { eq. }), \text { PTSA }(0.67 \mathrm{~mol} \%), \mathrm{MeOH}, \\
\text { reflux, } 5 \mathrm{~h}\end{array}$ & Undesired product \\
\hline 2 & $\mathrm{Me}_{3} \mathrm{OBF}_{4}(1.2$ eq. $), \mathrm{CH}_{2} \mathrm{Cl}_{2}$, r.t., 2 days & Undesired product \\
\hline
\end{tabular}

*As analysed from the ${ }^{1} \mathrm{H}$ NMR spectral data

\subsubsection{Investigation into unsuccessful enol ether synthesis}

Upon further investigation of the literature, it was found that reaction of $\alpha, \beta$-unsaturated ketones with TMSI resulted in addition to the double bond. Hence, strong electrophiles (such as trimethylsilyl iodide) react with $\alpha, \beta$-unsaturated ketones (scheme 2.17) generating iodotrimethylsilyl enol ethers 2.21 which could hydrolyse to $\beta$-iodocarbonyl derivatives 2.22 upon aqueous work-up. ${ }^{55}$ 
<smiles>[R]C=CC([R])=O</smiles>

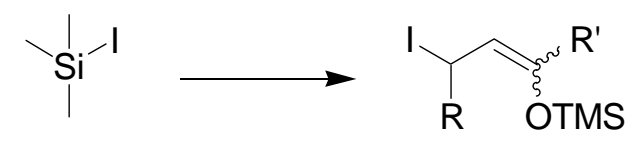

2.21

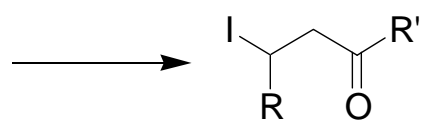

2.22

Scheme 2.17 Reaction of TMSI with $\alpha, \beta$-unsaturated ketones

This reaction could have occurred due to the stability of the compound generated after the addition reaction. As seen in scheme 2.18, the carbonyl group can provide resonance stabilisation to the resulting product of this reaction.
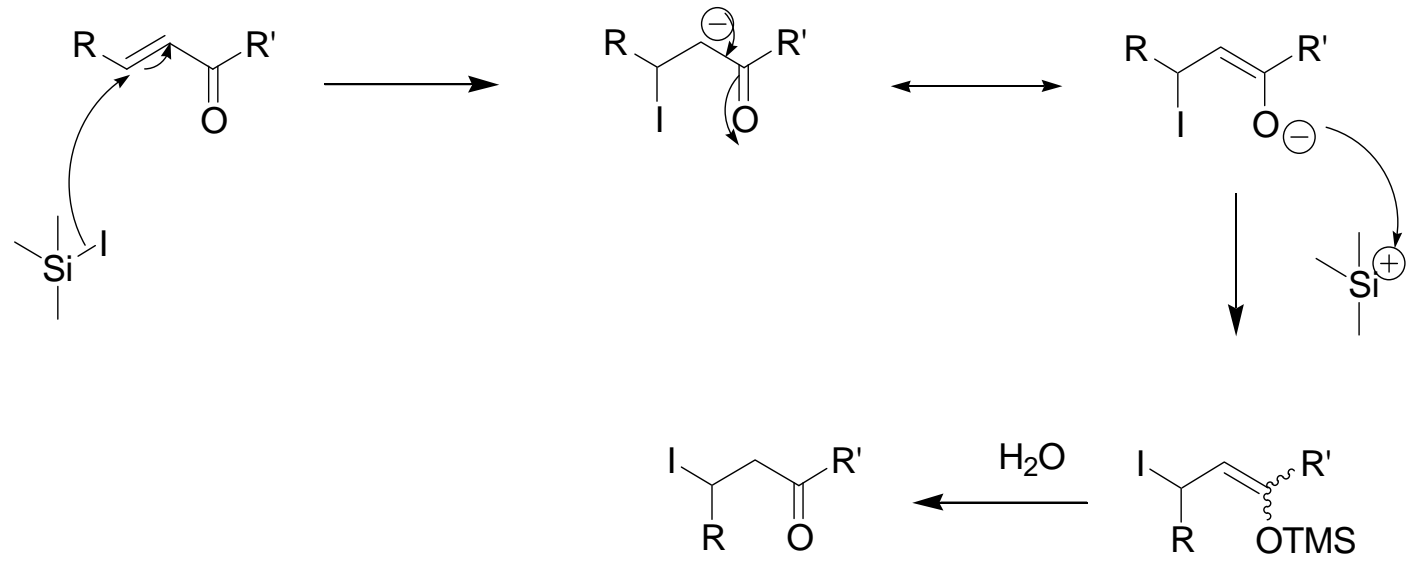

Scheme 2.18 Proposed mechanism of the reaction of TMSI with $\alpha, \beta$-unsaturated ketones

This reaction is plausible in our case though no concrete evidence of the formation of 2methyl-iodo cycloheptanone could be seen in the ${ }^{1}$ HNMR spectroscopic data.

Another paper was found which stated that 2-methylene cyclohexanone (similar to compound 2.7) was very reactive, dimerising readily, hence it is difficult to isolate the monomer itself. ${ }^{56}$ This explanation provides insight into the difficulty of the attempted enol ether synthesis particularly in the presence of Lewis acids. It is likely that the reactant $\mathbf{2 . 7}$ was forming dimers before it could undergo the desired reaction processes.

Our experience of dealing with $\alpha, \beta$ unsaturated ketone 2.7 found problems involving storage over a prolonged period of time. The compound could only be safely stored under 
nitrogen in the refrigerator. Decomposition could still occur at these low temperatures, hence it is not surprising we encountered problems at elevated temperatures. Given this issue and the problems faced with the stability of 2.7, we envisaged that synthesis of the desired diene could be achieved via enol ether formation of the amino compound 2.19. This reaction, however, led to the formation of the olefinic compound 2.7, and none of the methyl enol ether $\mathbf{1 . 4 1}$ formed.

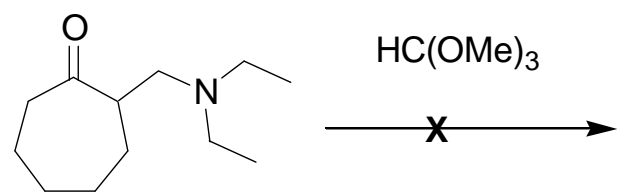

2.19

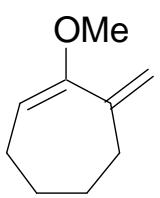

1.41

Figure 2.1 Attempted enol ether synthesis using amine 2.19

Having encountered problems with the stabilities of the intermediate species leading to the required diene (1.39-1.41), we were increasingly concerned that the 7-membered system may be problematic in the radical addition reactions. Thus, we decided to investigate the stabilities of the various precursor compounds under radical conditions. Model studies of the radical reactions were formulated to investigate the selectivity of the first radical addition reaction. If these more stable, isolatable compounds demonstrated dubious stability, there would be good cause to abandon the postulated pathway. Thus, 1-methoxy cycloheptene 2.24 was chosen as the model compound for these studies. Compound 2.24 was synthesized from cycloheptanone using $\mathrm{HC}(\mathrm{OMe})_{3}$ and PTSA (scheme 2.19). Distillation of dimethylacetal 2.23 led to the formation of compound 2.24. This compound could only be stored under nitrogen in the freezer, since decomposition was observed if left in the refrigerator or at room temperature, which did not bode well for the radical studies.

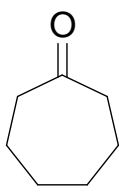

2.11
$+\mathrm{HC}(\mathrm{OMe})_{3}$

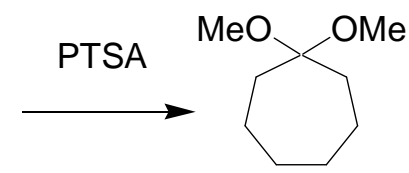

2.23

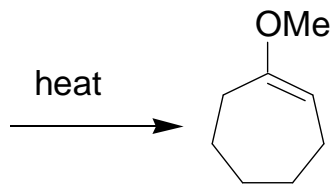

2.24

Scheme 2.19 1-Methoxy-cycloheptanone (2.24) synthesis 


\subsection{Radical Reactions on Various Systems}

\subsubsection{Model Studies with Styrene}

In order to ascertain optimal conditions for the radical reactivity on our model systems, we conducted initial experiments on styrene.

A number of different variations of radical methodology were employed to do this reaction.

The first reaction conditions used were ones reported by Bennasar and collegues, ${ }^{57}$ who also used styrene as an alkene acceptor for radical reactions. In our case bromobenzene was used with styrene. The results we obtained from reaction, and taking into consideration other reported methods, ${ }^{58,59}$ we optimised the reaction conditions and reactant stoichiometry in order to achieve the best radical conditions for styrene based radical reactions. All the reactions were carried out under argon atmosphere, refluxing in dry degassed toluene. Some reactions led to the formation of polystyrene, which could be identified from the ${ }^{1} \mathrm{H}$ NMR of the crude product. Other reactions led to the formation of 1,2-diphenyl ethane (2.27). The different reaction conditions and results are summarised in table 2.6

As, can be seen from table 2.6, the different approaches to this reaction varied in the relative amount of reactants used, the type of initiators used and the speed in which the reactants were added to the reaction mixture. In a few reactions tris(trimethylsilyl)silane $\left((\mathrm{TMS})_{3} \mathrm{SiH}\right)$ was used instead of the $\mathrm{Bu}_{3} \mathrm{SnH}$ and in some other reactions the initiator AIBN was used instead of ACN (azobiscyclohexylnitrile). The initial problem encountered was removal of $\mathrm{Bu}_{3} \mathrm{SnH}$ from the reaction mixture, as it streaked through the flash chromatography column. Literature search showed $\mathrm{Bu}_{3} \mathrm{SnH}$ could be removed using $\mathrm{KF},{ }^{60}$ and thus use of this led to successful removal of the tin compound.

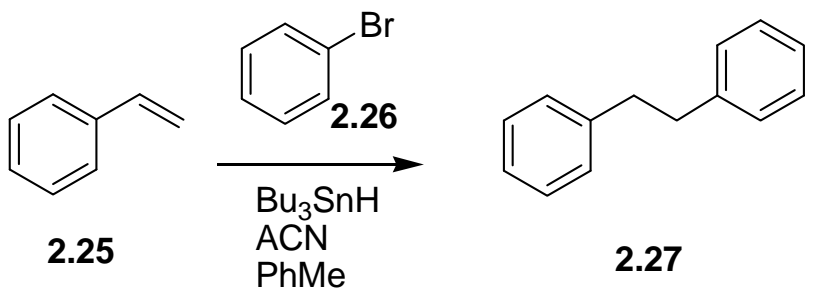

Scheme 2.20 Radical reaction of styrene (2.25) with bromobenzene (2.26) 
Table 2.6 Radical reaction of styrene with bromobenzene

\begin{tabular}{|c|c|c|c|}
\hline $\begin{array}{l}\text { Exp. } \\
\text { No. }\end{array}$ & Reaction Stoichiometry $^{\wedge}$ & $\begin{array}{l}\text { Reaction Conditions } \\
\text { (reagents were added in } \\
\text { toluene) }\end{array}$ & Result ${ }^{*}$ \\
\hline 1 & $\begin{array}{l}2.26 \text { ( } 0.8 \text { eq. }), \mathrm{Bu}_{3} \mathrm{SnH}(0.25 \text { eq. }) \\
\mathrm{ACN}(0.03 \text { eq. })\end{array}$ & $\mathrm{Bu}_{3} \mathrm{SnH}, 1 \mathrm{~h}$ addition. & $\begin{array}{l}\text { 2.27, polystyrene } 1: 1 \text { ratio } \\
(30 \%)\end{array}$ \\
\hline 2 & $\begin{array}{l}2.26 \text { ( } 0.8 \text { eq. }), \mathrm{Bu}_{3} \mathrm{SnH} \text { (0.25 eq.), } \\
\mathrm{ACN}(0.09 \text { eq. })\end{array}$ & $\begin{array}{l}\mathrm{Bu}_{3} \mathrm{SnH}, 1 \mathrm{hr} \text { addition } \\
\text { and } 0.03 \text { eq. ACN } 3 \text { times } \\
\text { over } 1 \mathrm{hr} \text { addition }\end{array}$ & $\begin{array}{l}2.27(60 \%) \text { polystyrene } \\
\text { (trace) }\end{array}$ \\
\hline 3 & $\begin{array}{l}2.26 \text { ( } 2 \text { eq. }), \mathrm{Bu}_{3} \mathrm{SnH}(1.5 \text { eq. }) \\
\operatorname{ACN}(0.5 \text { eq. })\end{array}$ & $\begin{array}{l}\mathrm{Bu}_{3} \mathrm{SnH} \text { and } \mathrm{ACN} 1 \mathrm{~h} \\
\text { addition }\end{array}$ & 2.27 (approx. 50\%) \\
\hline 4 & $\begin{array}{l}\left.2.26 \text { ( } 2 \text { eq. }),\left(\mathrm{CH}_{3}\right)_{3} \mathrm{Si}\right)_{3} \mathrm{SiH}(3 \\
\text { eq.), } \mathrm{ACN}(0.25 \text { eq. })\end{array}$ & $\begin{array}{l}\left.\left(\mathrm{CH}_{3}\right)_{3} \mathrm{Si}\right)_{3} \mathrm{SiH}, \mathrm{ACN} \text { in } \\
2 \mathrm{~h} \text { addition }\end{array}$ & Polystyrene $(50 \%)$ \\
\hline 5 & $\begin{array}{l}2.26 \text { ( } 0.8 \text { eq.), } \mathrm{Bu}_{3} \mathrm{SnH} \text { (0.25 eq.), } \\
\operatorname{AIBN}(0.09 \text { eq. })\end{array}$ & $\begin{array}{l}\mathrm{Bu}_{3} \mathrm{SnH}, 1 \mathrm{~h} \text { addition, } \\
\text { AIBN } 3 \text { times over } 1 \mathrm{~h} \\
\text { addition }\end{array}$ & Polystyrene $(60 \%)$ \\
\hline
\end{tabular}

${ }^{*}$ Results are based on ${ }^{1} \mathrm{H}$ NMR, resulting from peak integration

^ 1 eq. of 2.25 was used in all the reactions

Using $\mathrm{Bu}_{3} \mathrm{SnH}$ results in the formation of tributyltin halides, which also makes isolation of product difficult, ${ }^{61}$ and due to toxicity and disposal issues another compound was sought to replace the tin reagent. Preliminary studies on the use of tris(trimethylsilyl)silane this compound as a reducing agent reported by Chatgilialoglu and colleagues showed that $(\mathrm{TMS})_{3} \mathrm{SiH}$ can be effective as a free radical reducing agent without the ecological and toxicological hazards of the tin compounds. ${ }^{61}$ In this molecule the $\mathrm{Si}-\mathrm{H}$ bond is weak, and given the right conditions can be cleaved, and act a radical initiator. However, this silane compound is a weaker $\mathrm{H}$ donor and an excess of this compound is required in order to initiate radical reaction. In our case, the use of (TMS) $)_{3} \mathrm{SiH}$ (entry 4, table 2.6) did not result in favoured product and only polystyrene was obtained from the reaction. 
Burnett and Keck found that ACN gave more favourable yields in higher temperature reactions as compared to AIBN. ${ }^{62}$ Our attempted in using AIBN, instead of ACN for radical reaction on styrene (entry 5, table 2.6) resulted in formation of polystyrene

Once the radical reaction conditions with bromobenzene had been optimised, reaction of styrene with isopropyl bromide (2.28) was carried out as shown in table 2.7.

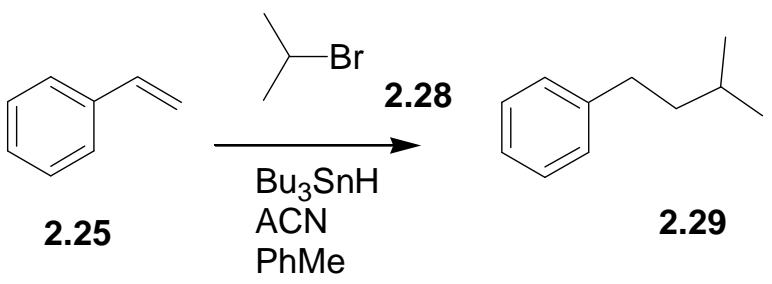

Table 2.7 Radical reactions of styrene and isopropyl bromide

\begin{tabular}{|c|c|c|c|}
\hline $\begin{array}{l}\text { Exp } \\
\text { No. }\end{array}$ & Reaction Stiochiometry ${ }^{\wedge}$ & $\begin{array}{l}\text { Reaction Conditions } \\
\text { (reagents were added in } \\
\text { toluene) }\end{array}$ & Result ${ }^{*}$ \\
\hline 1 & $\begin{array}{l}2.28 \text { ( } 0.8 \text { eq. }), \mathrm{Bu}_{3} \mathrm{SnH}(0.25 \\
\text { eq.) } \mathrm{ACN} \text { ( } 0.09 \text { eq. })\end{array}$ & $\begin{array}{l}\mathrm{Bu}_{3} \mathrm{SnH}, 1 \mathrm{~h} \text { addition, } \mathrm{ACN} 3 \\
\text { times over } 1 \mathrm{~h} \text { addition }\end{array}$ & $\begin{array}{l}\text { Major product polystyrene } \\
\text { and minor } \mathbf{2 . 2 9}\end{array}$ \\
\hline 2 & $\begin{array}{l}2.28 \text { ( } 2 \text { eq. }), \mathrm{Bu}_{3} \mathrm{SnH}(1.2 \\
\text { eq. }), \mathrm{ACN}(0.18 \text { eq. })\end{array}$ & $\begin{array}{l}\mathrm{Bu}_{3} \mathrm{SnH}, 1 \mathrm{hr} \text { addition, } \mathrm{ACN} 3 \\
\text { times over } 1 \mathrm{~h} \text { addition. }\end{array}$ & $\begin{array}{l}\text { Compound } 2.29(20 \%) \\
\text { polystyrene }(30 \%)\end{array}$ \\
\hline 3 & $\begin{array}{l}2.28 \text { ( } 2 \text { eq. }), \mathrm{Bu}_{3} \mathrm{SnH}(1.5 \\
\text { eq. }), \mathrm{ACN}(0.5 \text { eq. })\end{array}$ & $\mathrm{Bu}_{3} \mathrm{SnH}, \mathrm{ACN}, 1 \mathrm{~h}$ addition & Compound $2.29(30 \%)$ \\
\hline
\end{tabular}

${ }^{*}$ As analyzed from the ${ }^{1} \mathrm{H}$ NMR spectroscopy of the crude reaction mixture based on peak integration.

${ }^{\wedge} 1$ eq. of 2.25 was used in all reactions

The best conditions for both the bromobenzene and isopropyl bromide studies, was found to be entry 3 in both table 2.6 and 2.7. These conditions were applied for radical reactions of 1-methoxy cycloheptene (2.24) and 2-methylidene cycloheptanone (2.7). 


\subsubsection{Radical reaction of 1-methoxy cycloheptene (2.24)}

The first radical reaction performed with 1-methoxycycloheptene (2.24) involved reacting it with bromobenzene, and was carried out using the standard conditions mentioned previously. The ${ }^{1} \mathrm{H}$ NMR spectrum from this reaction showed that the methoxy cycloheptene $\mathbf{2 . 2 4}$ did not react with the bromobenzene. This could be because the phenyl radical is very reactive and reduction to benzene occurred over the desired reaction with compound 2.24.

As isopropyl bromine is less reactive and we had performed model studies with this compound, radical reaction using $\mathbf{2 . 2 4}$ and isopropyl bromine was carried out according to our standards conditions. The ${ }^{1} \mathrm{H}$ NMR spectrum from this reaction showed the loss of the methoxy peak from the starting compound, which made us believe that polymerisation of the starting material was occurring. This product was not identified, as the TLC indicated a number of products were present, with similar $\mathrm{R}_{f}$ values.

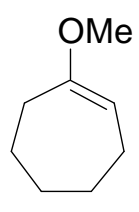

2.24



PhMe

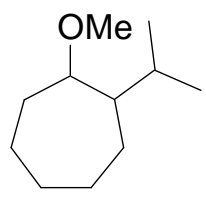

2.30

Figure 2.2 Attempted radical reaction of compound 2.24

\subsubsection{Radical reaction of 2-methylidene cycloheptanone (2.7)}

At this stage we were certain that the radical conditions were not compatible with our starting material, but for completeness we investigated the radical reaction of methylidene compound 2.7, to see if the radical precursors had preference for the exo-cyclic double bond. If the radical addition occurred at the exo-cyclic double bond, to produce undesired products, then an alternative protection strategy of the exo-cyclic double bond could be used. The enol ether could be synthesised after protection of the double bond, and then later the protecting groups could be removed and the product derivatised accordingly to form the $5,5,7$ ring system after the ring cyclisation reaction. 
Reactions were performed with bromobenzene, as it would be easy to determine the attachment of this to the compound 2.7, since this would not further complicate the aliphatic region of the ${ }^{1} \mathrm{H}$ NMR spectrum. The ${ }^{1} \mathrm{H}$ NMR data of the crude mixture showed that mostly polymerisation of the compound occurred, as many peaks could be seen in the 1-3 ppm region in ${ }^{1} \mathrm{H}$ NMR spectrum with no COSY or HMBC correlation to the aromatic region. Flash chromatography was very difficult, as a number of compounds were eluting together. One small fraction contained a few small peaks in the aromatic region of the ${ }^{1} \mathrm{H}$ NMR spectrum and also in the 1-3 ppm region but due to other impurities being present in the sample and the quantity obtained, structure elucidation and characterisation were not possible. At this stage, it was concluded that the radical reaction on these systems was not feasible and other alternate ways of gaining access to the 5,5,7 ring system had investigated.

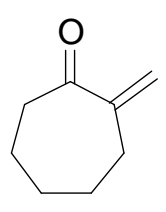

2.7

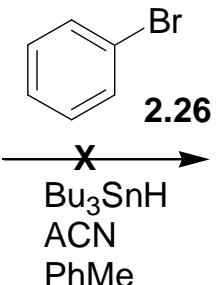

PhMe

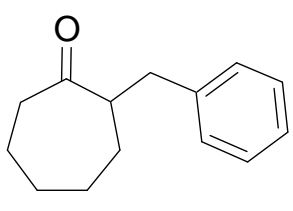

2.31

Figure 2.3 Attempted radical reaction on compound 2.7 


\section{Chapter 3: The Carbene Cycloaddition Cyclisation Cascade $\underline{\text { Route - Results and Discussion }}$}

\subsection{Carbene Cyloaddition Cyclisation Cascade Approach}

After an array of radical reactions had proven to be futile for the formation of the core of daphnioldhanin A, it was decided that a carbene cycloaddition cyclisation cascade process (CCCC) approach should be investigated (scheme 3.1). We envisaged that the carboskeleton of the 5,5,7 system could be furnished following a CCCC pathway from the diazo skeleton 1.94 or 1.95. This in turn could be derived from acid 1.90 or 1.91 , which would be accessible from functional group conversion of precursors $\mathbf{1 . 8 6}$ or 1.87. Finally, $\mathbf{1 . 8 6}$ or $\mathbf{1 . 8 7}$ would be derived from readily accessible cyclopentanone derivatives $\mathbf{1 . 8 4}$ or 1.85 .

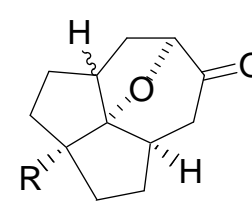

$1.98 \mathrm{R}=\mathrm{CO}_{2} \mathrm{Et}$

$1.99 \mathrm{R}=\mathrm{CO}_{2}{ }^{\mathrm{t}} \mathrm{Bu}$
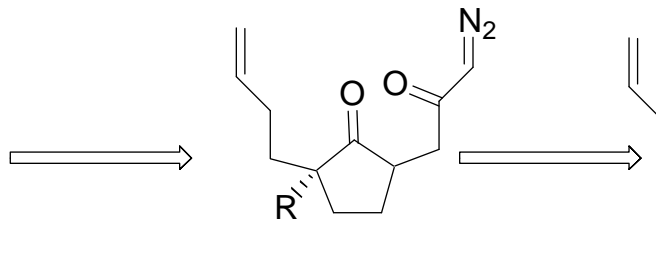

$1.94 \mathrm{R}=\mathrm{CO}_{2} \mathrm{Et}$

$1.95 \mathrm{R}=\mathrm{CO}_{2}{ }^{\mathrm{t}} \mathrm{Bu}$<smiles>[R]C1CCCC1=O</smiles>

3.5

$1.84 \mathrm{R}=\mathrm{CO}_{2} \mathrm{Et}$

$1.85 \mathrm{R}=\mathrm{CO}_{2}{ }^{\mathrm{t}} \mathrm{Bu}$

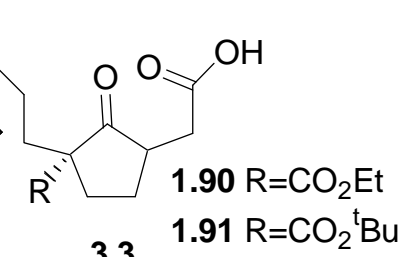

3.3
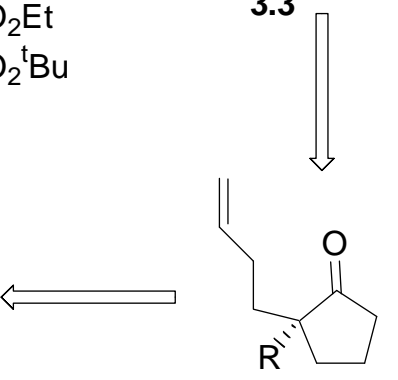

3.4

$1.86 \mathrm{R}=\mathrm{CO}_{2} \mathrm{Et}$

$1.87 \mathrm{R}=\mathrm{CO}_{2}{ }^{\mathrm{t}} \mathrm{Bu}$

Scheme 3.1 Retrosynthetic analysis for the CCCC approach 
The key step of this synthesis is the rhodium-catalysed cascade of the diazo skeleton 1.94 or 1.95 to afford 1.98 or 1.99 (scheme 3.2). In this sequence, 1.94 or 1.95 could undergo reaction with a rhodium catalyst to afford the metallo-carbenoids 1.96 or 1.97 , entropically driven by the expulsion of $\mathrm{N}_{2}$. Once the highly electrophilic rhodium carbenoid is formed, it could be attacked by the lone pair of electrons of the ring carbonyl oxygen, in order form a six-membered ring with an oxonium ylide. Ylides are known to undergo intramolecular cycloaddition with tethered alkenes, ${ }^{28}$ and in our case, it is hoped that the 5- and 7membered rings would form simultaneously; resulting in the functionalised pentacyclic ring system 1.98 or $\mathbf{1 . 9 9 .}$

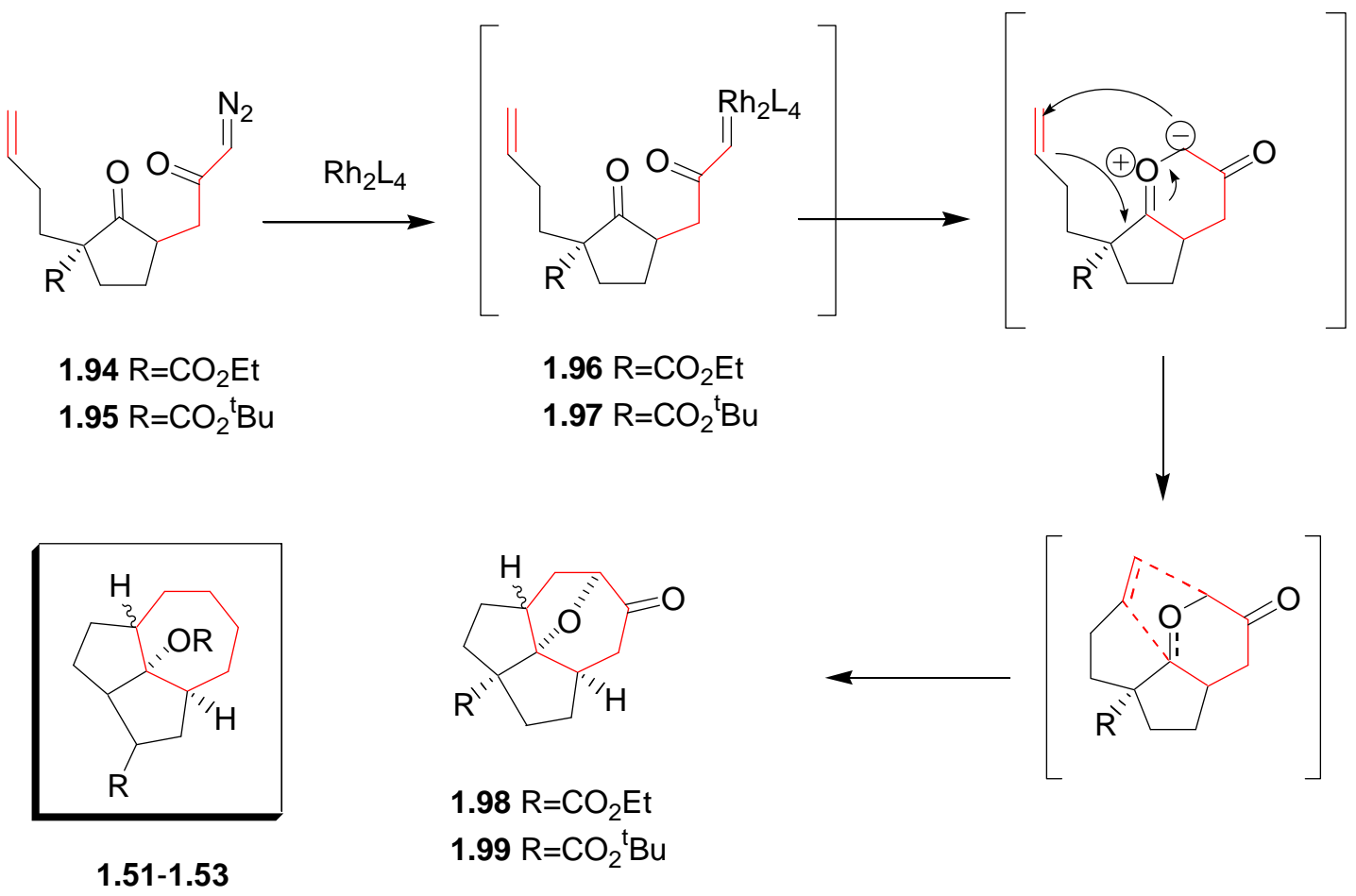

Scheme 3.2 Mechanistic approach to CCCC of 1.94 or1.95

After the formation of $\mathbf{1 . 9 8}$ or $\mathbf{1 . 9 9}$, a small number of subsequent reactions, involving removal of the ketone carbonyl, ring opening of the oxo-bridge and subsequent hydroxyl protection, hydrolysis and decarboxylation of the ester groups would lead to the resultant precursor being similar to the initially targeted 5,5,7 ring system 1.51-1.53 (scheme 1.11). 


\subsection{Synthesis of Cyclisation Precursors}

\subsubsection{Method 1- via diethyl adipate (3.1)}

The required cyclopentanone starting material for elaboration to the diazoskeleton precursors is easily accessible via a Dieckmann condensation of corresponding adipic acid derivatives. Dieckmann condensation involves intramolecular reaction of diesters under basic conditions to afford $\beta$-keto esters. The ester substituent at C-2 was considered unproblematic at this stage as we hypothesised it could be removed through decarboxylation later in the synthesis. Our initial studies utilised carboxypentanoate $\mathbf{1 . 8 4}$ as our starting material. This compound is available commercially, though synthesis of the compound was carried out in the course of this project using Dieckmann condensation method of diethyl adipate 3.1 (scheme 3.3), which was available in our laboratories. ${ }^{63}$

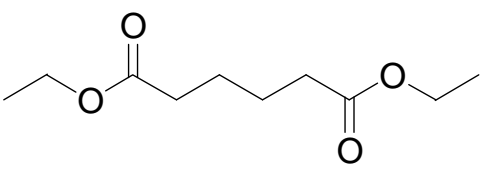

3.1

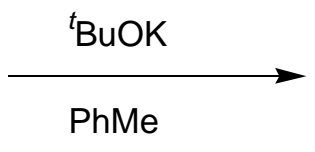

PhMe

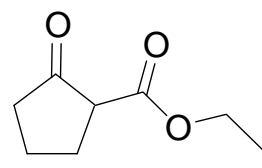

1.84

\section{Scheme 3.3 Dieckmann condensation on 3.1}

Potassium tert-butoxide was used for deprotonation at the ester's $\alpha$-positions; generating the carboanion, which then initiates cyclisation to form compound 1.84 in $42 \%$ yield (scheme 3.4). The characteristic peaks for compound 1.84 were seen in the ${ }^{1} \mathrm{H}$ NMR spectrum at $4.20 \mathrm{ppm}$ (quadruplet), and at $1.29 \mathrm{ppm}$ (triplet) for the ethyl ester, and most importantly, a triplet at $3.15 \mathrm{ppm}$ for the hydrogen at the substituted $\alpha$ position. These results matched that previously reported, ${ }^{63}$ and the crude product obtained after the work-up was of high purity. 


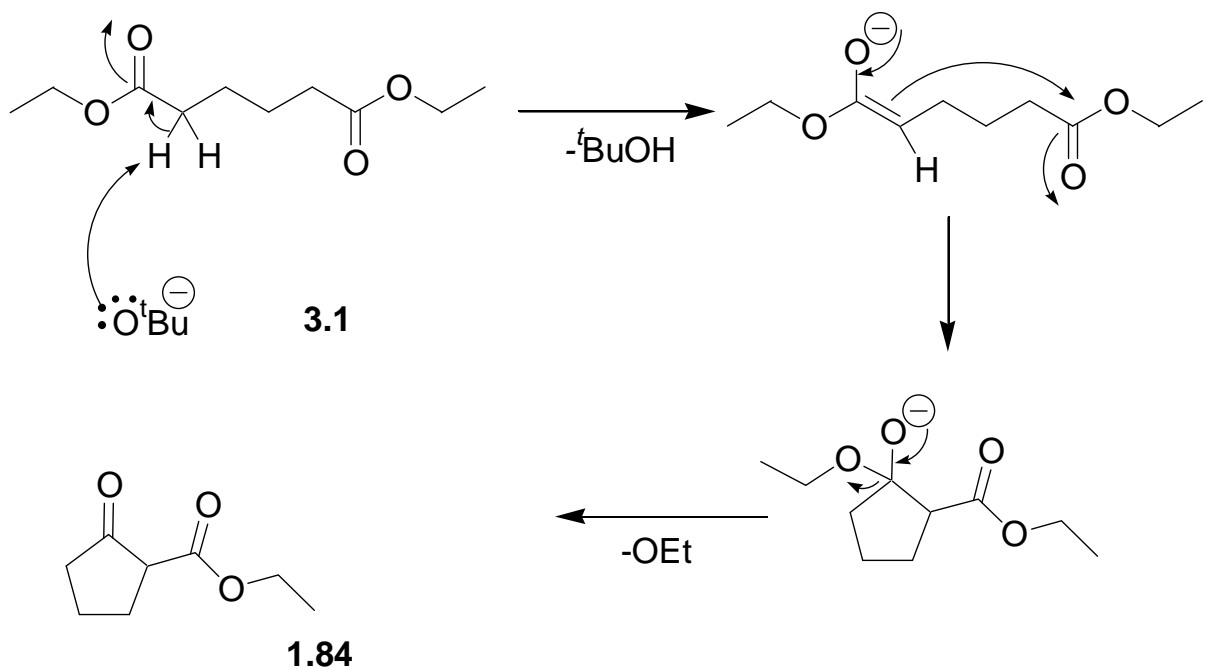

Scheme 3.4 Mechanism of Dieckmann condensation of compound 3.1

With compound 1.84 in hand, the first alkylation was carried out. As expected, the selective alkylation occurred at the substituted $\alpha$-position of the 1,3 dicarbonyl moiety. For this reaction, standard etherification methodology was used, ${ }^{64,65}$ utilising sodium hydride as a base (scheme 3.5). Yields of up to $65 \%$ of compound $\mathbf{1 . 8 6}$ could be achieved if the reaction was carried out overnight; however, longer reaction times resulted in decomposition of the product. Also observed was the formation of the $O$-alkylated product $3.2(5 \%)$. The yield of 3.2 was approximately $10 \%$ but seemed to increase if left to react for longer then overnight. The $C$-alkylated product $\mathbf{1 . 8 6}$ and the $O$-alkylated product 3.2 were collected after column chromatography as colourless liquids.

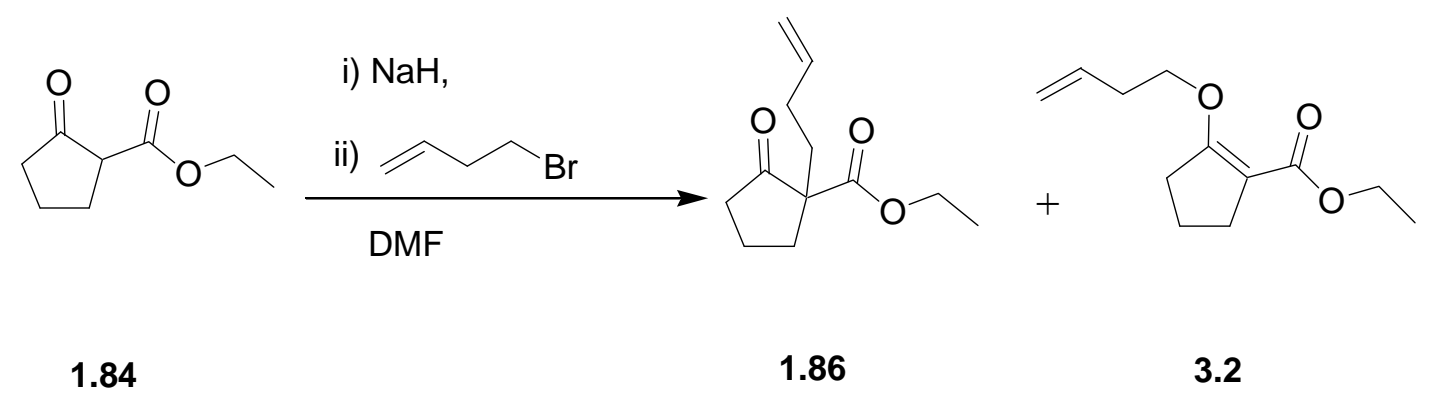

Scheme 3.5 Sodium hydride mediated alkylation of compound $\mathbf{1 . 8 4}$

Both compounds 1.86 and 3.2 were analysed and characterised after extensive NMR spectroscopic studies. For product 1.86, the ${ }^{1} \mathrm{H}$ NMR spectral data showed the peaks in the double bond region at approximately $5.8 \mathrm{ppm}$ and $5.0 \mathrm{ppm}$, and the $-\mathrm{OCH}_{2}$ protons as a 
quadruplet at approximately $4.1 \mathrm{ppm}$. A number of peaks were present in the 1-2 ppm region. The ${ }^{13} \mathrm{C}$ NMR spectrum showed the presence of a ketone carbon at $214.8 \mathrm{ppm}$, ester carbon at 170.9 and the alkene carbons at 137.7 and 115.1 for the terminal $\mathrm{sp}^{2}$ carbon. HSQC and COSY correlations and mass spectroscopy confirmed the identity as that of 1.86. For compound 3.2, the most striking observation from the ${ }^{1} \mathrm{H}$ NMR spectral data was the presence of two signals between 4.0 and $4.2 \mathrm{ppm}$. This indicated that there were two different types of protons next to an oxygen atom. The $-\mathrm{OCH}_{2}$ protons of the ethyl ester appeared as a quartet at $4.17 \mathrm{ppm}$ and a triplet was also seen at $4.06 \mathrm{ppm}$. The ${ }^{13} \mathrm{C} \mathrm{NMR}$ spectrum showed that there was no ketone carbon present in the molecule, instead two carbons signals were found in the region of 165-167 ppm. These observations lead us to believe that the unknown compound was the $O$-alkylated product 3.2, which was confirmed through HSQC and COSY correlations and high-resolution mass spectrum (HRMS) data.

With 1.86 in hand, the next step involved substitution at the remaining available $\alpha$-position. For this reaction LDA was employed as the base $^{66}$ to abstract the $\alpha$ - hydrogen (scheme 3.6). Initial attempts to form the desired compound were not successful, with starting material isolated (table 3.1, entry 1). Formation of the desired product was only seen when the temperature during the deprotonation step was increased from $-78^{\circ} \mathrm{C}$ to $-40^{\circ} \mathrm{C}$ (entries 2 and 3 ) and the starting material was dried using azeotropic conditions to remove water (entry 3).

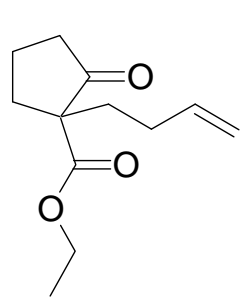

1.86

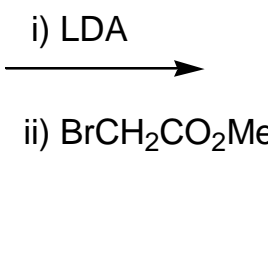

ii) $\mathrm{BrCH}_{2} \mathrm{CO}_{2} \mathrm{Me}$

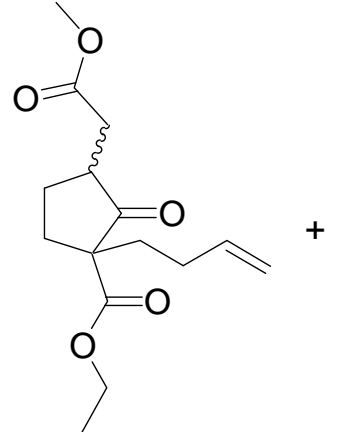

1.88

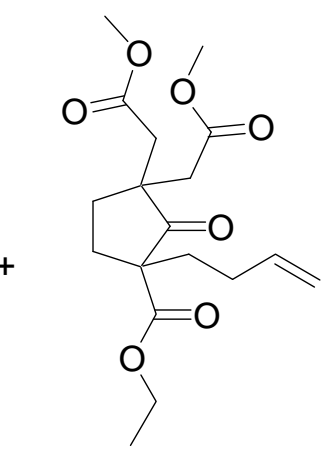

3.3

Scheme 3.6 LDA mediated alkylation of compound $\mathbf{1 . 8 6}$

A number of products were isolated following flash chromatography purification. In addition to the starting material $(20 \%)$, equal weights of two other compounds were obtained. ${ }^{1} \mathrm{H}$ NMR spectroscopic analysis of the more polar of the two compounds showed 
two prominent singlets at 3.42 and $3.45 \mathrm{ppm}$, characteristic of oxyalkyl protons. Investigation of the ${ }^{13} \mathrm{C}$ NMR spectrum revealed a single compound hence there was no diastereoisomeric mixture. Since the molecule has two methoxy peaks and no diastereoisomers, it was proposed that this compound was the dialkylated product 3.3 (scheme 3.6). HSQC and COSY correlations and HRMS data confirmed this to be the case. The second product obtained displayed one prominent peak at $3.61 \mathrm{ppm}$ in the ${ }^{1} \mathrm{H}$ NMR spectrum and ${ }^{13} \mathrm{C}$ NMR spectroscopic analysis indicated there was a mixture of diastereoisomers. Based on these observations it was proposed that this was our target molecule 1.88. HSQC and COSY correlations, in addition to HRMS information confirmed the structure of the molecule to be $\mathbf{1 . 8 8}$.

The different conditions and the results obtained for this reaction are summarised below:

Table 3.1 LDA reaction conditions

\begin{tabular}{|c|c|c|c|}
\hline $\begin{array}{l}\text { Exp } \\
\text { No. }\end{array}$ & Reaction Stiochiometry ${ }^{\wedge}$ & $\begin{array}{l}\text { Reaction Conditions } \\
\text { (reagents were added in } \\
\text { toluene) }\end{array}$ & Result ${ }^{*}$ \\
\hline 1 & $\begin{array}{l}\text { i) } \mathrm{LDA}(1.2 \text { eq.), } 1.86 \text { ( } 1 \text { eq.) } \\
\text { ii) } \mathrm{BrCH}_{2} \mathrm{CO}_{2} \mathrm{Me}(1.2 \text { eq.) }\end{array}$ & $\begin{array}{l}\text { i) }-78^{\circ} \mathrm{C}, 1 \mathrm{~h} \\
\text { ii) r.t., overnight }\end{array}$ & Starting material \\
\hline 2 & $\begin{array}{l}\text { i) } \mathrm{LDA}(1.2 \text { eq.), } 1.86 \text { (1 eq.) } \\
\text { ii) } \mathrm{BrCH}_{2} \mathrm{CO}_{2} \mathrm{Me} \text { (1.2 eq.) }\end{array}$ & $\begin{array}{l}\text { i) }-40^{\circ} \mathrm{C}, 1 \mathrm{~h} \\
\text { ii) r.t., overnight }\end{array}$ & $\mathbf{1 . 8 8}$ (10\% diastereomers) \\
\hline 3 & $\begin{array}{l}\text { i) } \operatorname{LDA}(1.2 \text { eq.), } 1.86 \text { (1 eq.) } \\
\text { ii) } \mathrm{BrCH}_{2} \mathrm{CO}_{2} \mathrm{Me}(1.2 \text { eq.) }\end{array}$ & $\begin{array}{l}\text { i) }-40^{\circ} \mathrm{C}, 1 \mathrm{~h} \\
\text { ii) r.t., overnight }\end{array}$ & $\begin{array}{l}\mathbf{1 . 8 8}(30 \% \text { diastereomers }), \\
3.3(30 \%)^{\wedge}\end{array}$ \\
\hline
\end{tabular}

${ }^{*}$ Results are based on ${ }^{1} \mathrm{H}$ NMR, resulting from peak integration

A Azeotropic drying was used

$£$ All reactions were carried out in THF

Our proposed route to the diazo ketone precursor involved the selective hydrolysis of the methyl ester whilst the ethyl ester remained intact. We had hoped that the very different steric environments of the two esters would result in selectivity in the hydrolysis reaction. 
We envisaged the hydrolysis of the methyl ester would be preferred, as it is a smaller group and has less steric hinderance compared to the ethyl ester.

The reaction of compound $\mathbf{1 . 8 8}$ with $\mathrm{NaOH}$ in absolute ethanol appeared to form diethyl ester 3.4 (scheme 3.7). Analysis of ${ }^{1} \mathrm{H}$ NMR spectrum of the crude reaction showed that the integration of the $-\mathrm{OCH}_{2}$ protons integrated for 4 protons, and disappearance of the methyl ester protons was also seen. TLC analysis of this reaction also showed that the products formed were less polar than the starting material. These results, in addition to mass spectral analysis all indicated the formation of the diethyl ester 3.4. Thus it appeared that transesterification had occurred.

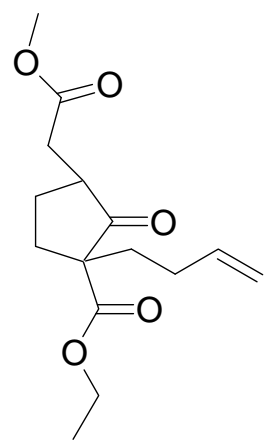

1.88

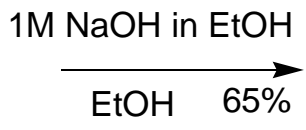

Scheme 3.7 Methyl ester hydrolysis of $\mathbf{1 . 8 8}$ with $1 \mathrm{M} \mathrm{NaOH}$ in EtOH solution

The next attempt for selective hydrolysis of $\mathbf{1 . 8 8}$ used the method reported by Ghosh and Miller, whereby they used a 2:1 THF/water mixture as solvent system, and $\mathrm{NaOH}$ (1M aq.) as a base for the reaction. ${ }^{67}$ This reaction was unsuccessful in our case, as only the starting material 1.88 was isolated from the reaction. Selective hydrolysis (of orthogonal diesters; tert-butyl ester and methyl ester) has been observed by Johnson and colleagues, ${ }^{68}$ when aqueous $\mathrm{NaOH}$ in ethanol was used. Under these conditions, after 2 days, the desired monoacid did not form but instead the formation of what is assumed to be hemiacetal 3.5 (scheme 3.8) was seen. This structure was postulated from the absence of the ketone carbon signal in the range of $200-210 \mathrm{ppm}$ in the ${ }^{13} \mathrm{C}$ NMR spectrum, and absence of methoxy protons near $3.5 \mathrm{ppm}$ in the ${ }^{1} \mathrm{H}$ NMR spectrum.

The reaction was repeated, with stirring for just 3 hours this time and a mixture of both acetal compound 3.5 and desired acid $\mathbf{1 . 9 0}$ was seen in the crude mixture of product 
(scheme 3.8). This time the ${ }^{13} \mathrm{C}$ NMR spectrum showed two carbons at around $220 \mathrm{ppm}$, and four ester peaks were seen, in addition to four alkene carbon signals. Mass spectral analysis also indicated that both compound $\mathbf{3 . 5}$ and $\mathbf{1 . 9 0}$ were present, with compound $\mathbf{3 . 5}$ as the major product, as observed in ${ }^{13} \mathrm{C}$ NMR spectrum. It was possible that the formation of 3.5 occurred due to the strain in the cyclopentanone ring, which could be relieved through attack of ethanol to provide a $\mathrm{sp}^{3}$ centre at the initial ketone carbon.

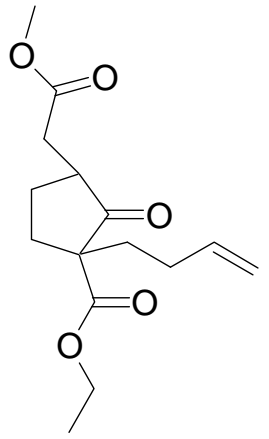

1.88
$1 \mathrm{M} \mathrm{NaOH}$

$\mathrm{EtOH}$

Scheme $3.8 \mathrm{NaOH}$ mediated methyl ester hydrolysis of $\mathbf{1 . 8 8}$

Crude product 1.90 was used without further purification owing to the scale of the reaction, and difficulties in column chromatography caused by co-elution of the products. The next step in the synthesis involved activation of the monoacid with pivaloyl chloride using a known method (scheme 3.9). ${ }^{68,27}$

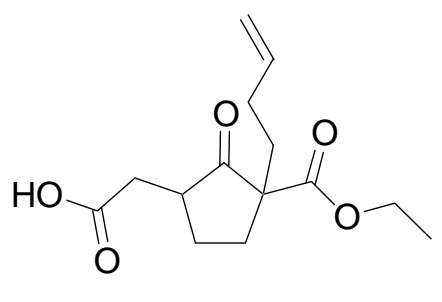

1.90



3.5

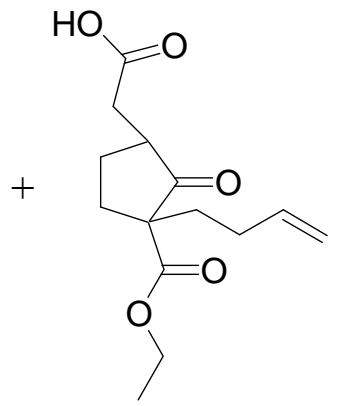

1.90

$$
\text { known method (schent } 3.9) \text {. }
$$

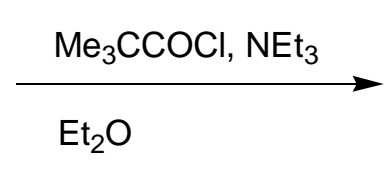

Scheme 3.9 Activation of monoacid 1.90 pivaloyl chloride

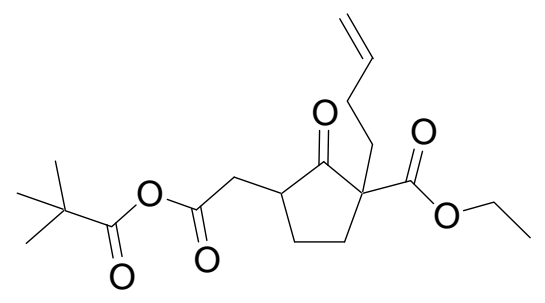

1.92

The ${ }^{1} \mathrm{H}$ NMR spectrum of the crude mixture looked promising, as a prominent singlet was seen at approximately $1.0 \mathrm{ppm}$ (possibly from the $\left.-\mathrm{C}\left(\mathrm{CH}_{3}\right)_{3}\right)$ and starting material 1.90 was also detected. However, purification of the compounds proved to be surprisingly difficult by flash chromatography. The compounds could not be separated on the column, with only 
about 20\% material recovered upon stripping the column with EtOAc. Our attention then turned to using reverse phase chromatography. The underlying idea for using reverse phase chromatography was that this would provide good separation of the monoacids 3.5 and 1.90, from the anhydride product 1.92, if the column was eluted with a basic elutent. The base would react with the acids and 'charge' the molecules, making them very polar. This would increase the polarity of the acids and thus elute them in the most polar solvent mixture used (acetone: 2\% $\mathrm{NH}_{3}(\mathrm{aq})$ solution 50:50 mixture). This would keep the desired compound 1.92, in the column, adhered to the reverse phase beads, which would later elute with a less polar solvent system. The solvent mixture used were acetone: $2 \% \mathrm{NH}_{3}$ (aq) solution, 1:1 mixture, acetone: $2 \% \mathrm{NH}_{3}$ (aq.) solution $75: 25$, mixture and $100 \%$ acetone.

The fraction of $1: 1$ acetone: $2 \% \mathrm{NH}_{3}$ solution appeared to contain most material, with ${ }^{1} \mathrm{H}$ NMR spectral data indicating presence of starting materials and another minor compound. This method turned out to be quite complex and it seemed that separation of the desired compound would prove to be quite tedious and time-consuming. At this point other methods for forming the desired diazo compound $\mathbf{1 . 9 4}$ were investigated.

\section{$\underline{\text { 3.2.2 Method } 2 \text { - via LDA mediated diazo reaction on } \mathbf{1 . 8 6}}$}

An alternative method of accessing the diazo ketone 1.94, which was investigated involves direct installation of the diazo ketone moiety via alkylation of $\alpha$-bromo diazo ketone 3.7, with cyclopentanone derivative 1.86. This method was appealing since it removed two steps from the initial planned synthesis. Formation of the diazo methyl derivative 3.7 (80\% yield) was achieved through preparation of diazomethane then reacting it with bromo acetyl bromide 3.6 (scheme 3.10), using a reported procedure. ${ }^{69}$<smiles>O=C(Br)CBr</smiles>

3.6

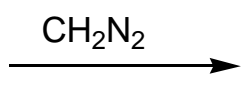

3.7

Scheme 3.10 Diazo reaction of bromo acetyl bromide (3.6) 
The reaction was successful and the ${ }^{1} \mathrm{H}$ NMR spectrum showed the formation of the desired compound $3.7(60 \%)$ along with another compound present in approximately $20 \%$ yield. The ${ }^{1} \mathrm{H}$ NMR spectrum showed the minor compound had two doublets at around $3.5 \mathrm{ppm}$, leading to our conclusion that the protons were held in a rigid framework (most probably in a cyclic system) and a singlet at $3.12 \mathrm{ppm}$ hinted that a proton might be next to a bromine atom. The high-resolution mass spectral data of these products confirmed that both the compound $\mathbf{3 . 7}$ and the minor compound had the same molecular formula and the signals were indicative of two bromine isotopes ${ }^{79} \mathrm{Br}$ and ${ }^{81} \mathrm{Br}$, present in the molecule. Based on this, we deduced that the structure of the unknown is probably 3.8, although a feasible mechanism could not be derived for its formation.

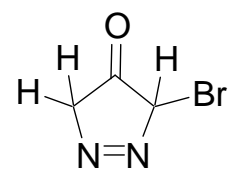

3.8

Figure 3.1 Cyclic diazo compound 3.8

The diazo compound 3.7 was then reacted with alkylated cyclopentanone 1.86 (scheme 3.11) in an attempt to form diazo derivative $\mathbf{1 . 9 4}$.

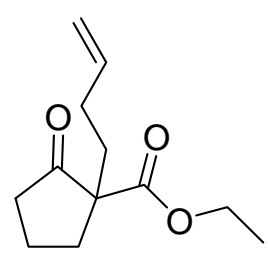

1.86

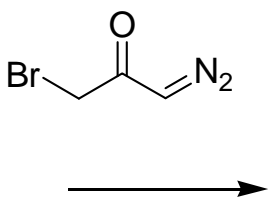

1.94

Scheme 3.11 Attempted formation of diazo compound $\mathbf{1 . 9 4}$

Similar substitution reactions, had been performed by Padwa and co-workers, whereby they compared the reactivity of diazo derivative 3.9 with various nucleophiles (scheme 3.12 ). ${ }^{70}$ 


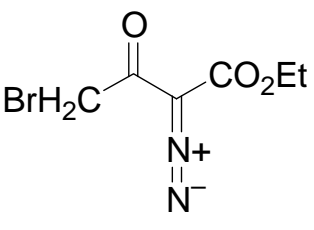

3.9

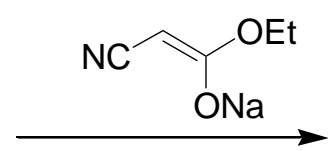

Scheme 3.12 Reported substitution reaction of diazo compound

The base used by Padwa, was sodium hydride, but since our substitution needed to occur at the unsubstituted $\alpha$-position, our first attempt used LDA as a base instead of sodium hydride. Unfortunately, the diazo compound 3.7 appeared to decompose in the presence of LDA. This was apparent as the colour of the solution turned to red-brown as soon as the compound 3.7 was added. The ${ }^{1} \mathrm{H}$ NMR spectral data from the reaction showed the presence of starting material $\mathbf{1 . 8 6}$ and by-product $\mathbf{3 . 8}$ with no traces of compound 3.7.

We then investigated the use of sodium hydride as a base for this reaction, using the method reported by Padwa. ${ }^{70}$ However, this method was also unsuccessful, with both the starting material 1.86 and 3.7 recovered. Another uncharacterised compound was isolated in trace amounts from the purification. Given that many issues from original pathway relied on selective hydrolysis of similar esters, we decided to use a system with ester functions of greater orthogonality then ethyl and methyl esters. Thus the tert-butyl ester was used in place of ethyl ester in the initial cyclopentanone derivative.

\subsubsection{Method 3-via tert-butyl adipate (3.12)}

Bis-tert-butyl adipic ester was not readily available, and therefore this was synthesised from adipic acid via the acid chloride 3.11 (scheme 3.13). Compound 3.11 was formed (57\%) by reacting adipic acid (3.10) with thionyl chloride by following a reported procedure. ${ }^{71}$ The ${ }^{13} \mathrm{C}$ NMR spectrum of the product matched the reported values, ${ }^{71}$ displaying peaks at 173.0, 46.2 and $23.7 \mathrm{ppm}$. Subsequent treatment of $\mathbf{3 . 1 1}$ with tert-butanol using the method of Babler and Sarussi ${ }^{72}$ furnished $3.12(53 \%)$. 


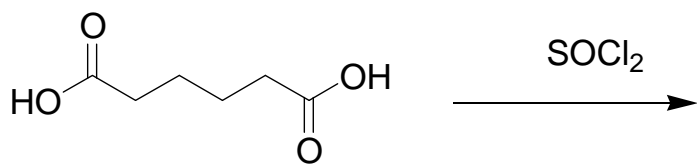

3.10<smiles>O=C(Cl)CCCCC(=O)Cl</smiles>

3.11

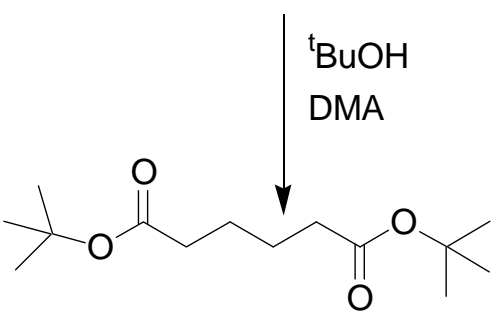

3.12

Scheme 3.13 Formation of bis tert-butyl adipate from adipic acid

Dieckmann condensation was carried out using the method previously described for diethyl adipate to obtain $\mathbf{1 . 8 5}$ in $75 \%$ yield (scheme 3.14). The ${ }^{1} \mathrm{H}$ NMR spectroscopic analysis of the compound 1.85 showed a triplet at $3.05 \mathrm{ppm}$ corresponding to the proton at the substituted $\alpha$-position, and a singlet integrating for 9 atoms for the tert-butyl protons at $1.47 \mathrm{ppm} .{ }^{13} \mathrm{C}$ NMR, COSY and HSQC spectroscopic analysis in addition to with mass spectral data confirmed the structure.

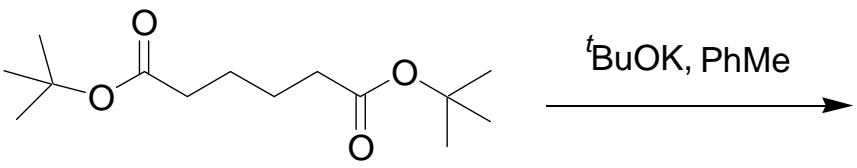

3.12

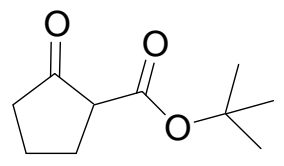

1.85

Scheme 3.14 Dieckmann condensation of bis-tert-butyl adipate 3.12

Product 1.85 was then subjected to sodium hydride based alkylation (scheme 3.15), using the method used in the formation of ethyl ester derivative 1.86. Flash chromatography was performed to purify the cyclopentanone derivative $1.87(40 \%)$ and elution was possible in 40:1 Hex: EtOAc mixture. The $O$-alkylated product $3.13(5 \%)$ was also collected in the same solvent elution. ${ }^{1} \mathrm{H}$ and ${ }^{13} \mathrm{C}$ NMR spectroscopic data along with high-resolution mass spectral data corresponded with the product. 


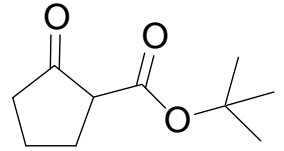

1.85

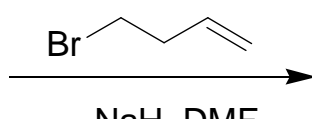

$\mathrm{NaH}, \mathrm{DMF}$

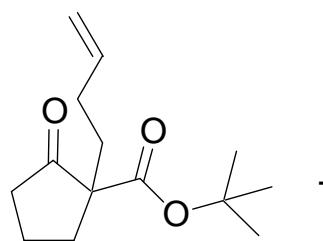

1.87

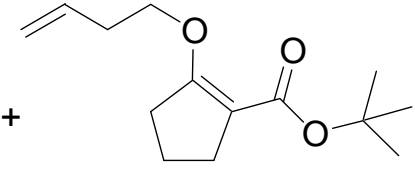

3.13

Scheme 3.15 Sodium hydride mediated alkylation on compound 3.20

Product 1.87 was then subjected treatment with LDA in order to form diester derivative 1.89 (scheme 3.16). The LDA reaction proceeded smoothly and the method used for the ethyl ester derivative was employed again for this reaction. The yield obtained in this reaction was low (18\%), as compared to the alkylation of the corresponding ethyl ester derivative and no double alkylation was seen. This could be due to the bulkiness of the tertbutyl ester, hindering reaction at the $\alpha$ - position in the molecule.

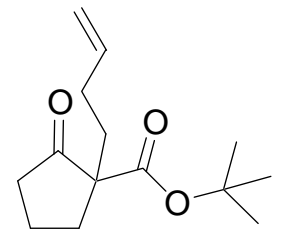

1.87

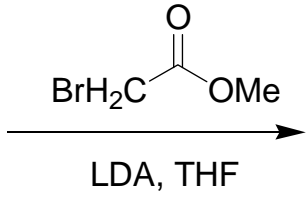

LDA, THF

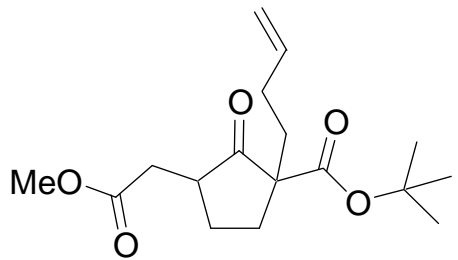

1.89

Scheme 3.16 LDA reaction of compound $\mathbf{1 . 8 7}$

After the formation of compound $\mathbf{1 . 8 9}$ was achieved, selective hydrolysis of the methyl ester was carried out using $\mathrm{NaOH}$. The conditions required for the cleavage of tert-butyl esters and methyl esters are orthogonal, thus the basic conditions would enable to selectively cleave only the methyl ester. The method employed, ${ }^{73}$ indicated stirring was necessary for 2 days. Surprisingly, the ${ }^{13} \mathrm{C}$ NMR spectrum showed that the ketone was no longer present in the molecule. Instead of observing the signal from the ketone carbon at approximately $210 \mathrm{ppm}$, a new signal at $175 \mathrm{ppm}$ was seen for the product. The ${ }^{1} \mathrm{H}$ NMR showed that the methyl ester was no longer present in the molecule, both the alkene protons and the tert-butyl ester protons appeared unaltered. The mass spectral analysis showed that the compound has a molecular formula of $\mathrm{C}_{16} \mathrm{H}_{26} \mathrm{O}_{6}$. Based on these results, it was initially thought that the structure of the molecule could be acetal 3.14 (figure 3.2). 


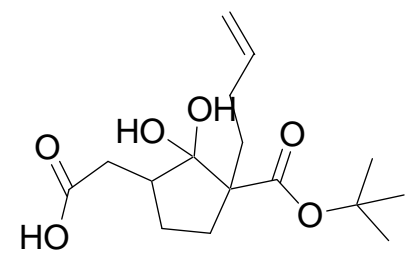

3.14

Figure 3.2 Initially proposed hydrolysis product

However, no evidence of this acetal was seen in the spectral data, as the new carbon signal at $175 \mathrm{ppm}$ was not at the expected place for an acetal carbon, which would have occurred around 90-100 ppm. Therefore it was concluded that this was possibly diacid 3.15 (figure 3.3, obtained in $57 \%$ yield). The ${ }^{13} \mathrm{C}$ NMR spectrum also showed that there were diastereomers present, as all the carbon signals appeared to double up. ${ }^{13} \mathrm{C}$ NMR spectral data showed signals at 180.9 and $178.1 \mathrm{ppm}$, which were corresponded to the two acids and HMBC, HSQC, COSY and mass spectral data confirmed the structure to be that of diacid 3.15

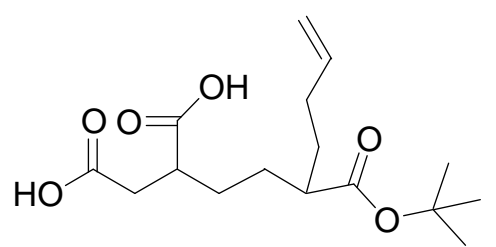

3.15

Figure 3.3 Corrected structure for hydrolysis product 3.15

The mechanism for formation of compound 3.15 could be explained as shown in scheme 3.17, after initial hydrolysis of the methyl ester. 


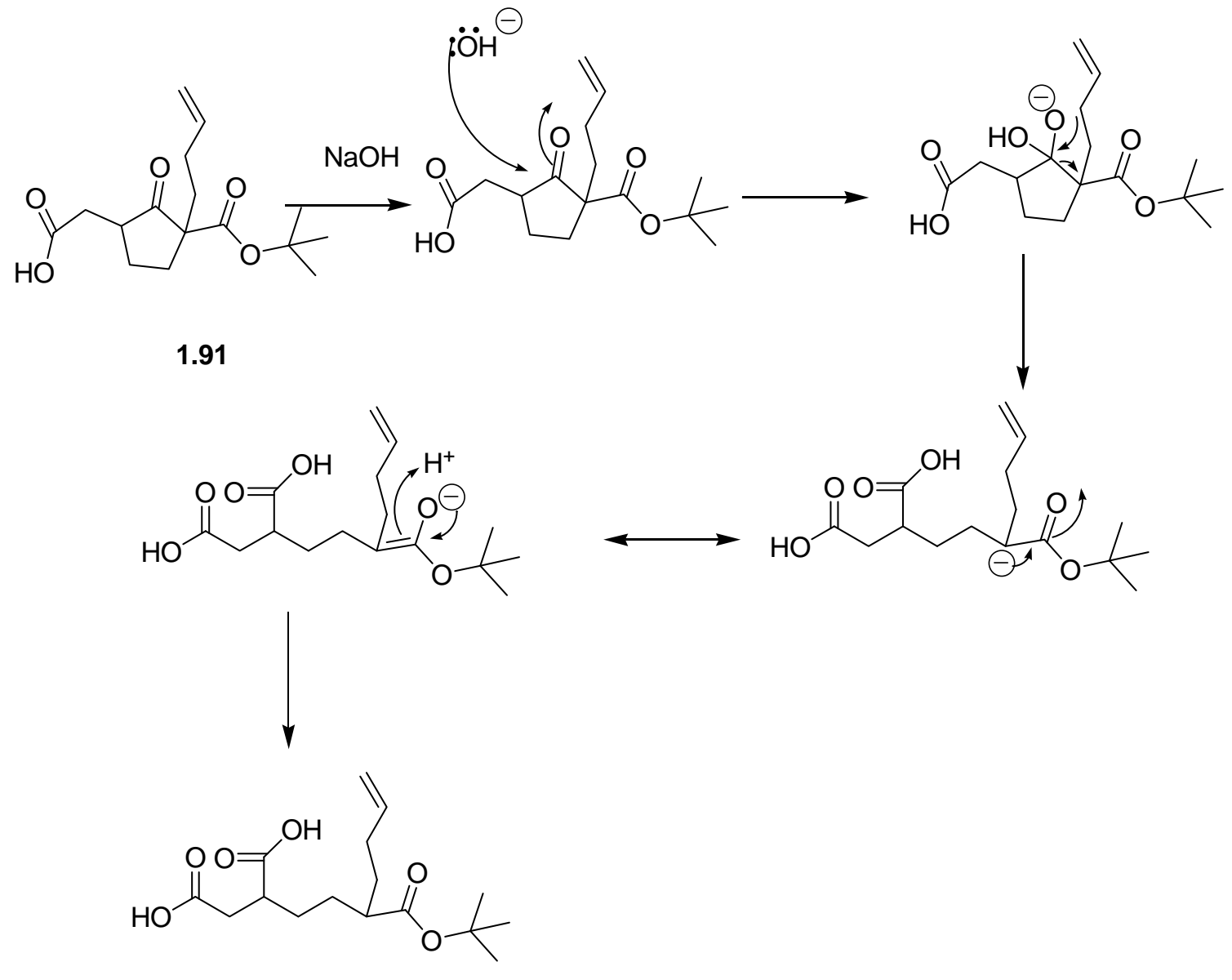

3.15

Scheme 3.17 Proposed mechanism for ring opening of compound 1.91

The anion is stabilised by the resonance form with the tert-butyl ester, which aids in the ring opening reaction of the hydrolysed product.

In retrospect, it is possible that the hydrolysis of the ethyl ester derivative $\mathbf{1 . 8 8}$ could have resulted in a similar ring opened product, and not product 3.5 as believed previously. The assumed product 3.5 was not fully characterised through extensive NMR studies and could have had the structure as shown in figure 3.4. 


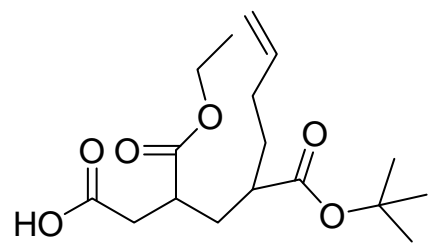

3.5

Figure 3.4 Alternative structure for molecule 3.5

Once the problems with the hydrolysis had been identified, our attention turned to ways of preventing this second hydrolysis from happening. The reaction time was very important in this reaction, as it was feasible that the ring opening reaction (Scheme 3.17) could be happening with prolonged reaction times. We ultimately found that reaction at $0{ }^{\circ} \mathrm{C}$ for 3 hours enabled good formation of product, with only trace amounts of starting material remaining. The ${ }^{13} \mathrm{C}$ NMR spectrum clearly showed the presence of ketone peak at 213.7 ppm and $214.2 \mathrm{ppm}$ (due to distereoisomers), and the mass spectral data of this material suggested that the product was compound $\mathbf{1 . 9 1}$ (figure 3.5).

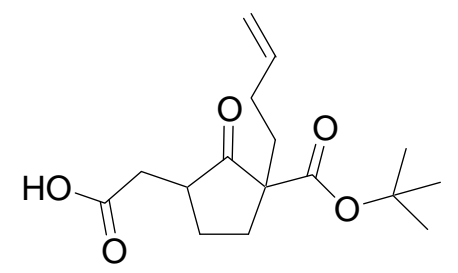

1.91

Figure 3.5 Hydrolysis product

Once it was fully deduced that this was the desired product; it was subjected to the reported pivaloyl chloride reaction, ${ }^{68}$ in order to form the mixed anhydride derivative $\mathbf{1 . 9 3}$ (figure 3.6). However, this reaction did not seem to work, as none of the desired compound 1.93 was evident from the mass spectral results. This could be due to the steric hinderance, inflicted by the highly substituted cyclopentanone. 


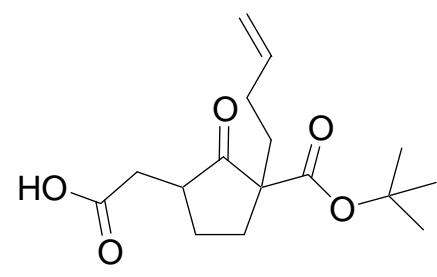

1.91
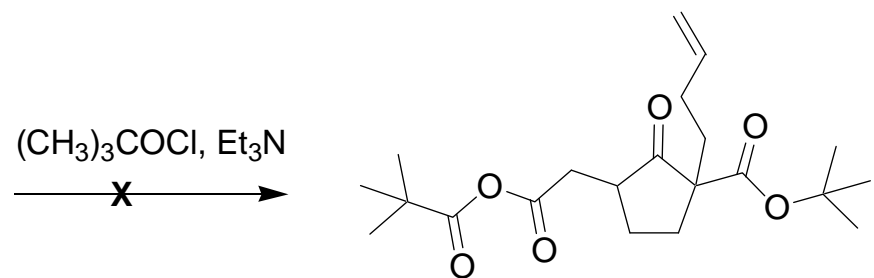

1.93

Figure 3.6 Attempted pivaloyl chloride reaction on $\mathbf{1 . 9 1}$

The next approach for the formation of the mixed anhydride was to use methyl chloroformate, using the procedure employed by Fadel and colleagues. ${ }^{74}$ It was envisaged that as the pivaloyl group is quite bulky, this could have prevented the anhydride from forming and thus the use of a smaller group could enhance the anhydride formation (figure 3.7). However, even this reaction did not seem to work as the mass spectral data indicated the presence of starting material only. At this point, it became clear that the formation of anhydride derivatives of acid 3.16 might not possible most probably due to the high degree of steric hinderance.

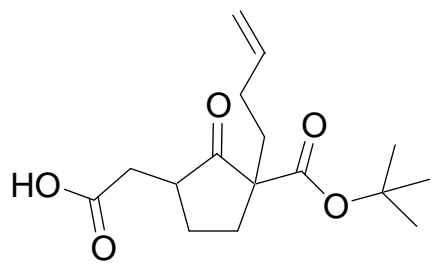

1.91

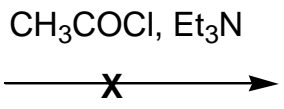

3.16

Figure 3.7 Attempted methyl chloroformate reaction of $\mathbf{1 . 9 1}$

Since we could not purify any compound due to the small reaction scale, in order to test if any of the (so far undetected) methyl and pivaloyl anhydride had formed, the product from these reactions was subjected to treatment with diazomethane (scheme 3.18). If any of these anhydrides were present then the diazo compound $\mathbf{1 . 9 5}$ would form and could be easily characterised by ${ }^{1} \mathrm{H}$ NMR spectroscopic data. 
<smiles>C=CCCC1(C(=O)OC(C)(C)C)CCC(CC(=O)OC(=O)C(C)(C)C)C1=O</smiles>

1.93
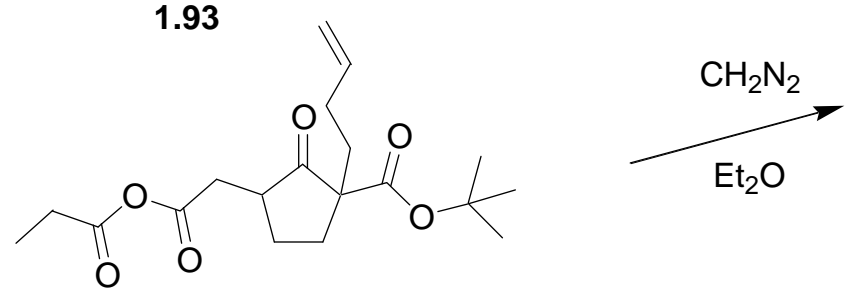

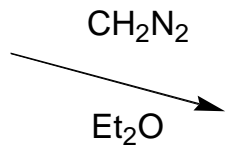

3.16

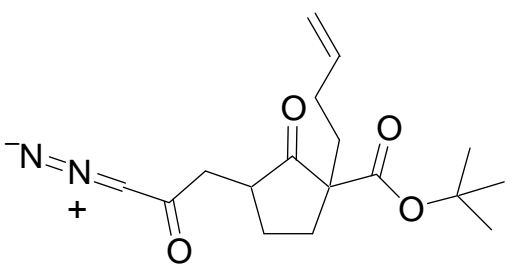

1.95

Scheme 3.18 Proposed diazomethane reaction on anhydrides 1.93 and 3.16

The ${ }^{1} \mathrm{H}$ NMR spectrum of the crude product corresponded to compound 1.89. This provided further evidence that the compound $\mathbf{1 . 9 3}$ and $\mathbf{3 . 1 6}$ did not form and so the acid 1.91 simply underwent methylation, which is typical reaction of carboxylic acid with diazomethane (scheme 3.19). ${ }^{75,76}$

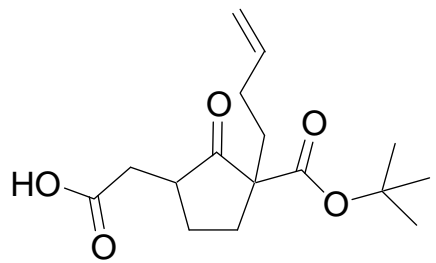

1.91

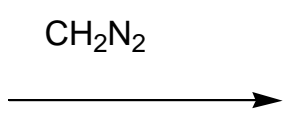

1.89

Scheme 3.19 Diazomethane as a methylating agent

At this point, attempts to carry the research further was suspended due to time restrictions and our attention focused on planning further improvements which could be undertaken in to form the desired diazo compound and subsequent 5,5,7 ring system. 


\section{Chapter 4 Concluding Remarks and Future Work}

\section{$\underline{4.1 \text { Conclusion }}$}

Although, the synthesis of the 5,5,7 tricyclic ring system of daphnioldhanin A, has not been achieved in this research, significant advances has been achieved towards its synthesis. For the radical cascade approach, compound 2-methylidene cycloheptanone (2.7) has been achieved. It has been demonstrated that it is $\mathbf{2 . 7}$ is a highly reactive molecule which forms dimers readily, thus would not be a suitable precursor for the radical approach towards daphnioldhanin A synthesis.

For the CCCC approach, the formation of monoacid 1.91 has been achieved successfully over a series of steps starting from adipic acid 3.10. The results obtained from reactions done on compound $\mathbf{1 . 9 1}$ indicated that a different approach should be taken from this point in the synthesis and a few of these routes are discussed later in this section.

\subsection{Future Work}

The radical approach could be exploited more to see the feasibility of this reaction in forming the core of the daphnioldhanin A. However, since 2-methylidene cycloheptanone (2.7) is so reactive, another intermediate must be employed to carry out these reactions. Hence, we believe it is not feasible to pursue the radical reactions through this compound and another approach must be sought.

However, for the CCCC approach, the difficulties with this methodology arose from the failure to form the anhydride derivative of acid 1.91. The acid chloride derivative of acid 1.91 might be a suitable alternative precursor for diazo compound 1.95, which could avoid this problem. The chloride group of the acid chloride 4.1 is smaller than the anhydride derivatives targeted during this research, thereby reducing the unfavourable steric interactions due to the bulky methyl and pivaloyl anhydride groups. Acid chlorides have been used previously by researchers, to activate acid precursors for CCCC approach. ${ }^{77}$ 


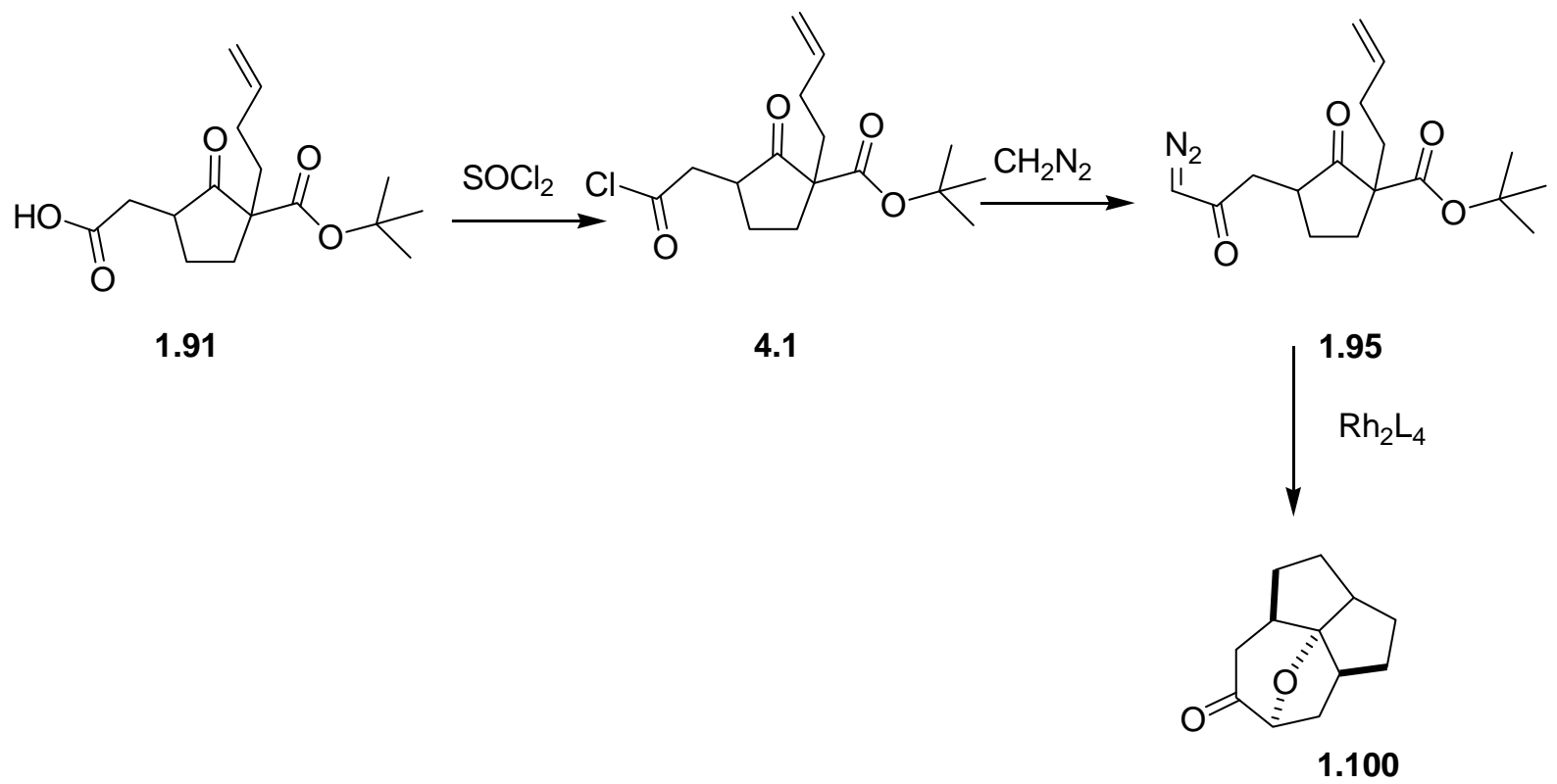

Scheme 4.1 Alternative CCCC approach to compound $\mathbf{1 . 1 0 0}$

The tert-butyl ester is used in this reaction in order to drive the stereochemistry of the methyl ester and the butene group, to being on the same face of the molecule. This stereochemistry is essential for the preferred CCCC reaction to take place in order to form compound 1.100.

Another approach might involve hydrolysis of the tert-butyl ester group and then subsequent decarboxylation of the resulting acid after the stereochemistry of the tethers has been set. The hydrolysis of the tert-butyl ester would be selective, since the hydrolysis of the methyl and the tert -butyl ester is orthogonal and thus by using a strong acid, such as TFA, the selective hydrolysis of the tert-butyl ester could be undertaken. Decarboxylation of the resulting acid could be achieved via, Barton-McCombie radical methods. The removal of this bulky tert-butyl ester could help to reduce the steric hinderance and thus could result in successful anhydride formation. 

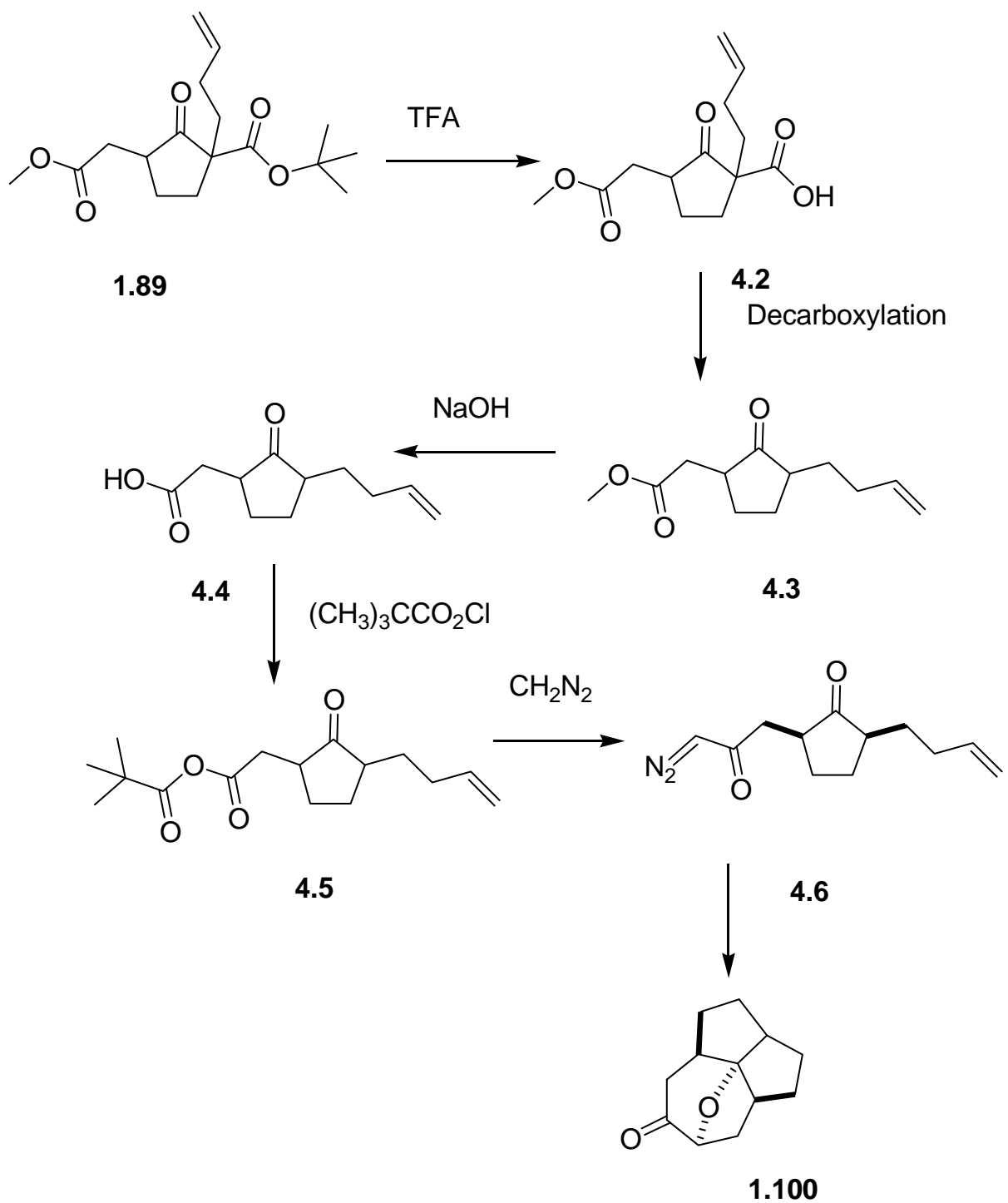

Scheme 4.2 Another CCCC approach to 5,5,7 ring system of daphnioldhanin A 


\section{Chapter 5 Experimental}

\section{$\underline{5.1 \text { General Experimental Procedures }}$}

Unless otherwise stated, the following conditions apply. All reactions were carried out in oven-dried Pyrex round-bottom flasks, sealed with rubber septa, and stirred with a Tefloncoated magnetic stir-bar. All the radical reactions were carried out under argon in flamedried glassware. Addition of liquid reagents was achieved using syringes fitted with flamedried needles or disposable needles. For reactions where heating was required, oil baths were used. Reactions at $0{ }^{\circ} \mathrm{C}$ were achieved using ice baths, and reactions at $-78{ }^{\circ} \mathrm{C}$ were maintained using dry ice with acetone bath, enclosed in a thermostat container. For reaction at $-40{ }^{\circ} \mathrm{C}$, acetonitrile with dry ice bath was used.

Solvents were removed using a Büchi Rotary evaporator also referred to as 'under reduced pressure'. Rotary evaporation took place in a water bath $\left(20-30{ }^{\circ} \mathrm{C}\right)$. High-vacuum rotary evaporation was achieved using a Büchi Rotavapor RE-111 fixed with a vacuum pump (ca. $2 \mathrm{~mm} \mathrm{Hg})$

Room temperature (r.t.) was assumed to be approximately $20{ }^{\circ} \mathrm{C}$. Anhydrous magnesium sulphate was used as the drying agent in all the experiments, unless otherwise stated.

THF and diethyl ether used for reactions were freshly distilled over sodium wire, under argon. Dichloromethane used for reactions was distilled over calcium hydride. Diisopropylamine and triethylamine were distilled from sodium hydroxide and toluene (dry and distilled from $\mathrm{Na}$ ) was used for the radical reactions. Acetone used for reactions was distilled from potassium carbonate. All other reagents used were of commercial quality and used without further purification.

Reaction progress was monitored using aluminium-backed TLC plates coated with silica gel 60 and products were detected using iodine dip, UV radiation at $254 \mathrm{~nm}$ and an acidic solution of anisaldehyde. 
Fractional distillation and flash column chromatography were used for the purification of products. Silica gel 60 was used for flash chromatography and solvents systems used were composed of hexanes:ethyl acetate in the ratios indicated in the relevant procedures. The retention factor $\left(\mathrm{R}_{f}\right)$ was derived from the distance of the substance's travel as compared to the solvent front, upon a TLC plate.

${ }^{1} \mathrm{H}$ and ${ }^{13} \mathrm{C}$ spectra were obtained on a Varian Innova 300 instrument, running at $300 \mathrm{MHz}$ for ${ }^{1} \mathrm{H}$ and $75 \mathrm{MHz}$ for ${ }^{13} \mathrm{C}$ or an Innova 500 instrument, running at $500 \mathrm{MHz}$ for ${ }^{1} \mathrm{H}$ and $125 \mathrm{MHz}$ for ${ }^{13} \mathrm{C}$. All samples were run in $\mathrm{CDCl}_{3}$ and referenced to solvent peaks (7.26 ppm for $\left.{ }^{1} \mathrm{H}\right)$ and $\left({ }^{13} \mathrm{C}\right.$ at $\left.77.0 \mathrm{ppm}{ }^{13} \mathrm{C}\right)$. NMR data has been recorded as follows: Chemical shift ( $\delta$, parts per million, ppm), peak multiplicity (multiplet (m), singlet (s), doublet (d), triplet ( $\mathrm{t}$ ), quadruplet (q) or a combination of these), coupling constants ( $J$ expressed in Hertz). 2D spectral data (COSY, HSQC, HMBC) was also obtained in addition to 1D spectral data.

All HRMS (mass spectroscopy) data was obtained on a Micromass Q-TOF Premier mass spectrometer.

Infrared spectra were obtained on a Bruker tensor 27 FTIR spectrometer. The samples were analysed neat.

Degassing of the samples for radical reactions took place in a Unisonics FX P8 Sonicator, within a water bath, at room temperature. 


\subsection{Synthesis of Radical Approach Precursors}

5.2.1. 2-(diethylamino) methyl cycloheptanone (2.19)

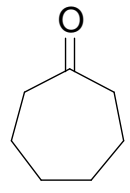

2.8

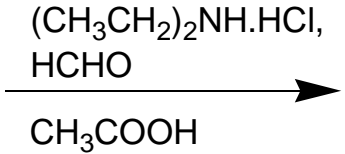



2.19

As reported by Lee and co-workers, ${ }^{46}$ cycloheptanone (1 eq., $\left.11.8 \mathrm{~mL}, 0.100 \mathrm{~mol}\right)$ and diethylamine hydrochloride salt (1 eq., $10.97 \mathrm{~g}, 0.100 \mathrm{~mol}$ ) was taken and formaldehyde (1.2 eq., $3.71 \mathrm{~mL}, 0.120 \mathrm{~mol})$ added to it. Conc. $\mathrm{HCl}(0.5 \mathrm{~mL})$ was then added to the reaction mixture and the solution was refluxed for 3 hours, after which it was allowed to cool down to r.t. The reaction mixture was then washed with $\mathrm{Et}_{2} \mathrm{O}(100 \mathrm{~mL})$ and then basified using $2 \mathrm{M} \mathrm{KOH}$ solution to a $\mathrm{pH}$ of 10-12. The upper organic layer was then removed and the aqueous layer extracted twice with diethyl ether $(2 \mathrm{x} 100 \mathrm{~mL})$. The organic layers were combined, washed with brine solution $(2 \times 50 \mathrm{~mL})$ and dried. The ethereal solution was concentrated under reduced pressure. Distillation under vacuum afforded $14.8 \mathrm{~g}$ of product in $75 \%$ yield as colorless oil $\left(116^{\circ} \mathrm{C}, 10 \mathrm{Torr}\right)$. In subsequent reaction, the crude product was not purified and used as crude product.

${ }^{1}$ H NMR: $\delta$ 2.74-2.61 (m, 2H), 2.40-2.53 (m, 6H), $2.31(\mathrm{~d}, 1 \mathrm{H}, J=5 \mathrm{~Hz}), 2.00-1.51$ (complex m, 6H), 1.41-1.17 (complex m, 2H), $0.97\left(\mathrm{t}, 6 \mathrm{H}, J=7 \mathrm{~Hz},-\mathrm{NCH}_{2} \mathrm{CH}_{3}\right)^{{ }^{13} \mathrm{C}}$ NMR: $\delta 215.9,54.7,50.9,47.4,43.9,43.5,29.5,29.4,28.6,11.7$

IR $\left(\mathrm{cm}^{-1}\right): 2966,2925,2853,2800,1698,1453,1381,1202,1069,934$.

Mass Spec: HRMS-ESI $(\mathrm{m} / \mathrm{z})$ : $[\mathrm{M}+\mathrm{H}]^{+}$calculated for $\mathrm{C}_{12} \mathrm{H}_{23} \mathrm{NO}+\mathrm{H}^{+}$, 198.1780; found 198.1853. 


\subsubsection{2-methylene cycloheptanone (2.7)}

$\underline{\text { Method A }}^{44}$
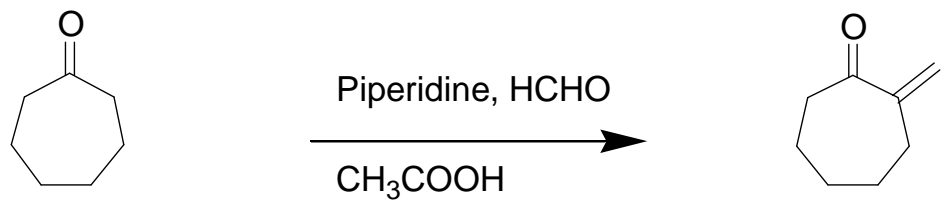

2.8

2.7

To a solution of cycloheptanone (1 eq., $6.2 \mathrm{~mL}, 0.05 \mathrm{~mol})$ in $\mathrm{MeOH}(50 \mathrm{~mL})$, was added formaldehyde (1.2 equiv, 37\% solution in water, $5.5 \mathrm{~mL})$, piperidine $(0.25 \mathrm{~mL}$, cat.) and $\mathrm{AcOH}(0.25 \mathrm{~mL}$, cat.). This was refluxed for two days after which the reaction mixture was cooled down and then extracted with $\mathrm{Et}_{2} \mathrm{O}(2 \times 50 \mathrm{~mL})$. The organic layer was then washed with saturated brine solution $(2 \times 25 \mathrm{~mL})$ and dried. Pale yellow oil was obtained (4.2 g), which was a 2:1 mixture of $\mathbf{2 . 8}$ and 2.7 as determined by ${ }^{1} \mathrm{H}$ NMR spectral data.

$\underline{\text { Method B }}$

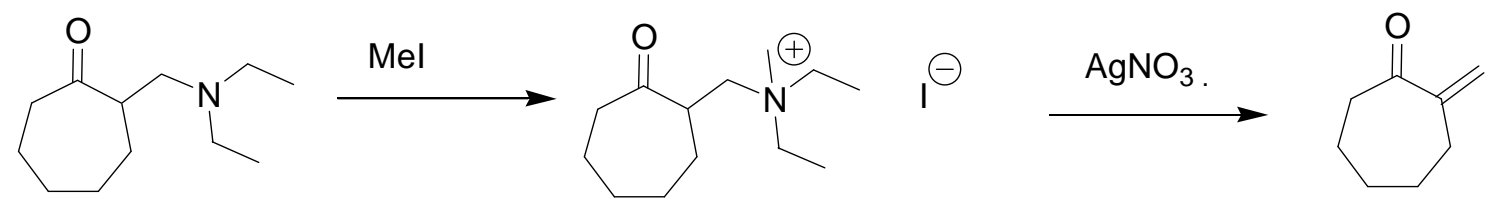

Adapted from Szmuszkovicz, ${ }^{49}$ MeI (1.2 eq., $\left.1.00 \mathrm{~g}, 0.007 \mathrm{~mol}\right)$ was added to aminocycloheptanone 2.19 ( 1 eq., $1.00 \mathrm{~g}, 0.005 \mathrm{mmol}$.) and this was left to react in the dark for two days. Product formed was seen to be a brown viscous liquid, containing 2(diethylamino)methyl-cycloheptanone iodide. The product was then washed with $\mathrm{Et}_{2} \mathrm{O}(2 \mathrm{x}$ $30 \mathrm{~mL}$ ), and dissolved in $30 \mathrm{~mL} \mathrm{MeOH}: 7 \mathrm{~mL} \mathrm{H} \mathrm{H}_{2} \mathrm{O}$ mixture. $\mathrm{Ag}_{2} \mathrm{O}$ (2.3 g, $\left.0.01 \mathrm{mmol}\right)$ was added to it and the mixture was then stirred vigorously overnight. $\mathrm{MeOH}$ was removed from the reaction mixture and the mixture extracted using $\mathrm{Et}_{2} \mathrm{O}(2 \times 40 \mathrm{~mL})$, after which the organic layer was dried and concentrated under reduced pressure. The product was obtained as a yellow oil (0.32 g), which was a complex mixture of unidentified products including 2.7 (approximately 20\%) as observed in the ${ }^{1} \mathrm{H}$ NMR spectrum. 
Method C

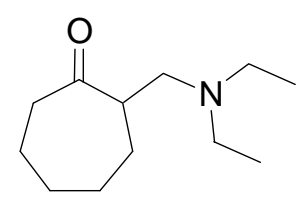

2.19

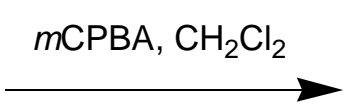

A procedure similar to one previously reported was used, ${ }^{50}$ whereby crude amine compound 2.19 (1 eq., $0.50 \mathrm{~g}, 2.75 \mathrm{mmol}$ ) was taken in $\mathrm{CH}_{2} \mathrm{Cl}_{2}(20 \mathrm{~mL})$ and treated with $m$ CPBA (1.5 equiv, $70 \%$ in meta-chlorobenzoic acid and $\mathrm{H}_{2} \mathrm{O}, 1.01 \mathrm{~g}$ ). The reaction was stirred at r.t. overnight and worked up by washing with dilute $\mathrm{HCl}(30 \mathrm{~mL})$ and then with $\mathrm{NaHCO}_{3}$ solution $(30 \mathrm{~mL}$, aq.) to remove excess $m$ CPBA. The organic layer was then washed with brine solution $(30 \mathrm{~mL})$, dried and concentrated to liberate pale yellow oil. 2Methylidene cycloheptanone 2.10 was purified using Kugelrohr distillation. $\left(75-80{ }^{\circ} \mathrm{C}\right.$ at 13 Torr) resulting in $70 \%(0.24 \mathrm{~g})$ of product 2.7 as a colorless liquid. The spectral data results were consistent with the previously reported results. ${ }^{39}$

${ }^{1} \mathbf{H}$ NMR: $\delta 5.92(\mathrm{~s}, 1 \mathrm{H},-\mathrm{CH}=\mathrm{CHH}$, cis to carbonyl), $5.20(\mathrm{~s}, 1 \mathrm{H},-\mathrm{CH}=\mathrm{CH}$, trans to carbonyl), $2.56(\mathrm{~d}, 2 \mathrm{H}), 2.45$ (d, 2H), 1.67-1.63 (complex m, 6H). ${ }^{13} \mathrm{C}$ NMR: $\delta 203.8$, $148.3,122.5,43.4,33.8,31.3,30.5,25.3$.

IR $\left(\mathrm{cm}^{-1}\right): 3003,2926,2360,2341,1711,1420,1359,1219,1091,901$.

\subsubsection{1-methoxy cycloheptene (2.24)}

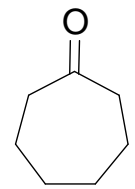

2.11

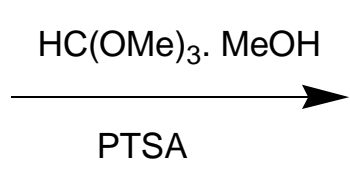

PTSA

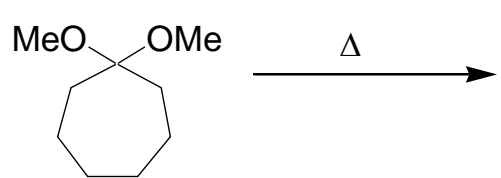

2.23

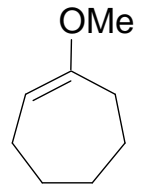

2.24

Adapted from Shishido and collegues, ${ }^{78}$ a solution of cycloheptanone (1 eq., $3.16 \mathrm{~mL}, 26.7$ $\mathrm{mol}), \mathrm{HC}(\mathrm{OMe})_{3}(6.3$ eq. $17.76 \mathrm{~g}, 167.9 \mathrm{mmol})$ and PTSA (0.07 eq., $\left.0.36 \mathrm{~g}\right)$ in dry $\mathrm{MeOH}$ 
(26 mL) was refluxed under nitrogen for 30 minutes. An extra portion of PTSA (0.07 eq.) was added to the flask and then it was allowed to cool down. The reaction mixture was extracted using $\mathrm{Et}_{2} \mathrm{O}(2 \times 70 \mathrm{~mL})$, washed with brine $(50 \mathrm{~mL})$ and dried. The organic layer was concentrated to produce dimethoxycycloheptane (2.23). Distillation of the crude product at atmospheric pressure $\left(155-165^{\circ} \mathrm{C}\right)$ gave the desired product 1-methoxy cycloheptanone (2.24) as a colorless oil in 60\% overall yield. The NMR data were consistent with one reported previously. ${ }^{79}$

2.23: ${ }^{1}$ H NMR: $\delta 3.28(\mathrm{~s}, 6 \mathrm{H}), 1.72(\mathrm{~s}, 4 \mathrm{H})$ and $1.50(\mathrm{~s}, 8 \mathrm{H})$

2.24: ${ }^{1}$ H NMR: $\delta 4.69(\mathrm{t}, 1 \mathrm{H}, J=7 \mathrm{~Hz}), 3.42(\mathrm{~s}, 3 \mathrm{H}), 2.24(\mathrm{t}, 2 \mathrm{H}, J=5 \mathrm{~Hz}), 2.06(\mathrm{q}, 2 \mathrm{H}, J=$ $4 \mathrm{~Hz}$ ), 1.72-1.64 (complex m, 2H) and 1.56-1.43 (complex m, 4H) ${ }^{13} \mathrm{C}$ NMR: $\delta$ 162.0, $96.4,54.2,33.8,32.2,28.2,25.6,25.4$

\subsubsection{Representative procedure for Radical reactions:}

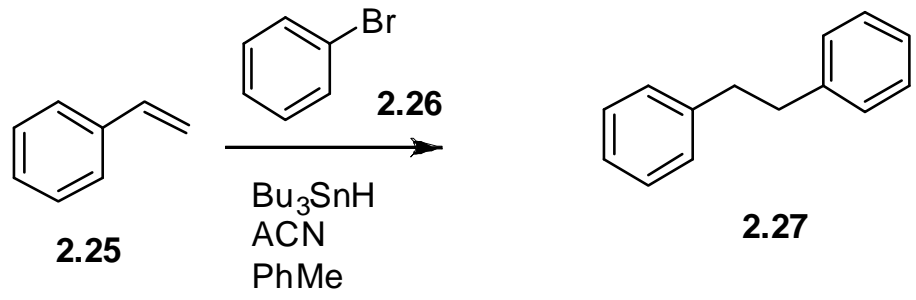

To a refluxing solution of styrene ( 1 eq.) and bromobenzene $(0.8$ eq. $)$ in toluene $(2 \mathrm{~mL}$ per mmol of styrene), was added $\mathrm{Bu}_{3} \mathrm{SnH}$ (1.5 eq.) and $\mathrm{ACN}$ (0.5 eq.) in toluene ( $0.2 \mathrm{~mL}$ per mmol of $\mathrm{Bu}_{3} \mathrm{SnH}$ ) through a syringe pump at a rate of $3 \mathrm{~mL}$ per $\mathrm{hr}$ and refluxed for an additional 3 hours. The reaction was then cooled down KF (2 eq.) added to it and this was left stirring at r.t. overnight. The reaction was worked up by removing toluene under reduced pressure, followed by dilution of the reaction mixture with $\mathrm{Et}_{2} \mathrm{O}(20 \mathrm{~mL})$. The ethereal layer was then washed with water $(15 \mathrm{~mL})$ and brine $(10 \mathrm{~mL})$ and dried using magnesium sulfate, to yield a yellow oil, which was characterized to be diphenyl methane $(50 \%)$.

The same procedure was applied for radical reaction involving the methylidene compound 2.7 and methoxy compound $\mathbf{2 . 2 4}$ 


\section{$\underline{5.3 \text { Synthesis of Carbene Cycloaddition Cyclisation Cascade precursors }}$}

\subsubsection{Synthesis of ethyl 1-(2-oxo) cyclopentane carboxylate (1.84)}<smiles>CCOC(=O)CCCCC(=O)OCC</smiles>

3.1

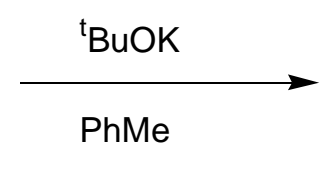

1.84

Adapted from Pinkney et al., ${ }^{63}$ diethyl adipate 3.1 (1 eq., $5.12 \mathrm{~g}, 25.2 \mathrm{mmol}$ ) was added to dry, degassed toluene $(25 \mathrm{~mL})$ in a reaction flask, and ${ }^{\mathrm{t}} \mathrm{BuOK}(1.5$ eq., $4.24 \mathrm{~g}, 37.8 \mathrm{mmol})$ was added. The reaction mixture was refluxed under argon for 3 hours. During the course of the reaction, additional toluene $(100 \mathrm{~mL})$ was added and the temperature maintained between $115-120{ }^{\circ} \mathrm{C}$ to prevent the formation of solid material. The reaction was quenched by, cooling in an ice bath and $10 \% \mathrm{AcOH}$ (aq.) $(25 \mathrm{~mL})$ was added.

The toluene layer was separated and washed once with water $(50 \mathrm{~mL})$, twice with $30 \mathrm{~mL}$ cold $7 \% \mathrm{Na}_{2} \mathrm{CO}_{3}$ solution and then again with water $(50 \mathrm{~mL})$. The organic layer was washed with brine $(50 \mathrm{~mL})$, dried and reduced under pressure. Product $\mathbf{1 . 8 4}$ was obtained as yellow oil ( $1.52 \mathrm{~g})$ in $42 \%$ yield, and used without further purification.

${ }^{1} \mathbf{H}$ NMR: $\delta 4.20$ (q, $J=7 \mathrm{~Hz}, 2 \mathrm{H},-\mathrm{CO}_{2} \mathrm{CH}_{2} \mathrm{CH}_{3}$ ), 3.15 (t, $\left.J=9 \mathrm{~Hz}, 1 \mathrm{H},-\mathrm{COCHCO}\right), 2.35-$ 2.28 (complex m, 4H), 2.18-2.10 (m, 1H), 1.92-1.82 (m, 1H), 1.29 (t, $J=8 \mathrm{~Hz}, 3 \mathrm{H},-$ $\left.\mathrm{CO}_{2} \mathrm{CH}_{2} \mathrm{CH}_{3}\right)$

${ }^{13}$ C NMR: $\delta$ 212.5, 169.4, 61.4, 54.8, 38.1, 27.4, 21.0, 14.2 . 


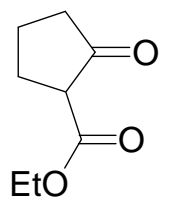

1.84

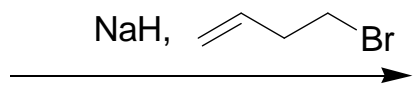

anhydrous DMF

Using a modified procedure, ${ }^{65} \mathrm{NaH}$ (1.2eq., $0.102 \mathrm{~g}, 4.26 \mathrm{mmol}, 60 \%$ dispersion in mineral oil) was washed with hexanes $(30 \mathrm{~mL})$ and dried under high vacuum. This was then placed under an argon atmosphere and $20 \mathrm{~mL}$ of anhydrous DMF added. Compound 1.84 (1 eq., $0.504 \mathrm{~g}, 3.46 \mathrm{mmol}$ ) was added to the reaction vessel and stirred until all the $\mathrm{NaH}$ had reacted. 4-Bromobut-1-ene (1.2 eq., $0.572 \mathrm{~g}, 4.15 \mathrm{mmol}$ ) was then added dropwise, the reaction was then stirred at $80{ }^{\circ} \mathrm{C}$ overnight. DMF was removed under reduced pressure and the reaction mixture was extracted twice with $\mathrm{Et}_{2} \mathrm{O}(2 \times 40 \mathrm{~mL})$. The ethereal layer was washed with $\mathrm{NaHCO}_{3}$ solution $(30 \mathrm{~mL})$ and brine $(30 \mathrm{~mL})$. The organic layer was then dried with magnesium sulfate and concentrated under vacuum. Flash chromatography (Hex: EtOAc 40:1) of the crude product separated out both $C$ - and $O$-alkylated compounds

\subsection{6 and 3.2.}

Compound 1.86 was collected as colourless oil $\left(\mathrm{R}_{f}=0.5,0.46 \mathrm{~g}, 65 \%\right)$

${ }^{1}$ H NMR: $\delta 5.82-5.74\left(\mathrm{~m}, 1 \mathrm{H}-\mathrm{CH}=\mathrm{CH}_{2}\right), 5.01(\mathrm{~d}, 1 \mathrm{H}, \mathrm{J}=17 \mathrm{~Hz},-\mathrm{CH}=\mathrm{CHH}), 4.96(\mathrm{~d}, 1 \mathrm{H}$, $J=10 \mathrm{~Hz},-\mathrm{CH}=\mathrm{CHH}), 4.14\left(\mathrm{q}, 2 \mathrm{H}, J=7 \mathrm{~Hz},-\mathrm{CO}_{2} \mathrm{CH}_{2} \mathrm{CH}_{3}\right), 2.58-2.52(\mathrm{~m}, 1 \mathrm{H}), 2.45-$ $2.37(\mathrm{~m}, 1 \mathrm{H}), 2.31-2.22(\mathrm{~m}, 1 \mathrm{H}), 2.35-1.87$ (complex m, 6H), 1.69-1.63 (m, 1H), $1.25(\mathrm{t}$, $\left.3 \mathrm{H}, \mathrm{J}=7 \mathrm{~Hz},-\mathrm{CO}_{2} \mathrm{CH}_{2} \mathrm{CH}_{3}\right)$

${ }^{13}$ C NMR: $\delta 214.8,170.9,137.7,115.1,61.4,60.2,38.0,33.0,32.8,29.1,19.6,14.1$

IR $\left(\mathrm{cm}^{-1}\right): 2972,1699,1715,1453,1296,1251,1142,912,827$.

Mass Spec: HRMS-ESI (m/z): $[\mathrm{M}+\mathrm{Na}]^{+}$calculated for $\mathrm{C}_{12} \mathrm{H}_{18} \mathrm{O}_{3}+\mathrm{Na}^{+}, 233.1154$; found 233.1154 . 
Compound 3.2 (ethyl 1-(2-but-3-enoxy) cyclopentane carboxylate) $\left(\mathrm{R}_{f}=0.23,0.04 \mathrm{~g}, 5 \%\right)$

3.2: ${ }^{1} \mathbf{H}$ NMR $\delta$ 5.91-5.81 (m, $\left.1 \mathrm{H},-\mathrm{CH}=\mathrm{CH}_{2}\right), 5.14\left(\mathrm{~d}, 1 \mathrm{H}, J=17 \mathrm{~Hz},-\mathrm{CH}=\mathrm{CH}_{\mathrm{a}} \mathrm{H}_{\mathrm{b}}\right), 5.09$ (d, $\left.1 \mathrm{H}, J=10 \mathrm{~Hz},-\mathrm{CH}=\mathrm{CH}_{\mathrm{a}} \mathrm{H}_{\mathrm{b}}\right), 4.17\left(\mathrm{q}, 2 \mathrm{H}, J=7 \mathrm{~Hz},-\mathrm{CO}_{2} \mathrm{CH}_{2} \mathrm{CH}_{3}\right), 4.06(\mathrm{t}, 2 \mathrm{H}, J=$ $7 \mathrm{~Hz}), 2.63(\mathrm{t}, 2 \mathrm{H}, J=7 \mathrm{~Hz}), 2.56(\mathrm{t}, 2 \mathrm{H}, J=7 \mathrm{~Hz}), 2.48(\mathrm{q}, 2 \mathrm{H}, J=14 \mathrm{~Hz}), 1.85(\mathrm{~m}, 2 \mathrm{H})$, $1.28(\mathrm{t}, 3 \mathrm{H}, J=7 \mathrm{~Hz})$

${ }^{13}$ C NMR $\delta 168.1,165.4,133.9,117.4,104.6,69.8,59.3,34.2,31.6,29.3,19.3,14.4$

IR $\left(\mathrm{cm}^{-1}\right): 3005,1711,1420,1358,1220,1092$.

Mass Spec: HRMS-ESI $(m / z)$ : $[M+N a]^{+}$calculated for $\mathrm{C}_{12} \mathrm{H}_{18} \mathrm{O}_{3}+\mathrm{Na}^{+}, 233.1154$; found 233.1151

5.3.3 Synthesis of ethyl, 1-(but-3-ene) (2-oxo-3-methylacetyl) cyclopentane carboxylate $\underline{(1.88)}$

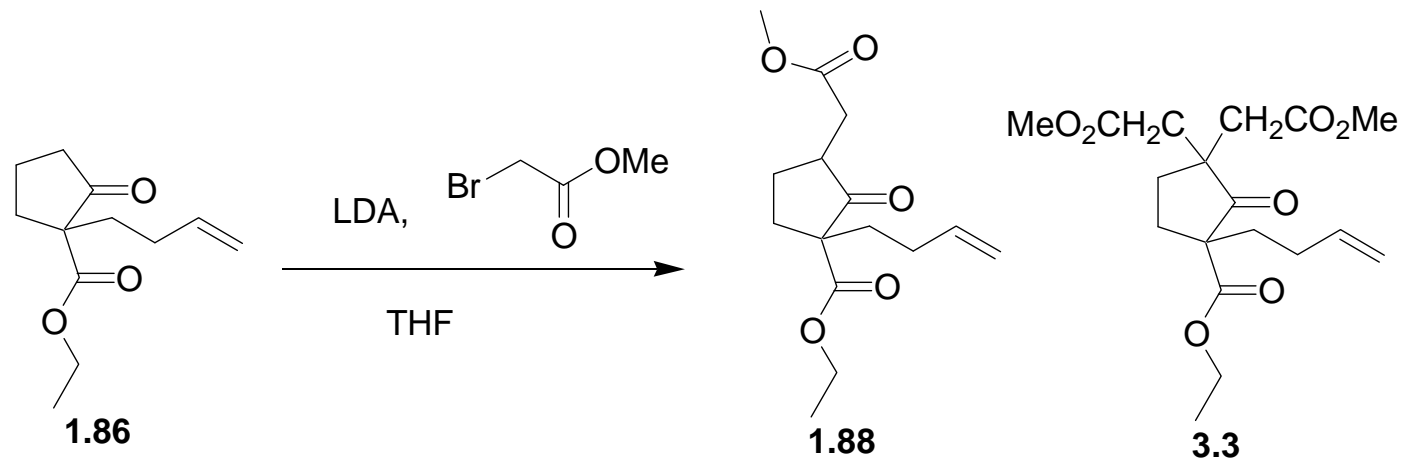

Adapted from Tzvetkov et al., ${ }^{66} \mathrm{iPr}_{2} \mathrm{NH}(1.2 \mathrm{eq} ., 0.24 \mathrm{~mL}, 1.70 \mathrm{mmol})$ was dissolved in THF $(3 \mathrm{~mL})$ under argon and cooled down to $-78^{\circ} \mathrm{C} . n$-BuLi (1.2 eq., $1.14 \mathrm{~mL}, 1.6 \mathrm{M}$ solution in hexanes) was then added to the reaction vessel and this was stirred at $-78^{\circ} \mathrm{C}$ for one hour. The reaction flask was warmed up to $-40{ }^{\circ} \mathrm{C}$ and compound 1.86 (1 eq., $0.29 \mathrm{~g}$ $1.42 \mathrm{mmol}$ in $2 \mathrm{~mL}$ THF) was added and stirred at this temperature for one hour. Methyl bromoacetate (1.2 eq., $0.13 \mathrm{~mL}, 1.70 \mathrm{mmol})$ was then added, stirred at $-40{ }^{\circ} \mathrm{C}$ for 30 minutes, and then was allowed to warm to r.t. overnight. THF was then removed under reduced pressure and the crude mixture was extracted with $\mathrm{Et}_{2} \mathrm{O}(20 \mathrm{~mL})$. This was then washed with water $(10 \mathrm{~mL})$ and brine solution $(10 \mathrm{~mL})$. The organic layer was then dried 
and reduced under vacuum. Flash chromatography (Hex: EtOAc 20:1) provided compound 1.88 and compound 3.3

Compound 1.88 was collected as colourless oil $\left(\mathrm{R}_{f}=0.28,0.11 \mathrm{~g}, 27 \%\right)$ (mixture of diastereoisomers)

${ }^{1}$ H NMR: $\delta$ 5.73-5.65 (m, 1H, $\left.-\mathrm{CH}=\mathrm{CH}_{2}\right), 4.97(\mathrm{~d}, 1 \mathrm{H}, \mathrm{J}=15 \mathrm{~Hz},-\mathrm{CH}=\mathrm{CH} H), 4.88(\mathrm{~d}$, $1 \mathrm{H}, J=11 \mathrm{~Hz},-\mathrm{CH}=\mathrm{CHH}), 4.09\left(\mathrm{q}, 2 \mathrm{H}, \mathrm{J}=10 \mathrm{~Hz},-\mathrm{CO}_{2} \mathrm{CH}_{2} \mathrm{CH}_{3}\right), 3.61\left(\mathrm{~s}, 3 \mathrm{H},-\mathrm{CO}_{2} \mathrm{CH}_{3}\right)$, 2.67-2.76 (m, 1H), 2.67-2.19 (m, 2H), 2.05-1.78 (complex m, 5H), 1.76-1.58 (complex m, $3 \mathrm{H}), 1.18\left(\mathrm{t}, 3 \mathrm{H}, J=7 \mathrm{~Hz},-\mathrm{CO}_{2} \mathrm{CH}_{2} \mathrm{CH}_{3}\right) .{ }^{13} \mathbf{C}$ NMR $\delta: 214.1,213.5,172.3,172.2,171.2$, $170.6,137.7,137.5,115.2,115.1,61.5,61.4,60.2$, 59.5, 51.8, 45.8, 45.4, 34.6, 34.1, 33.8, 32.6, 31.1, 30.3, 29.1, 29.0, 27.0, 26.4, 25.6, 14.1,14.1.

IR $\left(\mathrm{cm}^{-1}\right):$ 3004, 3001, 1710, 1448, 1428, 1420, 1359, 1218, 956.

Mass Spec: HRMS-ESI (m/z): $[\mathrm{M}+\mathrm{Na}]^{+}$calculated for $\mathrm{C}_{15} \mathrm{H}_{22} \mathrm{O}_{5}+\mathrm{Na}^{+}, 305.1365$; found 305.1357

Compound 3.3 (ethyl, 1-(but-3-ene) (2-oxo-bis-3,3-dimethyl acetyl) cyclopentane carboxylate) was collected as a colorless oil $\left(\mathrm{R}_{f}=0.25,0.02 \mathrm{~g}, 5 \%\right)$

${ }^{1}$ H NMR: $\delta$ 5.81-5.75 (m, 1H, $\left.-\mathrm{CH}=\mathrm{CH}_{2}\right), 5.03(\mathrm{~d}, 2 \mathrm{H}, \mathrm{J}=18 \mathrm{~Hz},-\mathrm{CH}=\mathrm{CHH}), 4.96(\mathrm{~d}$, $2 \mathrm{H}, J=10 \mathrm{~Hz},-\mathrm{CH}=\mathrm{CHH}), 4.20\left(\mathrm{q}, 2 \mathrm{H}, J=7 \mathrm{~Hz},-\mathrm{CO}_{2} \mathrm{CH}_{2} \mathrm{CH}_{3}\right), 3.65\left(\mathrm{~s}, 3 \mathrm{H},-\mathrm{CO}_{2} \mathrm{CH}_{3}\right)$, $3.63\left(\mathrm{~s}, 3 \mathrm{H},-\mathrm{CO}_{2} \mathrm{CH}_{3}\right), 2.70-2.59\left(\mathrm{~m}, 3 \mathrm{H},-\mathrm{CHH}+-\mathrm{CH}_{2}\right), 2.61(\mathrm{~d}, 1 \mathrm{H}, J=18 \mathrm{~Hz},-\mathrm{CHH})$, $2.65(\mathrm{~m}, 1 \mathrm{H}), 2.28-2.21(\mathrm{~m}, 1 \mathrm{H}), 2.12\left(\mathrm{dd}, 2 \mathrm{H}, J=10 \mathrm{~Hz}, J=7 \mathrm{~Hz},-\mathrm{CH}_{2} \mathrm{CH}=\mathrm{CH}_{2}\right), 2.04$ $(\mathrm{q}, 2 \mathrm{H}, J=7.5 \mathrm{~Hz}), 1.89-1.83(\mathrm{~m}, 1 \mathrm{H}), 1.69-1.59(\mathrm{~m}, 1 \mathrm{H}), 1.25(\mathrm{t}, 3 \mathrm{H}, J=7 \mathrm{~Hz},-$ $\left.\mathrm{CO}_{2} \mathrm{CH}_{2} \mathrm{CH}_{3}\right)$.

${ }^{13}$ C NMR: $\delta 214.3,170.9,170.8,170.0,137.6,115.1,61.7,61.0,51.8,51.7,49.4,39.9$, $39.2,35.1,29.7,29.4,29.2,14.1$.

Mass Spec: HRMS-ESI (m/z): [M+ Na] ${ }^{+}$calculated for $\mathrm{C}_{18} \mathrm{H}_{26} \mathrm{O}_{7}+\mathrm{Na}^{+}, 377.1577$; found 377.1576 .

IR $\left(\mathrm{cm}^{-1}\right):$ 3004, 3002, 2997, 1710, 1450, 1428, 1420, 1359, 1220, 1156, 820, 
5.3.4 Synthesis of bis-adipic acid chloride (3.11)

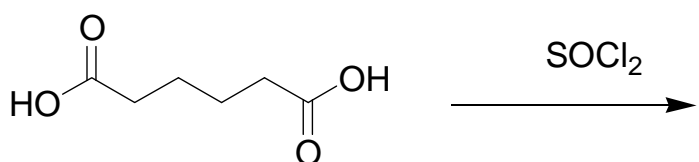

3.10

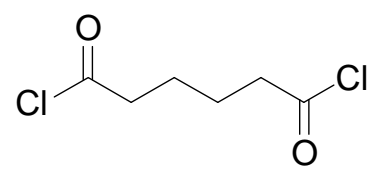

3.11

Adapted from the method of Lees ${ }^{71}$, adipic acid (1 eq., $6.00 \mathrm{~g}, 41.1 \mathrm{mmol}$,) and thionyl chloride (2.8 eq. $8.39 \mathrm{~mL}, 115 \mathrm{mmol})$ were heated at reflux for 2 hours. The NMR data correlated well with the literature data. ${ }^{71} 4.3 \mathrm{~g}$ of product 3.11, as yellow oil was obtained in $57 \%$ yield and used for the next reaction without purification.

${ }^{1}$ H NMR: $\delta 2.12(\mathrm{~s}, 4 \mathrm{H}), 1.56(\mathrm{~s}, 4 \mathrm{H})$,

${ }^{13}$ C NMR: $\delta$ 173.3, 46.4, 23.7

\subsubsection{Synthesis of bis tert-butyl adipate $(\mathbf{3 . 1 2})^{72}$}<smiles>O=C(Cl)CCCCC(=O)Cl</smiles>

3.11

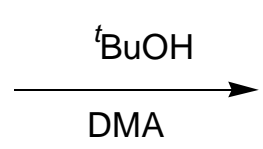

DMA

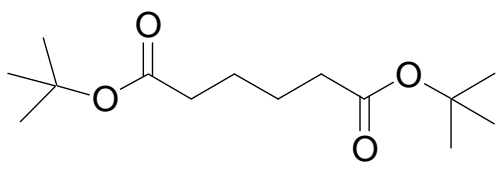

3.12

Adipic acid chloride 3.17 (1 eq., $3.00 \mathrm{~g}, 16.4 \mathrm{mmol}$ ) in $5 \mathrm{~mL}$ anhydrous $\mathrm{Et}_{2} \mathrm{O}$ was added over 5 minutes to a stirring solution of ${ }^{t} \mathrm{BuOH}(3.25$ equiv, $5.09 \mathrm{~mL}, 53.3 \mathrm{mmol})$ and DMA (3.25 eq., $6.75 \mathrm{~mL}, 53.3 \mathrm{mmol}$ ) in $10 \mathrm{~mL}$ of anhydrous $\mathrm{Et}_{2} \mathrm{O}$. The reaction mixture was stirred vigorously at room temperature over 2 days, then it was diluted with $10 \% \mathrm{NaCl}$ solution $(50 \mathrm{~mL})$ and the product isolated after extraction with $\mathrm{Et}_{2} \mathrm{O}(50 \mathrm{~mL})$. The organic layer was then washed with $3: 12 \mathrm{M}$ aqueous $\mathrm{HCl}$-saturated brine solution $(2 \times 50 \mathrm{~mL})$, 
followed by washing with $3: 11 \mathrm{M}$ aqueous $\mathrm{NaOH}$-saturated brine solution $(1 \mathrm{x} 50 \mathrm{~mL})$ and finally with saturated brine $(50 \mathrm{~mL})$. The organic layer was then dried and reduced under vacuum to afford $2.23 \mathrm{~g}(53 \%)$ of 3.12. The product was obtained as light yellow oil, which solidified upon cooling. The NMR data matched with that reported previously ${ }^{72}$ and this compound was used in the next step without further purification.

${ }^{1}$ H NMR: $\delta$ 2.24-2.20 (complex m, 4H), 1.62-1.58 (complex m, 4H), 1.44 (s, 18H)

${ }^{13}$ C NMR: $\delta 172.8,80.1,35.2,28.1,24.5$.

\subsubsection{Synthesis of tert-butyl (2-oxo)- cyclopentane carboxylate (1.85)}

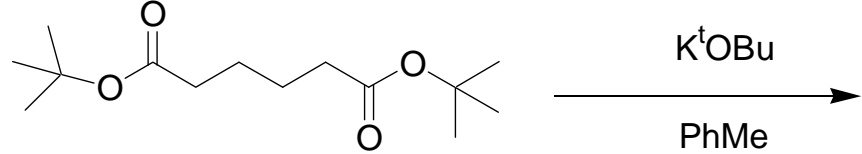

3.12

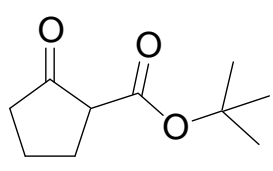

1.85

Compound 3.12 (1 eq., $2.23 \mathrm{~g}, 8.66 \mathrm{mmol}$ ) and potassium tert-butoxide (1.5 eq., $1.46 \mathrm{~g}$, $13.0 \mathrm{mmol}$ ) were taken in $25 \mathrm{~mL}$ toluene and subjected to Dieckmann condensation using conditions described for the synthesis of compound 1.84. Compound 1.85 was collected as yellow oil after work-up (1.2 g) in $75 \%$ yield.

${ }^{1}$ H NMR: $\delta 3.04\left(\mathrm{t}, J=9 \mathrm{~Hz}, 1 \mathrm{H},-\mathrm{COCHCO}_{2}{ }^{\mathrm{t}} \mathrm{Bu}\right), 2.30-2.23$ (complex m, 4H), $2.10(\mathrm{~m}$, $1 \mathrm{H}), 1.88-1.76(\mathrm{~m}, 1 \mathrm{H}), 1.46\left(\mathrm{~s}, 9 \mathrm{H},-\mathrm{CO}_{2}\left(\mathrm{CH}_{3}\right)_{3}\right)$.

${ }^{13}$ C NMR: $\delta 212.9,168.7,81.7,55.7,38.1,28.0,27.4,20.9$.

IR $(\mathrm{cm})^{-1}: 2976,1752,1717,1650,1368,1256,1146.5,912,843,729$.

Mass Spec: HRMS-ESI (m/z): $[\mathrm{M}+\mathrm{Na}]^{+}$calculated for $\mathrm{C}_{10} \mathrm{H}_{16} \mathrm{O}_{3}+\mathrm{Na}^{+}, 207.0998$; found 207.0995 


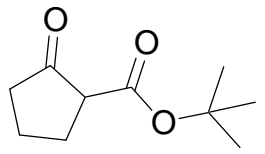

1.85

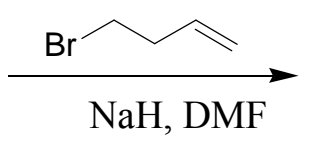

1.87

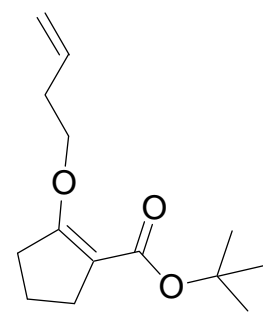

3.13

Compound 1.85 (1 eq., 0.512 g, 2.72 mmol) was reacted with $\mathrm{NaH}$ (1.2 eq., 0.078 g, 3.26 $\mathrm{mmol})$ and 4-bromo-but-1-ene (1.2 eq., $0.33 \mathrm{~mL}, 3.26 \mathrm{mmol})$ using the reaction conditions and work-up procedure as described for the synthesis of 1.86. Pure compound 1.87 and 3.13 were obtained after flash chromatography in 40: 1 Hex: EtOAc

Compound 1.87 collected as light yellow oil $\left(\mathrm{R}_{f}=0.53,0.22 \mathrm{~g}, 40 \%\right)$

${ }^{1}$ H NMR: $\delta$ 5.82-5.74 (m, 1H -CH= $\left.\mathrm{CH}_{2}\right), 5.02(\mathrm{~d}, 1 \mathrm{H},-\mathrm{CH}=\mathrm{CH}), 4.95(\mathrm{~d}, 1 \mathrm{H}$, $\mathrm{CH}=\mathrm{CHH}$ ), 2.49-2.38 (complex m, 2H), 2.25-2.09 (complex m, 2H, $-\mathrm{CH}_{2} \mathrm{CH}=\mathrm{CH}_{2}$ ), 2.101.84 (complex m, 4H), 1.67-1.56 (complex m, 2H), $1.44\left(\mathrm{~s}, 9 \mathrm{H},-\mathrm{CO}_{2}\left(\mathrm{CH}_{3}\right)_{3}\right)$

${ }^{13}$ C NMR: $\delta$ 215.2, 170.2, 137.9, 114.9, 81.7, 60.7, 37.9, 33.0, 32.8, 29.1, 27.9, 19.6

IR $(\mathrm{cm})^{-1}: 2974,1748,1715,1453,1368,1251,1142,912,846$

Mass Spec: HRMS-ESI (m/z): [M+ Na] $]^{+}$calculated for $\mathrm{C}_{14} \mathrm{H}_{22} \mathrm{O}_{3}+\mathrm{Na}^{+}, 261.1468$; found 261.1469

Compound 3.13 was collected as light yellow oil $\left(\mathrm{R}_{f}=0.38,0.03 \mathrm{~g}, 5 \%\right)$

${ }^{1}$ H NMR: $\delta 5.86\left(\mathrm{~m}, 1 \mathrm{H},-\mathrm{CH}=\mathrm{CH}_{2}\right), 5.11(\mathrm{~d}, 1 \mathrm{H} J=17 \mathrm{~Hz},(\mathrm{~d}, 1 \mathrm{H},-\mathrm{CH}=\mathrm{CHH}), 5.08(\mathrm{~d}$, $1 \mathrm{H}, J=10 \mathrm{~Hz},-\mathrm{CH}=\mathrm{CHH}), 4.03\left(\mathrm{t}, 2 \mathrm{H}, J=7 \mathrm{~Hz},-\mathrm{OCH}_{2} \mathrm{CH}=\mathrm{CH}_{2}\right), 2.62$ (t, $\left.J=7 \mathrm{~Hz}, 2 \mathrm{H}\right)$, $2.52(\mathrm{t}, 2 \mathrm{H}, J=7 \mathrm{~Hz}), 2.47\left(\mathrm{q}, 2 \mathrm{H}, J=8 \mathrm{~Hz},-\mathrm{OCH}_{2} \mathrm{CH}_{2} \mathrm{CH}\right), 1.81($ complex m, $2 \mathrm{H}), 1.48$ (s, $\left.\left.9 \mathrm{H}, \mathrm{CO}_{2}\left(\mathrm{CH}_{3}\right)_{3}\right)\right)$

${ }^{13}$ C NMR: $\delta 166.9,165.0,133.9,117.3,106.1,79.1,69.6,34.2,31.6,29.6,28.4,19.2$.

IR $(\mathrm{cm})^{-1}:$ 3004, 1710, 1420, 1358, 1220, 1092, 902. 
Mass Spec: HRMS-ESI (m/z): $[\mathrm{M}+\mathrm{Na}]^{+}$calculated for $\mathrm{C}_{10} \mathrm{H}_{14} \mathrm{O}_{3}+\mathrm{Na}^{+}, 261.1468$; found 261.1462 .

5.3.8 Synthesis of tert-butyl 1-(but-3-ene, 2-oxo, 3-methyl acetyl) cyclopentane carboxylate $\underline{(1.89)}$

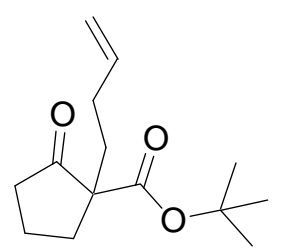

1.87

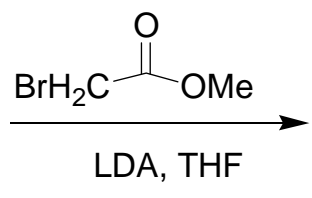

LDA, THF

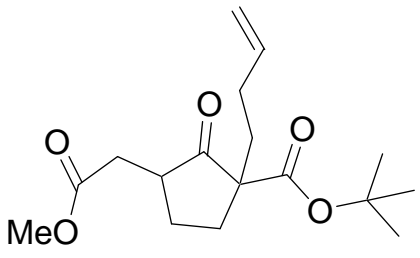

1.89

Adapted from Tzvetkov et al., ${ }^{66}{ }^{6} \operatorname{Pr}_{2} \mathrm{NH}$, (1.2 eq., $\left.0.06 \mathrm{~mL}, 0.40 \mathrm{mmol}\right)$ was dissolved in THF (3 mL) under argon and cooled down to $-78^{\circ} \mathrm{C}$. $n$-BuLi (1.2 eq., $0.22 \mathrm{~mL}, 0.40 \mathrm{mmol}$, 1.6 M solution in hexanes) was then added to the reaction vessel and this was stirred at -78 ${ }^{\circ} \mathrm{C}$ for one hour and then warmed up to $-20{ }^{\circ} \mathrm{C}$ and left stirring for another 30 minutes. Compound 1.87 ( 1 eq., $0.08 \mathrm{~g}, 0.34 \mathrm{mmol}$ in $2 \mathrm{~mL}$ of THF) was added and stirred at this temperature for one hour. Methyl bromoacetate $(1.2 \mathrm{eq} ., 0.04 \mathrm{~mL}, 0.40 \mathrm{mmol})$ was then added, with stirring and then allowed to warm up to r.t. overnight. THF was then removed under reduced pressure and the crude mixture was extracted with $\mathrm{Et}_{2} \mathrm{O}(25 \mathrm{~mL})$. This was then washed with water $(10 \mathrm{~mL})$ and brine $(10 \mathrm{~mL})$. The organic layer was then dried and concentrated under reduced pressure. Flash chromatography (Hex: EtOAc 20:1) gave compound $1.89\left(\mathrm{R}_{f}=0.41,0.02 \mathrm{~g}, 18 \%\right)$ in addition to the starting material $(60 \%)$.

1.89: ${ }^{1} \mathbf{H}$ NMR: $\delta 5.87-5.73\left(\mathrm{~m}, 1 \mathrm{H},-\mathrm{CH}=\mathrm{CH}_{2}\right), 5.02(\mathrm{~d}, 1 \mathrm{H},-\mathrm{CH}=\mathrm{CHH}), 4.95(\mathrm{~d}, 1 \mathrm{H},-$ $\mathrm{CH}=\mathrm{CHH}), 3.70\left(\mathrm{~s}, 3 \mathrm{H}, \mathrm{CO}_{2} \mathrm{CH}_{3}\right), 2.82\left(\mathrm{dd}, 2 \mathrm{H}, J=12 \mathrm{~Hz}, 4.9 \mathrm{~Hz},-\mathrm{CH}_{2} \mathrm{CO}_{2} \mathrm{Me}\right), 2.66-$ $2.56(\mathrm{~m}, 1 \mathrm{H}), 2.44-2.34(\mathrm{~m}, 1 \mathrm{H}), 2.33-2.26$ (complex m, 2H), 2.19-2.10 (m, 1H,), 2.061.89 (complex m, 2H, $-\mathrm{CH}_{2} \mathrm{CH}=\mathrm{CH}_{2}$ ), 1.84-1.62 (complex m, 2H), 1.44 (s, 9H, $-\mathrm{CO}_{2}$ $\left.\left(\mathrm{CH}_{3}\right)_{3}\right)$

${ }^{13}$ C NMR (as distereoisomers): $\delta$ 214.7, 213.8, 172.5, 172.3, 170.4, 170.1, 137.9, 137.8, $115.0,114.9,82.0,81.8,60.6,60.2,51.9,51.8,46.0,45.2,34.9,33.9,33.8,32.5,31.4,30.5$, 29.0, 28.9, 27.9, 27.9, 27.2, 25.6. 
IR $(\mathrm{cm})^{-1}:$ 3004, 1710, 1420, 1359, 1220.

Mass Spec: HRMS-ESI (m/z): $[\mathrm{M}+\mathrm{Na}]^{+}$calculated for $\mathrm{C}_{17} \mathrm{H}_{26} \mathrm{O}_{5}+\mathrm{Na}^{+}, 333.1678$; found 333.1669

5.3.9 Attempted synthesis of 2- ((2-oxo) -(3-but-3-ene)-3-tert butyl carboxylate cyclopentane) acetic acid

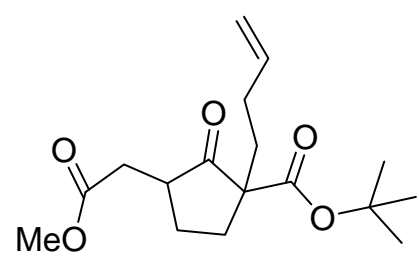

1.89

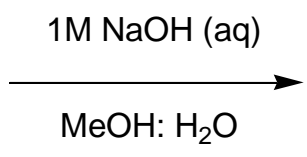

$\mathrm{MeOH}: \mathrm{H}_{2} \mathrm{O}$

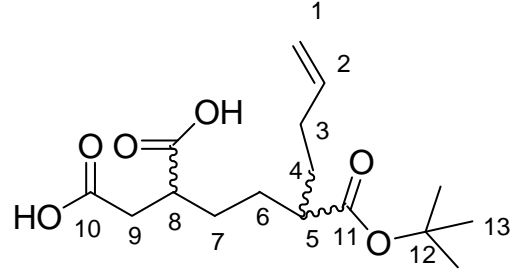

3.15

A previously reported procedure was used, ${ }^{73}$ whereby compound 1.89 (1 eq., 26mg, 0.09 mmol ) was dissolved in 1mL of $\mathrm{MeOH}$ : THF 2:1 mixture and 10\% $\mathrm{NaOH}$ (6.64 eq., 0.43 $\mathrm{mL}$ ) was added to it at r.t. and the reaction was stirred overnight. The reaction was quenched with $0.3 \mathrm{~mL}$ of $10 \% \mathrm{HCl}$ (aq.). The organic solvent was removed under reduced pressure and the aqueous layer was diluted with $\mathrm{H}_{2} \mathrm{O}(3 \mathrm{~mL})$ and extracted with EtOAc $(10 \mathrm{~mL})$. The organic layer was collected, washed with brine and dried with $\mathrm{MgSO}_{4}$, evaporated to yield, $15 \mathrm{mg}(57 \%)$ of $\mathbf{3 . 1 5}$.

3.15: ${ }^{1} \mathbf{H}$ NMR $\delta: ~ 5.74-5.66 ~\left(m, ~ 1 H, ~-C H=\mathrm{CH}_{2}\right), 4.94(\mathrm{~d}, 1 \mathrm{H}, \mathrm{J}=18 \mathrm{~Hz} \mathrm{C}-2 \mathrm{Ha}), 4.88$ (d, $1 \mathrm{H}, J=11 \mathrm{~Hz}, \mathrm{C}-2 \mathrm{Hb}), 1.99-1.92(\mathrm{~m}, 2 \mathrm{H}, \mathrm{C}-3 \mathrm{H}), 2.80-2.73(\mathrm{~m}, 1 \mathrm{H}, \mathrm{C}-8 \mathrm{H}), 2.69-2.61$ (m, 1H, C-9 Ha), 2.47-2.40 (m, 1H, C-9 Hb), 2.22-2.15 (m, 1H, C-5 H), 1.66-1.40 (m, 6H C-4 $\left.\mathrm{H}_{2}, \mathrm{C}-6 \mathrm{H}_{2} \mathrm{C}-7 \mathrm{H}_{2}\right), 1.38\left(\mathrm{~s}, 9 \mathrm{H},-\mathrm{CO}_{2}\left(\mathrm{CH}_{3}\right)_{3}\right.$

${ }^{13}$ C NMR $\delta$ : 180.9, 180.8, 178.1, 178.1, 175.0, 174.9, 137.8, 137.8, 115.2, 115.1, 80.6, $80.5,45.5,45.4,40.9,40.8,35.6,35.4,31.7,31.6,31.4,29.6,29.4,29.2$, 29.1, 28.1, 27.9, 14.2.

Mass Spec: HRMS-ESI $(\mathrm{m} / \mathrm{z})$ : $[\mathrm{M}+\mathrm{Na}]^{+}$calculated for $\mathrm{C}_{16} \mathrm{H}_{26} \mathrm{O}_{6}+\mathrm{Na}^{+}, 337.1620$; found 337.1630 . 
5.3.10 Synthesis of 2- ((2-oxo)- (3-but-3-ene) 3-tert-butyl carboxylate cyclopentane) acetic $\underline{\operatorname{acid}(1.91)}$

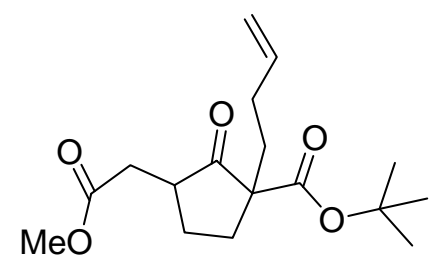

1.89

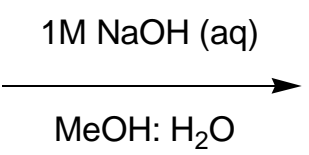

$\mathrm{MeOH}: \mathrm{H}_{2} \mathrm{O}$

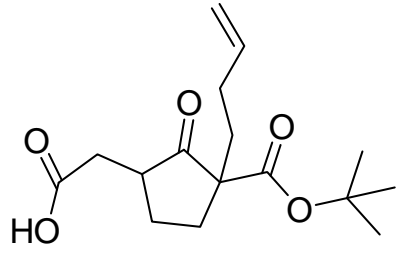

1.91

A modified previously reported procedure was used, ${ }^{73}$ whereby compound 1.89 (1 eq., 26 $\mathrm{mg}, 0.09 \mathrm{mmol})$ was dissolved in of $\mathrm{MeOH}$ : THF 2:1 (1 mL) mixture and 10\% $\mathrm{NaOH}(6.6$ eq., $0.43 \mathrm{~mL}$ ) was added to it at $0^{\circ} \mathrm{C}$. The reaction was stirred at $0^{\circ} \mathrm{C}$ for 3 hours (TLC showed trace of starting material), after which it was quenched with $0.3 \mathrm{~mL}$ of $10 \% \mathrm{HCl}$ (aq.). The organic solvent was removed under vacuum and the aqueous layer was diluted with water $(2 \mathrm{~mL})$ and extracted with EtOAc $(10 \mathrm{~mL})$. The organic layer was collected, washed with brine (4 mL), dried and reduced to yield, $15 \mathrm{mg}$ of $1.91(56 \%)$ as colourless oil.

$3.24{ }^{1}$ H NMR: $\delta$ 5.74-5.66 (m, 1H, $\left.-\mathrm{CHCH}_{2}\right), 4.95(\mathrm{~d}, 1 \mathrm{H},-\mathrm{CHCHH}, J=17 \mathrm{~Hz}), 4.88(\mathrm{~d}$, $1 \mathrm{H},-\mathrm{CHCHH}, J=10 \mathrm{~Hz}), 2.83\left(\mathrm{~d}, 2 \mathrm{H},-\mathrm{CH}_{2} \mathrm{COOH}, J=17 \mathrm{~Hz}\right), 2.52-2.48(\mathrm{~m}, 1 \mathrm{H},-$ $\mathrm{CHCH}_{2} \mathrm{COOH}$ ), 2.38-2.22 (complex m, 3H), 2.13-2.06 (m, 1H), 1.97-1.81 (complex m, $\left.2 \mathrm{H},-\mathrm{CH}_{2} \mathrm{CH}=\mathrm{CH}_{2}\right), 1.82-1.50($ complex m, $2 \mathrm{H}), 1.36\left(\mathrm{~s}, 9 \mathrm{H},-\mathrm{C}\left(\mathrm{CH}_{3}\right)_{3}\right)$

${ }^{13}$ C NMR: $\delta$ 214.2, 213.7, 177.2, 177.1, 170.4, 170.0, 137.9, 137.7, 115.1, 115.0, 82.1, $81.9,60.6,60.1,45.8,45.1,34.8,33.7,32.6,30.6,29.0,28.9,27.9,27.8,27.1,25.6$

Mass Spec: HRMS-ESI (m/z): $[\mathrm{M}+\mathrm{Na}]^{+}$calculated for $\mathrm{C}_{16} \mathrm{H}_{24} \mathrm{O}_{5}+\mathrm{Na}^{+}, 319.1529$; found 319.1516 


\subsubsection{Representative Procedure for mixed anhydride formation of compound $\mathbf{1 . 9 1}$}

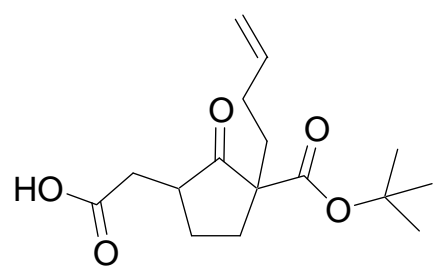

1.91
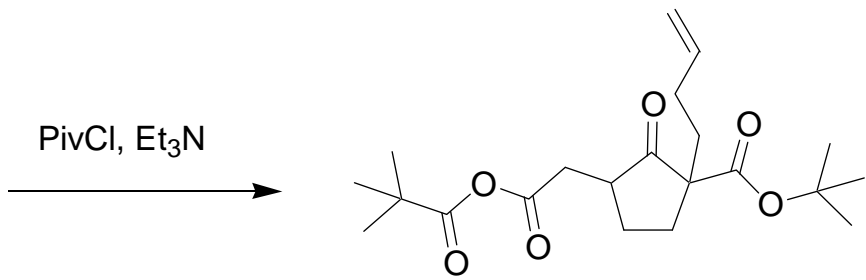

1.93

Compound 1.91 ( 1 eq.) was dissolved in $0.2 \mathrm{~mL} \mathrm{Et}_{2} \mathrm{O}$, cooled down to $0^{\circ} \mathrm{C}$ and then pivaloyl chloride (1.5 eq.) was added to it, followed by triethyl amine (1.5 eq.). The reaction was warmed to r.t. over 2 hours. The reaction was then quenched with $10 \%$ acetic acid $(0.2 \mathrm{~mL})$ and the organic layer washed with water $(0.2 \mathrm{~mL})$ and brine $(0.2 \mathrm{~mL})$. The solvent was removed under reduced pressure to yield the starting compound 1.91. The same conditions were applied for the anhydride formation of 1.91 with methyl chloroformate, and again only starting material was obtained from the reaction.

\subsubsection{Synthesis of acetyl diazo bromide 3.7}<smiles>O=C(Br)CBr</smiles>

3.6

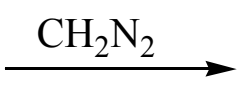<smiles>[15N]=CC(=O)CBr</smiles>

3.7

As reported previously, ${ }^{80}$ an ethereal solution $(43 \mathrm{~mL})$ of diazomethane $(\sim 0.45 \mathrm{~g}, \sim 10.6$ mmol), was generated from $3.2 \mathrm{~g}$ of $N$-methyl- $N$-nitroso- $p$-toulenesulfonamide and was cooled to $0{ }^{\circ} \mathrm{C}$. Bromoacetyl bromide $(0.72 \mathrm{~g}, 3.56 \mathrm{mmol})$ in $10 \mathrm{~mL}$ of anhydrous $\mathrm{Et}_{2} \mathrm{O}$ was added slowly over 5 minutes. The reaction was then left to warm up to ambient temperature overnight and the ether was removed under vacuum. The residual oil contained compound 
$3.7(0.52 \mathrm{~g})$, in $80 \%$ yield, including about $25 \%$ impurities. This impure compound was used in the next reaction without purification.

3.7: ${ }^{1}$ H NMR $\delta: 5.80(\mathrm{~s}, 1 \mathrm{H})$ and $3.84(\mathrm{~s}, 2 \mathrm{H})$

${ }^{13}$ C NMR $\delta: 187.3,55.9$, and 33.3

IR $\left(\mathrm{cm}^{-1}\right): 2926,1738,1368,1232$.

Mass Spec: HRMS-ESI $(\mathrm{m} / \mathrm{z})$ : $[\mathrm{M}+\mathrm{Na}]^{+}$calculated for $\mathrm{C}_{3} \mathrm{H}_{3} \mathrm{Br}^{79} \mathrm{~N}_{2} \mathrm{O}+\mathrm{Na}^{+}, 184.9328$; found $184.9329\left(\mathrm{Br}^{79}\right)$

\section{$\underline{\text { 5.3.13 Attempted diazo reaction on compound } \mathbf{1 . 8 6}}$}

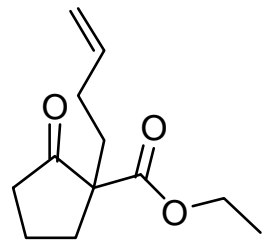

1.86

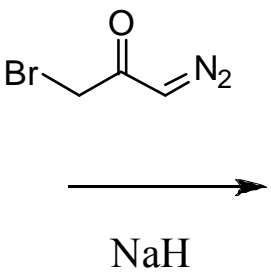

$\mathrm{NaH}$

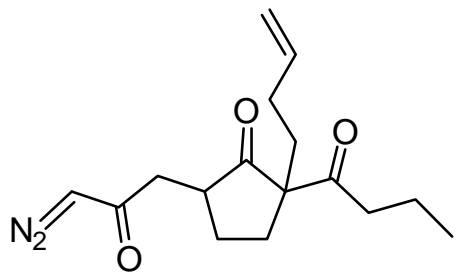

1.94

To a solution of compound 1.86 (1 eq., $0.221 \mathrm{~g}, 1.05 \mathrm{mmol})$ in THF $(10 \mathrm{~mL})$ at $0^{\circ} \mathrm{C}$, was added $\mathrm{NaH}$ (1.2 eq., 0.052g, $1.26 \mathrm{mmol}, 60 \%$ dispersion in mineral oil). This was stirred for 30 minutes at $0^{\circ} \mathrm{C}$ after which compound 3.7 was added to it and this was left stirring for 3 more hours at that temperature. The reaction was then quenched with water $(20 \mathrm{~mL})$ and extracted with EtOAc $(30 \mathrm{~mL})$. The organic layer was then washed with brine $(10 \mathrm{~mL})$, dried and reduced under vacuum to yield the starting compound $\mathbf{1 . 8 6}$ and 3.7. 


\section{$\underline{\text { References }}$}

(1) Zhan, Z.-J.; Yang, S.-P.; Yue, J.-M. J. Org. Chem. 2004, 69, 1726-1729.

(2) Bitar, H. E.; Nguyen, V. H.; Gramain, A.; Sevenet, T.; Bodo, B. J. Nat. Prod. 2004, 67, 1094-1099.

(3) Bitar, H. E.; Nguyen, V. H.; Gramain, A.; Sevenet, T.; Bodo, B. Tetrahedron Lett. 2004, 45, 515-518.

(4) Heathcock, C. H.; Davidson, S. K.; Mills, S. G.; Sanner, M. A. J. Am. Chem. Soc. 1986, 108, 5650-5651.

(5) Yamamura, S.; Hirata, Y. Tetrahedron Lett. 1974, 15, 3673-3676.

(6) Heathcock, C. H.; Hansen, M. M.; Ruggeri, R. B.; Kath, J. C. J. Org. Chem 1992, 57, 2544-2553.

(7) Morita, H.; Yoshida, N.; Kobayashi, J. J. Org. Chem. 2000, 65, 3558-3562.

(8) Kobayashi, J.; Ueno, S.; Morita, H. J. Org. Chem 2002, 67, 6546-6549.

(9) Jossang, A.; Bitar, H. E.; Pham, V. C.; Sevenet, T. J. Org. Chem 2003, 68, 300-304.

(10) Saito, S.; Kubota, T.; Kobayashi, J. Tetrahedron Lett. 2007, 48, 5693-5695.

(11) Mu, S.; Wang, Y.; He, H.; Yang, X.; Wang, Y.; Di, Y.; Lu, Y.; Chang, Y.; Hao, X. J. of Nat. Prod. 2006, 69, 1065-1069.

(12) Heathcock, C. H.; Davidson, S. K.; Mills, S. G.; Sanner, M. A. J. Org. Chem 1992, 57, 2531-2544.

(13) Wallace, G. A.; Heathcock, C. H. J. Org. Chem 2001, 66, 450-454.

(14) Walton, J. C.; McCarroll, A. J. Angew. Chem., Int. Ed. 2001, 40, 2224-2248.

(15) Song, H. Y.; Joo, J. M.; Kang, J. W.; Kim, D.; Jung, C.; Kwak, H. S.; Park, J. H.; Lee, E.; Hong, C. Y.; Jeong, S.; Jeon , K.; Park, J. H. J. Org. Chem. 2003, 68, 80808087.

(16) Sharma, G. V. M.; Gopinath, T. Tetrahedron 2003, 59, 6521-6530.

(17) Clark, A. J.; Dell, C. P.; Ellard, J. M.; Hunt, N. A.; McDonagh, J. P. Tetrahedron Lett. 1999, 40, 8619-8623.

(18) Curran, D. P.; Rakiewicz, D. M. Tetrahedron 1985, 41, 3943-3958.

(19) Parsons, P. J.; Cladingboel, D. E.; Ozlu, Y. Tetrahedron 1994, 50, 2183-2206. 
(20) Johnson, C. D. Acc. Chem. Res. 1993, 26, 476-482.

(21) Baldwin, J. J.C.S. Chem. Comm. 1976, 734-736.

(22) Baldwin, J.; Cutting, J.; Dupont, W.; Kruse, L.; Silberman, L.; Thomas, R., C. J.C.S. Chem. Comm. 1976, 736-738.

(23) Ishabashi, H.; Nakamura, N.; Sato, T.; Takeuchi, M.; Ikeda, M. Tetrahedron Lett. 1991, 32, 1725-1728.

(24) Mendenhall, G. D.; Protasiewicz, J. D.; Brown, C. E.; Ingold, K. U.; Lusztyk, J. J. Am. Chem. Soc. 1994, 116, 1718-1724.

(25) Burkett, B. 2008.

(26) Nair, V.; Suja, T. D. Tetrahedron 2007, 63, 12247-12275.

(27) McNulty, J.; Nair, J. J.; Sliwinski, M.; Harrington, L. E.; Pandey, S. Eur. J. Org. Chem 2007, 5669-5673.

(28) Padwa, A.; Carter, S. P.; Nimmesgern, H.; Stull, P. D. J. Am. Chem. Soc. 1988, 110, 2894-2900.

(29) Padwa, A.; Dean, D. C.; Zhi, L. J. Am. Chem. Soc. 1989, 111, 6451-6452.

(30) England, D. B.; Eaga, J. M.; Merey, G.; Anac, O.; Padwa, A. Tetrahedron 2008, 64, 988-1001.

(31) Graening, T.; Bette, V.; Neudorfl, J.; Lex, J.; Schmalz, H. G. Org. Lett. 2005, 7, 4317.

(32) Padwa, A.; Precedo, L.; Semones, M. A. J. Org. Chem 1999, 64, 4079.

(33) Hong, X.; France, S.; Mejia-Oneto, J. M.; Padwa, A. Org. Lett. 2006, 8, 5141-5144.

(34) Giese, B. Radicals in organic synthesis: formation of carbon-carbon bonds; Oxford, Permagon Press, 1986: New York, 1940.

(35) Fleming, I.; Maiti, P.; Ramarao, C. Org. Bioorg.Chem 2003, 1, 3989-4004.

(36) Drew, M. G. B.; Harwood, L. M.; Scott, R.; Thomas, R. M.; Uguen, D. Ang. Chem., Int. Ed. 2001, 40, 2311-2313.

(37) Uchiro, H.; Nagasawa, K.; Aiba, Y.; Kobayashi, S. Tetrahedron Lett. 2000, 41, 4165-4168.

(38) Ono, N.; Miyake, H.; Fujii, M.; Kaji, A. Tetrahedron Lett. 1983, 24, 3477-3480.

(39) Block, E.; Aslam, M.; Eswarakrishnan, V.; Gebreyes, K.; Hutchinson, J.; Iyer, R.; Laffitte, J.; Wall, A. J. Am. Chem. Soc. 1986, 108, 4568-4580. 
(40) Wipf, P.; Aslan, D. C. J. Org. Chem. 2001, 66, 337-343.

(41) Henin, F.; Pete, J. P. Synth. Commun. 1980, 895-897.

(42) Dimmock, J. R.; Jha, A.; Kumar, P.; Zello, G.; Quail, J.; Oloo, E. O.; Oucharek, J., Pasha, M.; Seitz, D.; Sharma, R.; Allen, T.; Santos, C.; Manavathu, E.; Clercq, E.; Balzarini, J.; Stables, J. Eur. J. Med. Chem 2002, 37, 35-44.

(43) Lieberman, S. V.; Wagner, E. C. J. Org. Chem 1949, 14, 1001-1012.

(44) Timmer, M., Personal Communication.

(45) Rochin, C.; Dunogues, J.; Duboudin, F. Synth. Commun. 1986, 667-668.

(46) Le, N. A.; Jones, M. J.; Bieckelhaupt, F.; Wolf, W. H. J. Am. Chem. Soc. 1989, 111, 8491-8493.

(47) Wilds, A., L.; C.H., S. J. Am. Chem. Soc. 1943, 65, 469-475.

(48) Gan, X.; Parveen; Smith, W. L.; Duesler, E.; Paine, R. T. Inorg. Chem. 2000, 39, 4591-4598.

(49) Szmuszkovicz, J. J. Org. Chem. 1954, 19, 1424-1427.

(50) Danishefsky, S.; Chacklamannil; Harrison, P.; Silvestr, i. M.; Cole, P. J. Am. Chem. Soc. 1984, 107, 2474-2484.

(51) Sestelo, J.; Real, M.; Sarandeses, L. J. Org. Chem 2001, 66.

(52) Aizpura, J. M.; Palomo, C. Tetrahedron Lett. 1985, 26, 6113-6114.

(53) House, H. O.; Czuba, L. J.; Gall, M.; Olmstead, H. D. J. Org. Chem 1969, 34, 23242331.

(54) Haag-Zeino, B.; Maier, M. E.; Schmidt, R. R. Chem. Ber. 1987, 120, 1505-1509.

(55) Miller, R. D.; McKean, D. R. Tetrahedron Lett. 1979, 20, 2305-2308.

(56) Wilhelm, T.; Manfred, M. Chem. Ber. 1954, 87, 407-411.

(57) Bennasar, M.; Roca, T.; Griera, R.; Bosch, J. Org. Lett. 2001, 3, 1697-1700.

(58) Chai, C. L. L.; King, A. R. J. Chem. Soc., Perkin Trans.1 1999, 1173-1182.

(59) Leemans, E.; M., D. h.; Dejaegher, Y.; Törnroos, K. W.; Kimpe, N. D. J. Org. Chem 2007.

(60) Giese, B.; Rupaner, R. Synth. Commun. 1988, 219-221.

(61) Chatgilialoglu, C.; Griller, D.; Lesage, M. J. Org. Chem. 1988, 53, 3641-3642.

(62) Keck, G. E.; Burnett, D. A. J. Org. Chem 1987, 52, 2958. 
(63) Pinkney, P. S. Org. Synth. Coll. 1943, 2, 116.

(64) Pflantz, R.; Tielmann, P.; Rossle, M.; Hoenke , C.; Christoffers, J. Eur. J. Org. Chem 2007, 3227-3238.

(65) Bien, S.; Ovadia, D. J. Org. Chem. 1974, 39, 2258-2260.

(66) Tzvetkov, N. T.; Arndt, T.; Mattay, J. Tetrahedron 2007, 63, 10497-10510.

(67) Ghosh, M.; Miller, M. J. Tetrahedron 1996, 52, 4225-4238.

(68) Johnson, F.; Marinelli, E. R. J. Org. Chem 1986, 51, 3911-3913.

(69) Mashraqui, S. H.; Keehn, P. M. J. Am. Chem. Soc. 1982, 104, 4461-4465.

(70) Padwa, A.; Sa, M. M.; Weingarten, M. D. Tetrahedron 1997, 53, 2371-2386.

(71) Lees, W. J.; Singh, R.; Whitesides, G. M. J.Org. Chem 1991, 56, 7328-7331.

(72) Babler, J. H.; Sarussi, S. J. J. Org. Chem 1987, 52, 3462-3464.

(73) Kondo, T.; Nekado, T.; Sugimoto, I.; Ochi, K.; Takai, S.; Kinoshita, A.; Tajima, Y.; Yamamoto, S.; Kazuhito, K.; Nakai, H.; Toda, M. Bioorg. Med. Chem. 2007, 15, 2631-2650.

(74) Fadel, A.; Canet, J.; Salaun, J. Tetrahedron Lett. 1989, 30.

(75) Cohen, M. J.; McNelis, E. J. Org. Chem 1984, 49, 515-518.

(76) Salomon, R. G.; Sachinvala, N. D.; Raychaudhuri, S. R.; Miller, D. B. J. Am. Chem. Soc. 1984, 106, 2211-2213.

(77) Muthusamy, S.; Babu, S. A.; Gunanathan, C.; Suresh, E.; Dasidar, P.; Jasra, R. V. Tetrahedron 2001, 57, 7009-7019.

(78) Shishido, K.; Hiroya, K.; Veno, Y.; Tetsuji, K.; Toshio, H. J. Chem. Soc., Perkin Trans. 1: Org. Biorg. Chem. 1986, 5, 829-836.

(79) Iqbal, M.; Paul, E.; Robert, S. M. PCT Int. Appl. 2003.

(80) Sabir, H. M.; Keehn, P. M. J. Am. Chem. Soc. 1982, 104, 4461-4465. 